Universidade de Brasília

Faculdade de Tecnologia

Departamento de Engenharia Elétrica

Relatório de Projeto Final 2

\title{
Projeto da fonte de alimentação para o nó remoto do Sistema de Controle de Irrigação (SCI)
}

Aluno: Marcelo Augusto Gozzer Viegas

Matrícula: 98/07934

Período: $2^{\circ} / 2003$ 
Orientador: Prof. José Camargo da Costa. 


\section{Sumário}

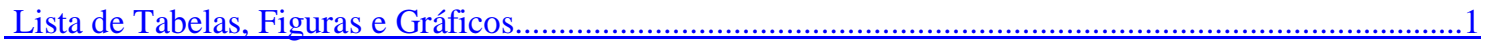

1. Introdução.................................................................................................................................................

1.1. Visão geral sobre o Sistema de Controle de Irrigação - SCI......................................................

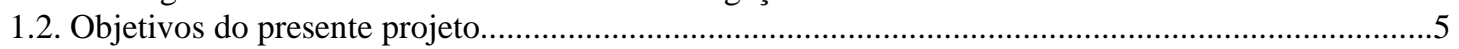

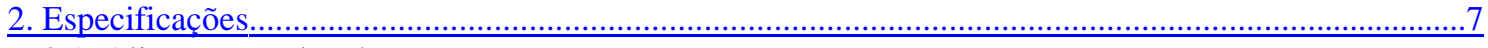

2.1. Alimentação do nó remoto..............................................................................................

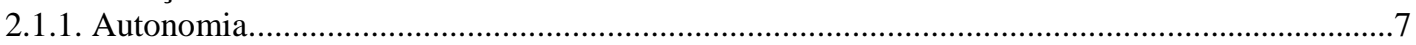

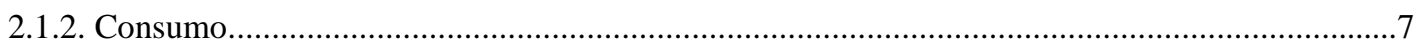

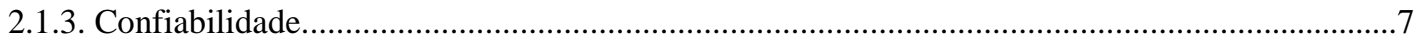

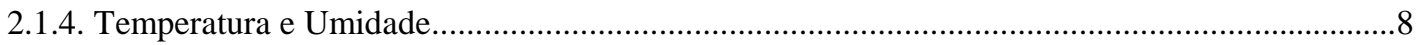

2.2. Solução proposta no projeto milênio.......................................................................................

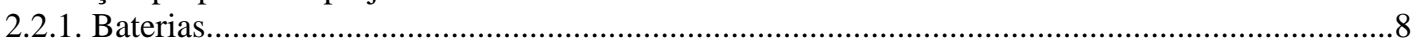

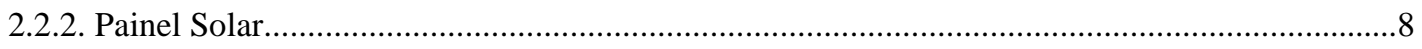

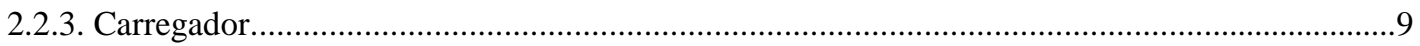

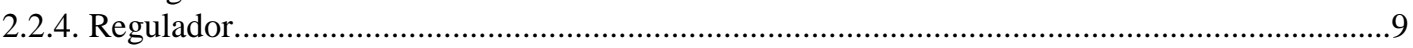

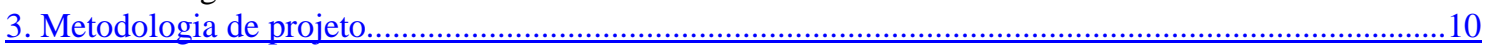

3.1. Passos para a realização do projeto......................................................................................

3.2. Análise das especificações................................................................................................11

3.2.1. Análise das Baterias [43] .............................................................................................11

3.2.2. Análise do Painel Solar - Células Solares.........................................................................12

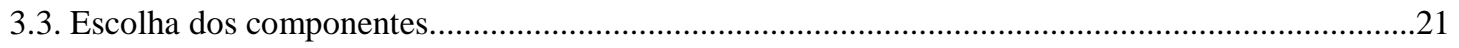

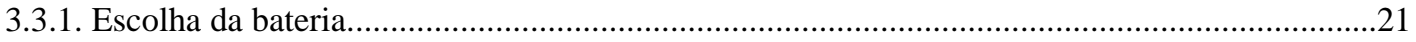

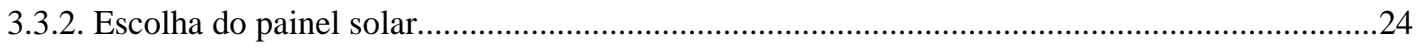

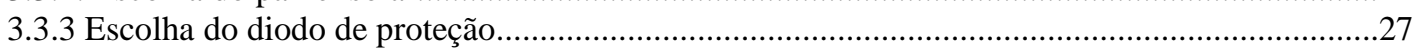

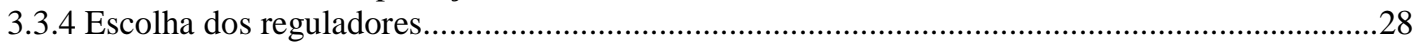

3.4. Topologias de circuito.........................................................................................................

3.4.1. Modelo usando um LM317 e um regulador multisaída..............................................................31

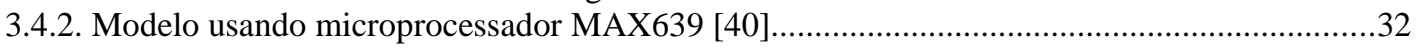

3.4.3. Modelo usando microprocessador PIC16C711 [8] .............................................................3

3.4.4. Modelo usando um LM317 e três LP3982............................................................................

3.4.5. Modelo usando um LM317, três reguladores LP2985 saída fixa e um regulador LP2983 saída

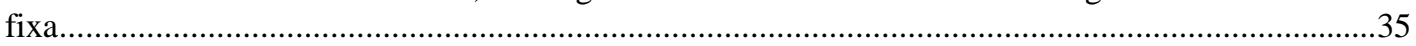

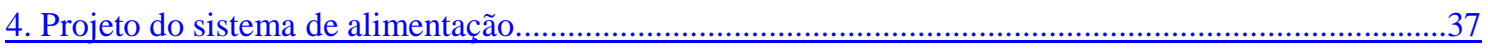

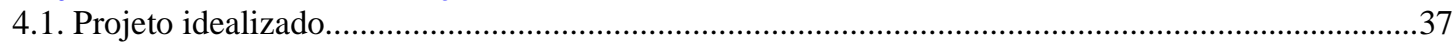

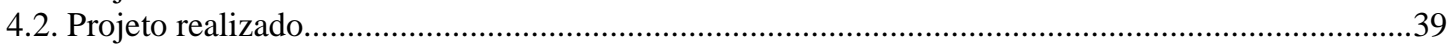

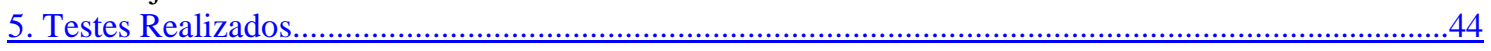

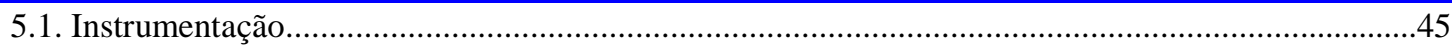

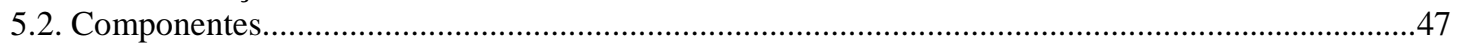

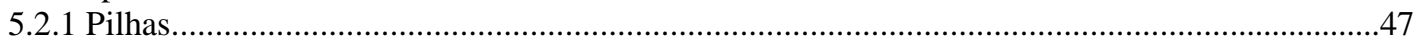

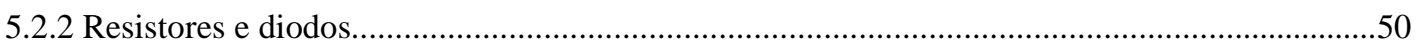

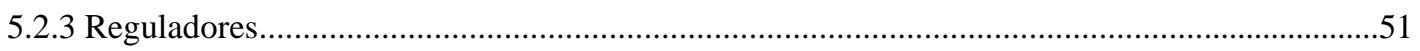

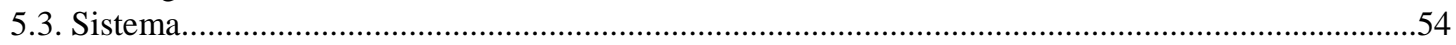

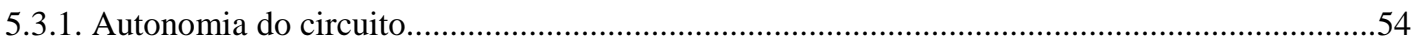

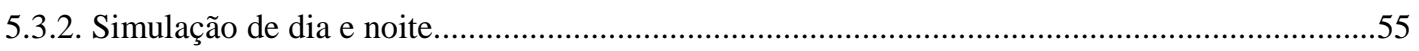

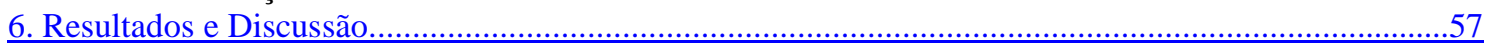

6.1 Resultado do teste de instrumentação............................................................................................57

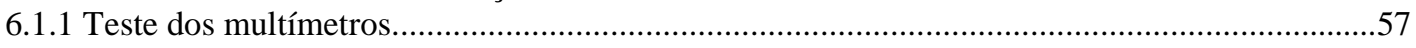

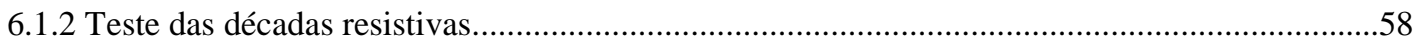

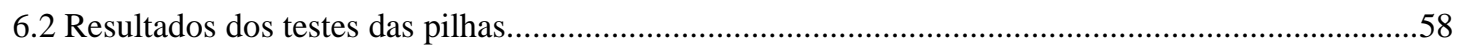

6.2.1. Primeiro teste de descarga lenta a $60 \mathrm{~mA}$..........................................................................59

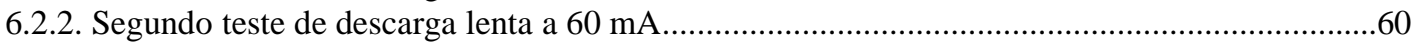

6.2.3. Primeiro teste de carga lenta a $60 \mathrm{~mA}$...............................................................................61

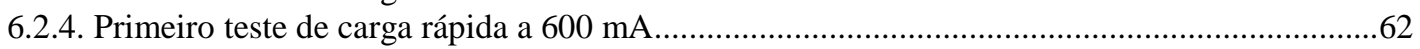

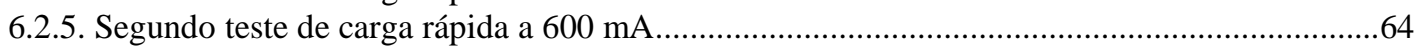

6.2.6. Terceiro teste de descarga lenta a $60 \mathrm{~mA}$............................................................................65

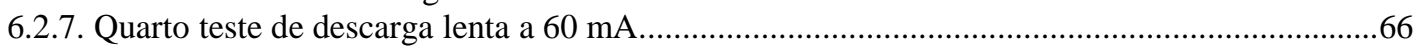

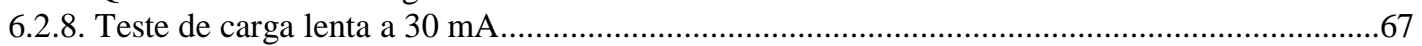

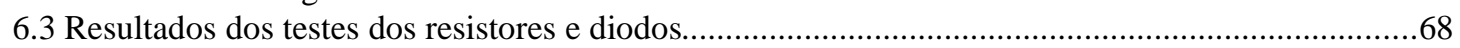

6.4 Resultados dos testes dos reguladores...................................................................................69 
6.4.1. Verificação dos parâmetros dos reguladores...................................................................69

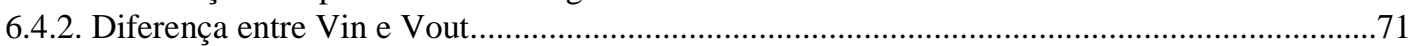

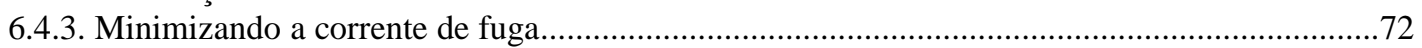

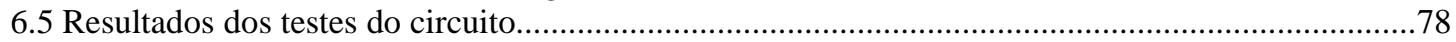

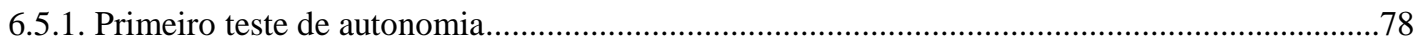

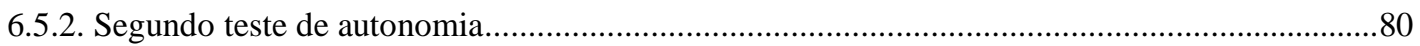

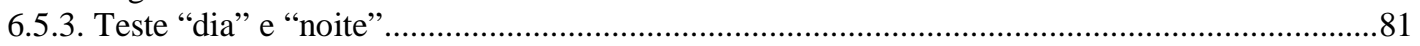

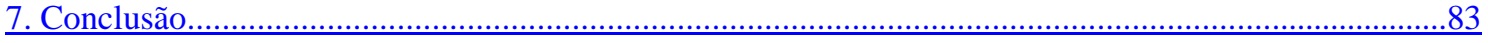

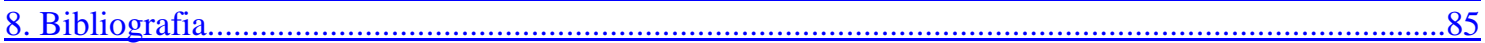

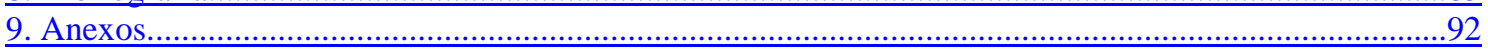

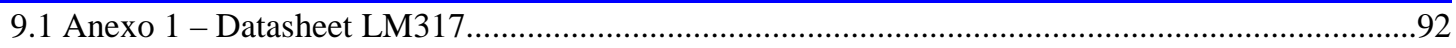

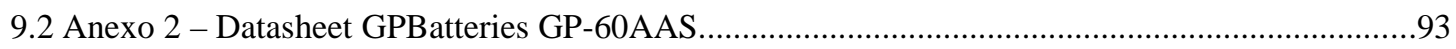

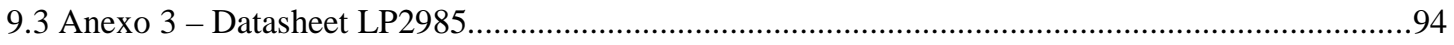

9.4 Anexo 4 - Datasheet LP2983 


\section{Lista de Tabelas, Figuras e Gráficos}

Figura 1.1 - Visão esquemática da cobertura de uma área irrigada, por meio de um arranjo de nós, associado a uma Estação de Campo

Figura 1.2 - Esquemático do sistema da fonte de alimentação...........................................................6

Figura 3.1 - Passos para a realização do projeto..........................................................................10

Tabela 3.1 - Comparativo entre tecnologias de baterias................................................................11

Figura 3.2 - Circuito equivalente simplificado de uma célula solar..................................................14

Figura 3.3 - a) Curvas I-V para as células solares b) Célula solar com o diodo...................................16

Figura 3.4 - Diagrama de circuito para uma célula solar real.......................................................17

Figura 3.5 - Dependência da temperatura nas curvas I-V..............................................................19

Figura 3.6 a) Mudança do ângulo da luz incidente b) Dependência da potência no ângulo de incidência

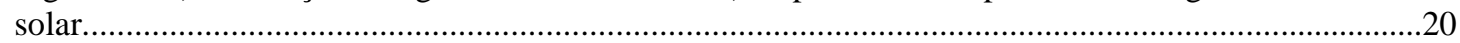

Tabela 3.2- Principais características da bateria modelo KR-AAH....................................................22

Tabela 3.3- Principais características da bateria modelo N-600AAK.................................................22

Tabela 3.4- Principais características da bateria modelo VT-AA......................................................22

Tabela 3.5 - Principais características da bateria modelo GP70AAST ...............................................23

Tabela 3.6 - Principais características da bateria modelo AA-800H................................................23

Tabela 3.7 - Principais características da bateria modelo D-AA-700H..............................................23

Tabela 3.8 - Dados para a cidade de São Paulo................................................................................24

Tabela 3.9 - Especificações das células solares da Canrom Photovoltaics............................................25

Tabela 3.10 - Especificações das células solares da Plastecs.............................................................25

Tabela 3.11 - Especificações das células solares da Quark...............................................................25

Tabela 3.12 - Especificações das células solares da Silicon Solar........................................................26

Tabela 3.13 - Especificações das células solares da AstroPower.......................................................26

Tabela 3.14 - Especificações das células solares da EspectroLab.......................................................26

Tabela 3.15 - Especificações das células solares da Shell...............................................................26

Tabela 3.16 - Especificações das células solares da Atlantic Solar...................................................27

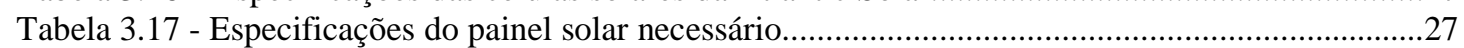

Tabela 3.18 - Principais características do diodo modelo 1N5818 .....................................................28

Figura 3.7 - Utilização do diodo de proteção.............................................................................28

Tabela 3.19 - Principais características do regulador modelo LP2986...............................................29

Tabela 3.20 - Principais características do regulador modelo LP2980 ..................................................29

Tabela 3.21 - Principais características do regulador modelo LP2980-ADJ......................................30

Tabela 3.22 - Principais características do regulador modelo LP2951..............................................30

Tabela 3.23 - Principais características do regulador modelo LP2983 ...............................................30

Tabela 3.24 - Principais características do regulador modelo LP2985...............................................30

Tabela 3.25 - Principais características do regulador modelo ADP3308............................................31

Figura 3.8 - Modelo utilizando um LM317 e um regulador multisaída..............................................32

Figura 3.9 - Modelo utilizando um microprocessador MAX639 ....................................................33

Figura 3.10 - Modelo utilizando um microprocessador PIC16C711 ................................................34

Figura 3.11 - Modelo utilizando um LM317 e três LP3982 ..................................................................35

Figura 3.12 - Modelo utilizando um LM317 e quatro reguladores de saída fixa...................................36

Tabela 3.26 - Principais diferenças entre os principais modelos.......................................................36

Tabela 4.1 - Reguladores escolhidos para o projeto..............................................................................37

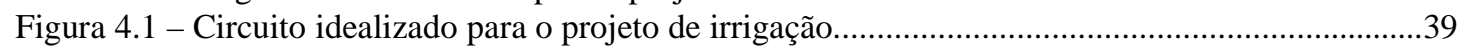

Tabela 4.2 - Valores de R2 para fornecer a tensão de saída.................................................................41

Tabela 4.3 - Valores da carga para cada um dos reguladores.........................................................41

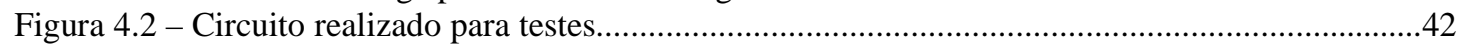

Figura 4.3 - Circuito implementado no laboratório............................................................................43

Figura 5.1 - Equipamentos utilizados no laboratório.......................................................................45

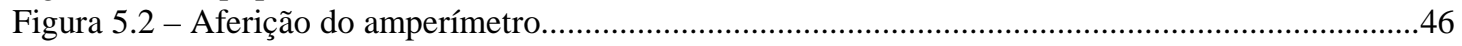

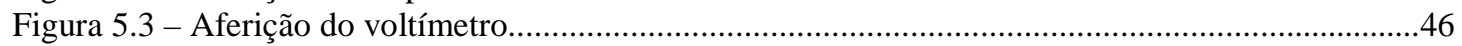

Figura 5.4 - Aferição da década resistiva.....................................................................................46

Figura 5.5 - Teste de carga a $60 \mathrm{~mA}$ para uma pilha......................................................................4

Figura 5.6 - Teste de carga a $60 \mathrm{~mA}$ para quatro pilhas................................................................48

Figura 5.7 - Teste de carga a $30 \mathrm{~mA}$ para quatro pilhas..................................................................48

Figura 5.8 - Teste de descarga a $60 \mathrm{~mA}$ para uma pilha.................................................................49 
Figura 5.9 - Teste de descarga a 60 mA para quatro pilhas..........................................................49

Figura 5.10 - Teste de carga a 600 mA para uma pilha..................................................................50

Figura 5.11 - Teste de carga a $600 \mathrm{~mA}$ para quatro pilhas...............................................................50

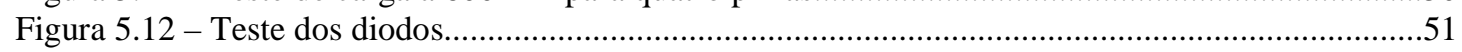

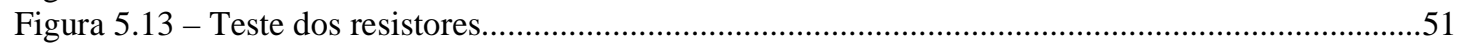

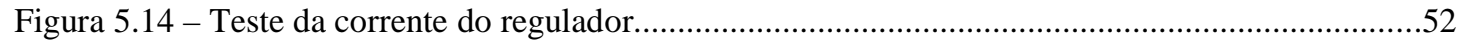

Figura 5.15 - Teste da tensão de saída do regulador.....................................................................52

Figura 5.16 - Teste da corrente quiescente do regulador................................................................53

Figura 5.17 - Teste de minimização da corrente de fuga....................................................................54

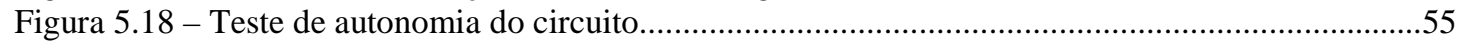

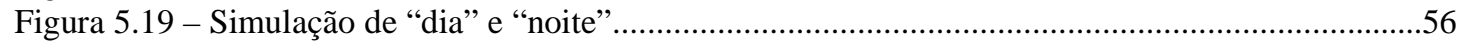

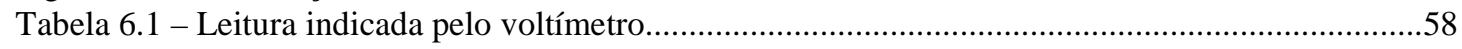

Tabela 6.2 - Leitura indicada pelo amperímetro...........................................................................58

Tabela 6.3 - Resistências aferidas pelo multímetro........................................................................58

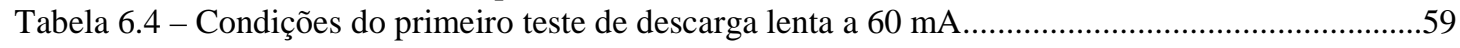

Tabela 6.5 - Resultados do primeiro teste de descarga lenta a $60 \mathrm{~mA}$................................................59

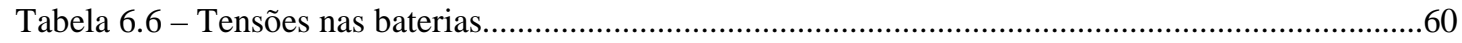

Tabela 6.7 - Condições do segundo teste de descarga lenta a 60 mA................................................60

Tabela 6.8 - Resultados do segundo teste de descarga lenta a $60 \mathrm{~mA}$...............................................60

Tabela 6.9 - Condições do primeiro teste de carga lenta a 60 mA......................................................61

Tabela 6.10 - Resultado do primeiro teste de carga lenta a 60 mA..................................................61

Tabela 6.11 - Tensão final das baterias 3A, 3B, 3C e 3D.............................................................62

Tabela 6.12 - Condições do primeiro teste de carga rápida a 600 mA...............................................62

Tabela 6.13 - Resultados do primeiro teste de carga rápida a 600 mA............................................63

Gráfico 6.1 - Resultado do primeiro teste de carga rápida a 600 mA................................................63

Tabela 6.14 - Tensão final das baterias 1A, 1B, 1C e 2A................................................................64

Tabela 6.15 - Condições do segundo teste de carga rápida a 600 mA...............................................64

Tabela 6.16 - Resultados do segundo teste de carga rápida a 600 mA.............................................64

Gráfico 6.2 - Resultado do segundo teste de carga rápida a 600 mA..................................................65

Tabela 6.17 - Condições do terceiro teste de descarga lenta a 60 mA...............................................66

Gráfico 6.3 - Resultado do terceiro teste de descarga lenta a 60 mA................................................66

Tabela 6.18 - Condições do quarto teste de descarga lenta a $60 \mathrm{~mA}$.................................................67

Gráfico 6.4 - Resultado do quarto teste de descarga lenta a $60 \mathrm{~mA}$....................................................67

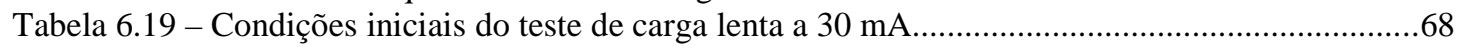

Gráfico 6.5 - Resultado do teste de carga lenta a 30 mA................................................................68

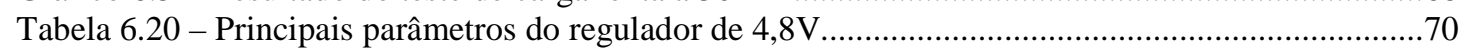

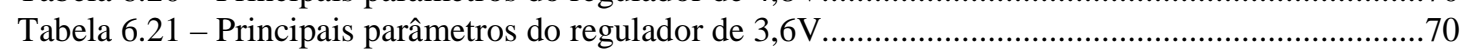

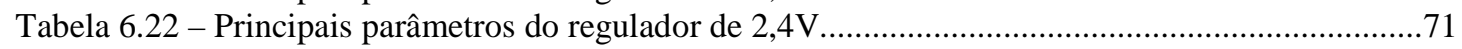

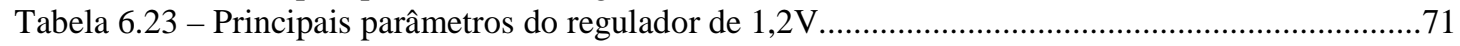

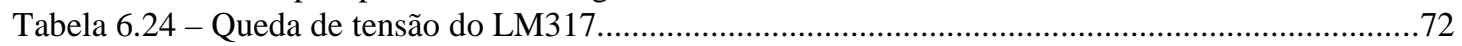

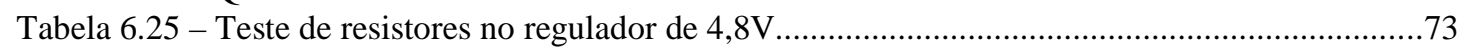

Gráfico 6.6 - Corrente de Fuga versus Tensão na carga no regulador de 4,8V...................................73

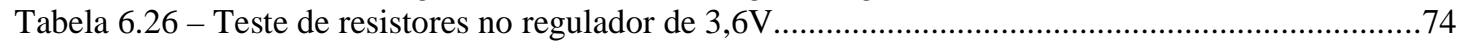

Gráfico 6.7 - Corrente de Fuga versus Tensão na carga no regulador de 3,6V ..................................75

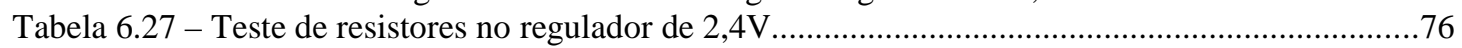

Gráfico 6.8 - Corrente de Fuga versus Tensão na carga no regulador de 2,4V ...................................76

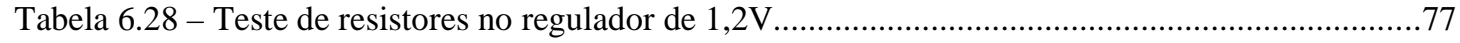

Gráfico 6.9 - Corrente de Fuga versus Tensão na carga no regulador de 1,2V..................................77

Tabela 6.29 - Valores de corrente antes e depois da troca dos resistores............................................78

Tabela 6.30 - Valores de tensão nos reguladores para cada tensão na pilha........................................79

Gráfico 6.10 - Tensão de saída na bateria e nos reguladores...........................................................79

Gráfico 6.11 - Tensão nas baterias no teste de autonomia.................................................................80

Gráfico 6.12 - Tensão nas baterias no teste de dia e noite................................................................82

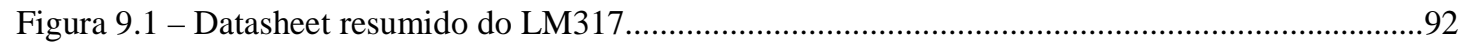

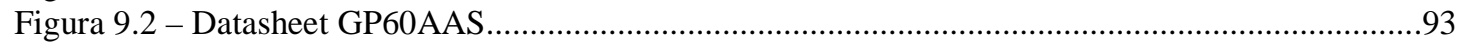

Figura 9.3 - Datasheet resumido LP2985 .............................................................................95

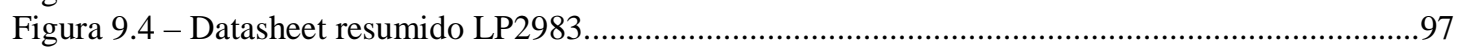




\section{Introdução}

No Brasil, considerando-se a extensa rede de distribuição de energia elétrica e sua interligação entre diversas regiões do país, o uso de painéis solares fotovoltaicos tem sido compensador, por exemplo, para a alimentação de sistemas pontuais situados em locais de difícil acesso.

O Projeto da fonte de alimentação para o nó remoto do Sistema de Controle de Irrigação (SCI) [1] se apresenta como uma atividade que justifica a utilização de painéis fotovoltaicos para seu funcionamento, podendo atender às áreas mais afastadas da rede elétrica comum e abrangendo lugares de difícil acesso, desde que haja luz solar disponível.

$\mathrm{O}$ projeto apresenta um modelo de circuito que atenderá às necessidades de um sistema de controle completo, com sensor de pressão, microprocessador, transceptor de RF, etc.

O modelo idealizado para o nó remoto do sistema de controle de irrigação não pode ser montado nem testado nesta oportunidade do projeto. No entanto, um modelo equivalente, utilizando dispositivos que desempenham a mesma função, foi montado e diversos testes de funcionalidade e eficiência foram realizados. O resumo dos testes realizados se encontra na seção 5, enquanto que seus resultados, gráficos e a análise se encontram na seção 6 .

\subsection{Visão geral sobre o Sistema de Controle de Irrigação - SCI}

O Sistema de Controle de Irrigação é uma atividade associada ao objetivo 5 (Projeto de dispositivos, circuitos integrados e microsistemas) e à meta de número 9 (Realização de uma aplicação: um sistema inteligente em chip com capacidade autônoma de comunicação, como exemplo um sistema de controle de umidade e irrigação para agricultura) do Instituto do Milênio - SCMN [18]. 
O sistema escolhido é de grande interesse para a otimização do aproveitamento de recursos hídricos na agricultura brasileira, pois permitirá a monitoração "in situ" do teor de umidade do solo e, por conseguinte, evitar o desperdício de recursos em práticas de irrigação.

Nesta atividade busca-se, além da implementação de uma aplicação com características inovadoras em microeletrônica, integrar as atividades implementadas ao longo do projeto, incorporando as contribuições cientificas e tecnológicas obtidas nas demais atividades, evidenciando a proposta de projeto em rede e todas as implicações associadas a esta complexa atividade multidisciplinar. Essa atividade servira, assim, também, como um veiculo de teste e de aprendizagem da metodologia de trabalho cooperativo que norteia todo o projeto, dando visibilidade a este "Instituto do Milênio".

Ela compreende uma especificação detalhada da aplicação, a qual estabelece parâmetros indicadores para o desenvolvimento das demais atividades. Em linhas gerais essa aplicação consistirá em um sistema em chip com capacidade para telemetria, processamento local de sinais e interfaceamento com sensores de pressão (a ele integrados ou não). A realização será efetuada em tecnologia CMOS. O projeto desse sistema demandará a implantação de um sistema de gerenciamento em larga escala, com troca constante de informações entre as diferentes equipes. Será adotada uma abordagem hierárquica e serão incorporadas técnicas de projeto voltadas à testabilidade e à compatibilidade eletromagnética. A figura 1.1 ilustra a visão esquemática da cobertura de uma área irrigada. 


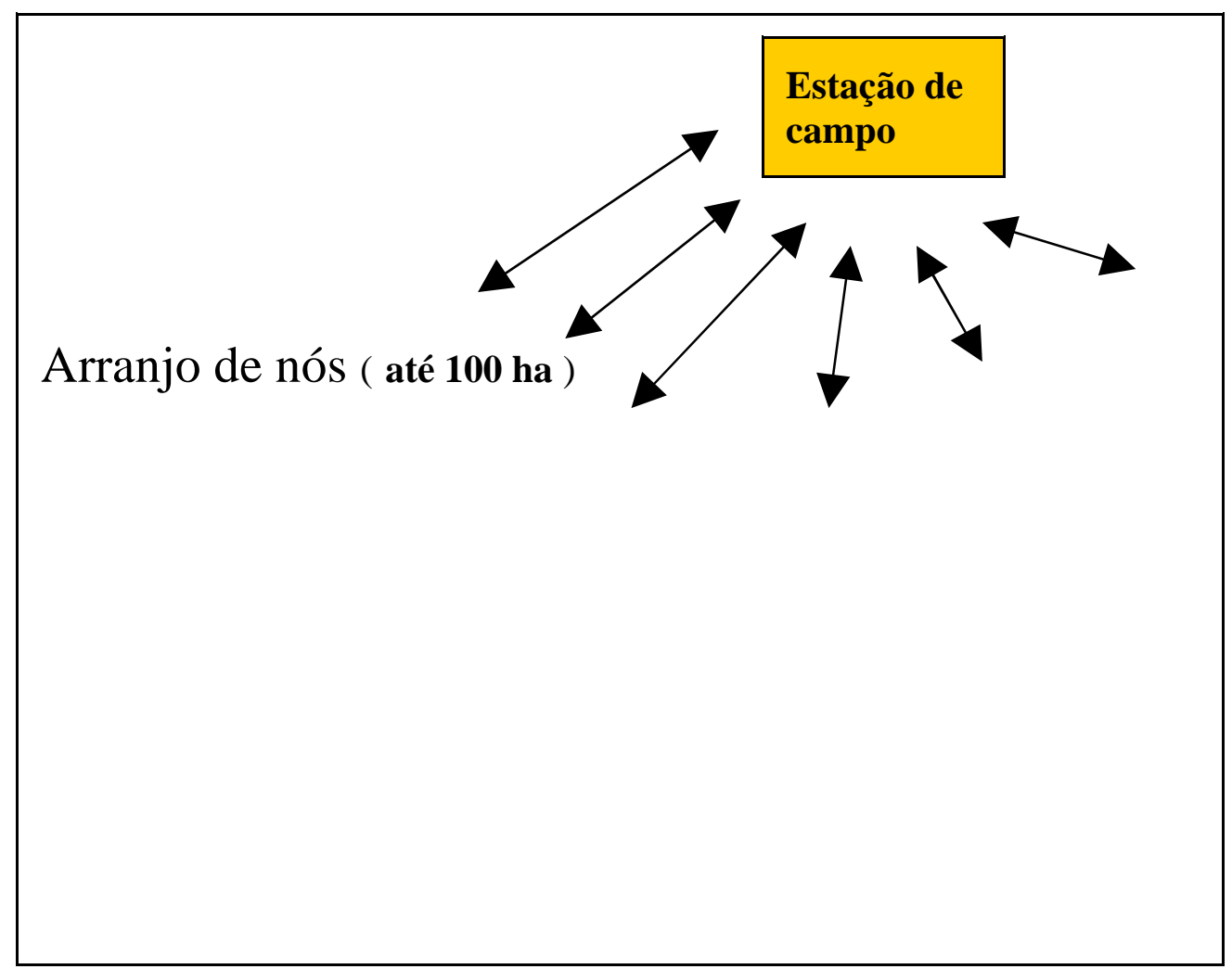

Figura 1.1 - Visão esquemática da cobertura de uma área irrigada, por meio de um arranjo de nós, associado a uma Estação de Campo.

\subsection{Objetivos do presente projeto}

O objetivo do seguinte projeto é idealizar, dimensionar e indicar uma topologia para a construção da fonte de alimentação das estações remotas de campo, levando em conta alguns aspectos importantes como autonomia, consumo, estabilidade, temperatura, umidade, preço, tamanho, eficiência, disponibilidade no mercado e facilidade de implementação e manutenção, dentre outros aspectos. Essa fonte deverá ser baseada em alimentação por painéis solares que manterão carregadas um conjunto de baterias.

O sistema deverá ser simples o bastante para prover um meio de carregamento das baterias com o mínimo custo possível, ao mesmo tempo em que maximiza o ciclo de vida delas.

Segue abaixo um pequeno esquemático de como deverá ser o sistema: 


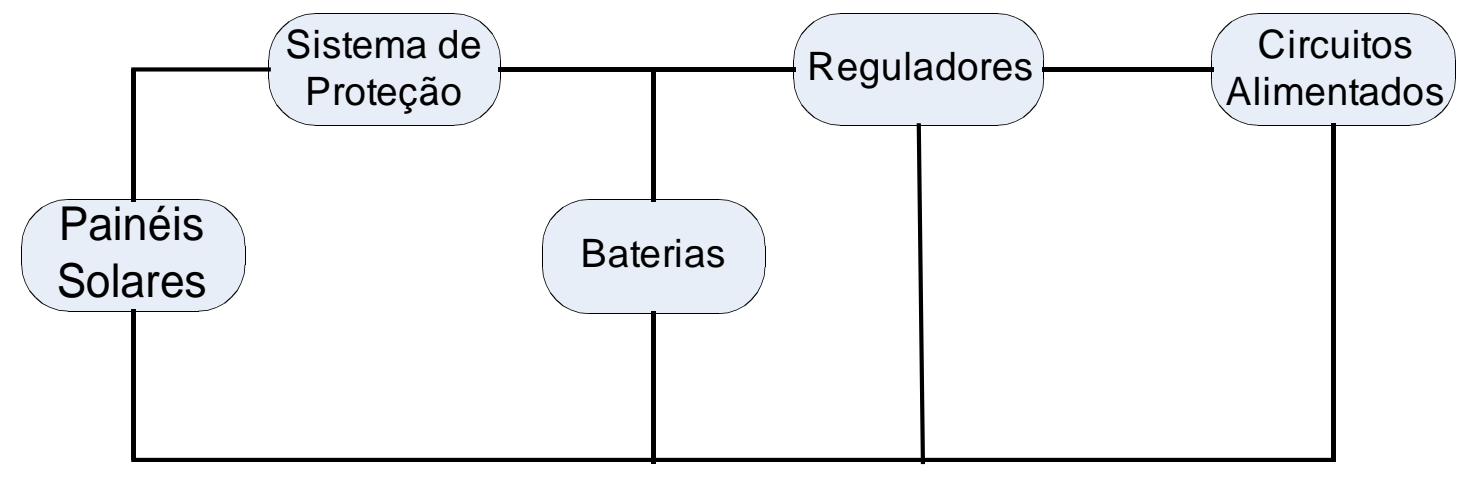

Figura 1.2 - Esquemático do sistema da fonte de alimentação 


\section{Especificações}

\subsection{Alimentação do nó remoto}

A fonte de alimentação do nó remoto deverá seguir uma série de características, a partir das quais parte-se para a escolha dos dispositivos e da topologia de projeto.

\subsubsection{Autonomia}

Dada a situação em que se encontrará a fonte de alimentação, uma vez implementada, é desejável que ela tenha uma autonomia razoável para que o sistema não deixe de funcionar em caso de dias prolongados de chuvas e nuvens. Essa autonomia deverá der da ordem de 10 dias sem que haja nenhum tipo de insolação que permita o carregamento das baterias.

Não haverá possibilidade de energia elétrica no local, dada a distância que o nó remoto poderá ficar da estação central. Isso nos remete ao uso de painéis solares para alimentar o sistema e carregar as baterias.

\subsubsection{Consumo}

O consumo do sistema e dos próprios dispositivos utilizados no projeto da fonte de alimentação deverá ser o mínimo possível, levando-se em conta o custo e a disponibilidade no mercado. Estima-se que o consumo total do sistema será da ordem de $250 \mathrm{~mW}$

\subsubsection{Confiabilidade}

A estabilidade é um item fundamental num projeto que é o cerne de todo um sistema, ou seja, se a fonte de alimentação não funcionar, o nó remoto não funcionará. Dessa maneira, devem ser escolhidos dispositivos de qualidade e procedência, bem como dimensionar o projeto com folga no consumo de potência. Isso garantirá que a fonte de alimentação não 
estará sub-dimensionada, podendo vir a falhar ou apresentar erros futuramente.

\subsubsection{Temperatura e Umidade}

A temperatura e a umidade são fatores preponderantes no desenvolvimento do projeto, visto que não serão nada comuns. Como o nó remoto ficará localizado logo acima do solo, espera-se uma temperatura variando entre $-10^{\circ} \mathrm{C}$ e $80^{\circ} \mathrm{C}$ e umidade do ar variando entre $30 \%$ e $90 \%$.

\subsection{Solução proposta no projeto milênio}

Essas são as especificações físicas iniciais da fonte de alimentação propostas pelo projeto Milênio [1]:

\subsubsection{Baterias}

- Baterias recarregáveis (tecnologia: NiCd, NiMh, Li-ion);

- Carga: 1000 mAh (típica);

- Tensão: mínima de 4,8 V (sem conversão DC-DC) ou compatível com o conversor DC-DC adotado;

- Formato: AA;

- Operação a alta temperatura (> 80 graus Celsius);

- Durabilidade mínima: 1 ano (nas especificações);

\subsubsection{Painel Solar}

Parâmetros a serem considerados:

- Potência mínima (para Si Voc= $0,6 \mathrm{~V}$ );

- Área mínima;

- Robustez;

- Baixo Custo;

- Circuitos de proteção; 


\subsubsection{Carregador}

- Compatível com a bateria especificada e com o painel solar adotado;

- Compacto;

- Eficiente;

- Baixo ruído;

- Robusto;

- Baixo custo;

\subsubsection{Regulador}

- Compatível com a especificação geral das tensões de alimentação do nó;

- Compatível com a bateria especificada;

- Compacto;

- Eficiente;

- Baixo ruído;

- Robusto;

- Baixo custo. 


\section{Metodologia de projeto}

\subsection{Passos para a realização do projeto}

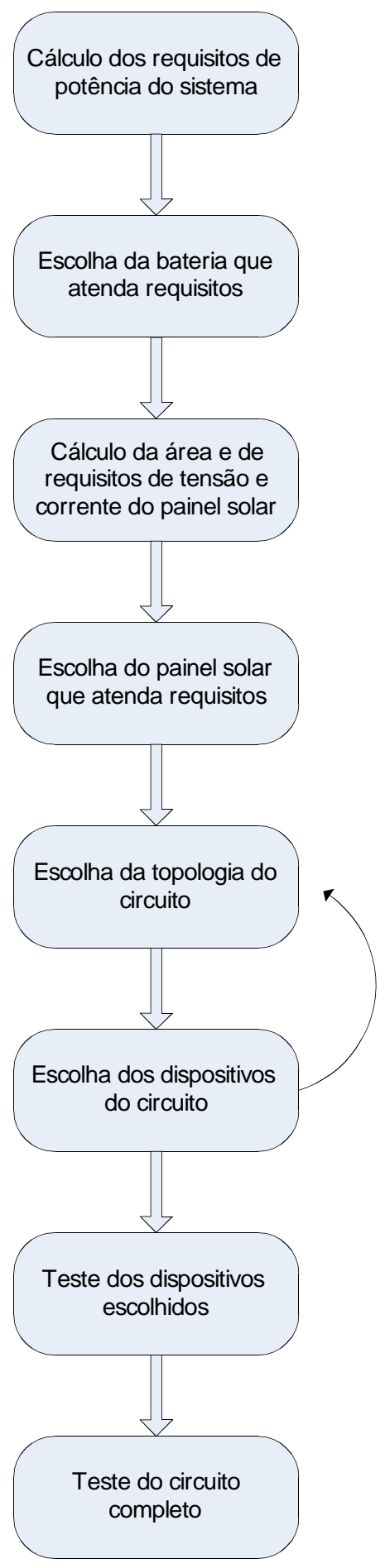

Figura 3.1 - Passos para a realização do projeto 


\subsection{Análise das especificações}

O sistema de alimentação deverá ser concebido a partir das características e especificações que foram enumeradas anteriormente. A proposta do projeto Milênio nos remete a vários tipos, marcas e modelos de dispositivos que oferecem as mesmas características, cada qual com suas vantagens e desvantagens. O objetivo deste capítulo é poder analisar os dispositivos disponíveis e, partindo de suas características, escolher os que melhor se adaptam às necessidades do projeto de controle de irrigação.

\subsubsection{Análise das Baterias [43]}

De acordo com as especificações, as baterias devem ser recarregáveis, ter uma capacidade nominal típica de $1000 \mathrm{mAh}$, ter formato AA, operarem em temperaturas acima de $80^{\circ} \mathrm{C}$, dentre outras. Existem três tipos de tecnologia candidatas para este tipo de aplicação: Níquel Cádmio (NiCd), Níquel Metal-Hidreto (NiMh) e Íons de Lítio (LiIon). Abaixo, uma tabela comparativa entre as tecnologias abordadas:

\begin{tabular}{|l|c|c|c|}
\hline \multicolumn{1}{|c|}{ Tipo } & NiCd & NiMH & Li-Ion \\
\hline Tensão Nominal Média (V) & $1.2 \mathrm{~V}$ & $1.2 \mathrm{~V}$ & $3.7 \mathrm{~V}$ \\
\hline Densidade de energia (W.h/l) & 140 & 180 & 200 \\
\hline Densidade de energia (W.h/Kg) & 39 & 57 & 83 \\
\hline Custo $(\$ / W h)$ & $0.75-1.5$ & $1.5-3.0$ & $2.5-3.5$ \\
\hline Corrente máxima para descarga & $20 \mathrm{C}$ & $4 \mathrm{C}$ & $2 \mathrm{C}$ \\
\hline Descarga (por dia) & $1 \%$ & $1,5 \%$ & $0,5 \%$ \\
\hline Tempo de carga (mais rápido) & $15 \mathrm{~min}$ & $30 \mathrm{~min}$ & $1 \mathrm{~h}$ \\
\hline Temperatura para carga $\left({ }^{\circ} \mathrm{C}\right)$ & 0 to +50 & 0 to +45 & 5 to+ 45 \\
\hline Temperatura para descarga $\left({ }^{\circ} \mathrm{C}\right)$ & -20 to +50 & -20 to +50 & 0 to +40 \\
\hline Resistência contra sobrecarga & Baixa & Baixa & Média \\
\hline Material do Cátodo & NiOOH & NiOOH & LiCoO2 \\
\hline Material do Ânodo & Cádmio & Liga metálica & Carbono \\
\hline Número Máximo de Ciclos & 1000 & 500 & 400 \\
\hline
\end{tabular}

Tabela 3.1 - Comparativo entre tecnologias de baterias

" $C$ " indica a capacidade nominal da pilha em $m A h$ 
O efeito memória acontece apenas nas baterias de Níquel Cádmio e é relativamente raro. Ele pode ocorrer durante o ciclo de descarga para um nível fixo definitivo e uma subseqüente recarga. Quando a célula é descarregada, seu potencial cai vários décimos de volt aquém do normal e permanece lá até o fim da descarga. A capacidade total da célula não é afetada significantemente e o efeito memória desaparece quando a célula é descarregada e depois carregada mais uma ou duas vezes. Em aplicações práticas, o efeito memória não é um problema porque as baterias de Níquel Cádmio são raramente descarregadas para o mesmo potencial antes de recarregar.

Existe um problema ambiental com relação à inutilização das baterias de NiCd devido ao poder poluidor do metal usado. Já as baterias de NiMH e Li-Ion não contem concentração significativa de poluente, entretanto, é sempre desejável que se tenha cuidado ao jogá-las fora. Uma consciência de reciclagem é desejável nas três tecnologias.

\subsubsection{Análise do Painel Solar - Células Solares}

Células solares são compostas de vários materiais semicondutores e podem ser divididas em três tipos [12]:

- Células de silício cristalino: são fabricadas com este tipo de material que consiste em finas camadas de puro silício cristalino tratado quimicamente. A espessura das camadas comerciais está entre 200 e 400 mícrons, sendo cobertas por uma grelha metálica em ambas as faces permitindo o contato elétrico;

- Células solares mono-cristalinas: fabricadas a partir de puro cristal de silício. Estas células são as mais eficientes de todas as células de silício, mas também são as mais caras;

- Células solares poli-cristalinas: também fabricadas a partir de silício puro, mas estas são fabricadas a partir de lingotes de grande 
dimensão. O processo de fabricação consiste em arrefecer lentamente o silício, mantido em estado líquido em fornos especiais, para permitir o crescimento de grandes cristais. As células poli-cristalinas são menos eficientes, mas também são mais baratas.

Para facilitar a análise das explicações e dos cálculos que virão a seguir, faz-se necessária uma breve teoria sobre conversão de energia [26].

A geração de eletricidade a partir da luz solar é obtida através de células solares, dispositivos que têm seu funcionamento fundamentado no efeito fotovoltaico que consiste, essencialmente, na conversão de energia luminosa incidente sobre materiais semicondutores, convenientemente tratados, em eletricidade.

Quando a luz do sol incide sobre certos materiais, chamados semicondutores, os fótons que a constituem são capazes de transmitir sua energia aos elétrons de valência do semicondutor, para que rompam a ligação que lhes mantém ligados aos respectivos átomos. Os semicondutores são materiais que se tornam eletricamente condutores quando expostos à luz ou calor, mas funcionam como isolantes em baixas temperaturas e no escuro.

Para cada ligação desfeita há um elétron livre para circular dentro do semicondutor. A falta do elétron na ligação desfeita, que se chama lacuna, também pode deslocar-se livremente no interior do semicondutor, transferindo-se de um átomo a outro devido ao deslocamento do resto dos elétrons das ligações. As lacunas se comportam, em muitos aspectos, como partículas com carga positiva igual a do elétron. O movimento dos elétrons e lacunas em direções opostas gera uma corrente elétrica no semicondutor capaz de circular por um circuito externo 
Para seu emprego prático, as células solares são associadas eletricamente em diferentes combinações que permitem obter os valores de corrente e tensão necessários para determinada aplicação. $\mathrm{O}$ conjunto de células, conexões e estrutura de proteção denominam-se módulo fotovoltaico. $\mathrm{O}$ processo explicado tem como principal semicondutor o silício. Depois do oxigênio, este é o material mais abundante na crosta terrestre. O silício é obtido do quartzito a partir da areia, matéria-prima usada na fabricação do vidro e das fibras óticas (quartzo). Purificado e transformado em lâminas, ele dá origem à célula-solar, a alma da placa fotovoltaica.

3.2.2.1. Caracterização ideal e parâmetros básicos das células solares [44]

O circuito equivalente simplificado de uma célula solar consiste em um diodo e uma fonte de corrente conectados em paralelo, conforme ilustrado na figura 3.2.

A fonte de corrente gera a corrente Iph, que é diretamente proporcional à irradiação solar $S$ e à temperatura $T$. A junção p-n de uma célula solar é equivalente a um diodo, que também está na figura 3.2. No fim das contas, uma célula solar é apenas um diodo.

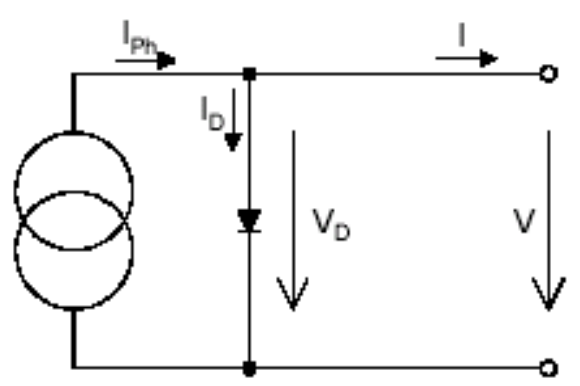

Figura 3.2 - Circuito equivalente simplificado de uma célula solar.

A equação característica de tensão e corrente de um diodo ideal é dada pela seguinte fórmula: 


$$
I_{D}=\mathrm{I}_{\mathrm{RS}} \cdot\left(e^{\frac{q \cdot V_{D}}{A \cdot k \cdot T}}-1\right)
$$

onde,

Irs é a corrente de saturação reversa;

$\mathrm{q}=1.6 \times 10-19[\mathrm{C}]$ é a unidade fundamental de carga;

$\mathrm{k}=1.38 \times 10-23[\mathrm{~J} / \mathrm{K}]$ é a constante de Boltzmann;

A é um fator de qualidade do diodo (1 a 5, 1 significa uma junção p-n ideal);

VD é a queda de tensão sobre o diodo [V];

T é a temperatura absoluta $[\mathrm{K}], 0^{\circ} \mathrm{C}=273.15 \mathrm{~K}$.

O comportamento teórico sobre irradiação solar é representado por:

$$
I=I_{p h}-I_{D}
$$

Onde,

Iph representa a corrente da célula solar;

Id é a corrente do diodo descrito acima.

$\mathrm{Na}$ figura 3.3a estão ilustradas as características I-V de uma célula ideal em duas posições diferente. A curva de cima (vermelha) mostra uma célula solar ideal no escuro. A curva de baixo (verde) mostra uma célula solar ideal sobre uma irradiação de $1000 \mathrm{~W} / \mathrm{m} 2$. Para uma célula ideal, as características I-V são simplesmente transferidas para cima no gráfico, graças à corrente Iph gerada pela luz incidente. No caso de uma célula no escuro, pode acontecer a situação de corrente negativa pelas células. Isto é devido ao comportamento da célula solar agindo como uma junção p-n em paralelo com uma fonte de corrente. Para evitar esse tipo de situação, 
pode-se usar um diodo conectado em série com a célula solar em polarização negativa, conforme figura $3.3 \mathrm{~b}$.
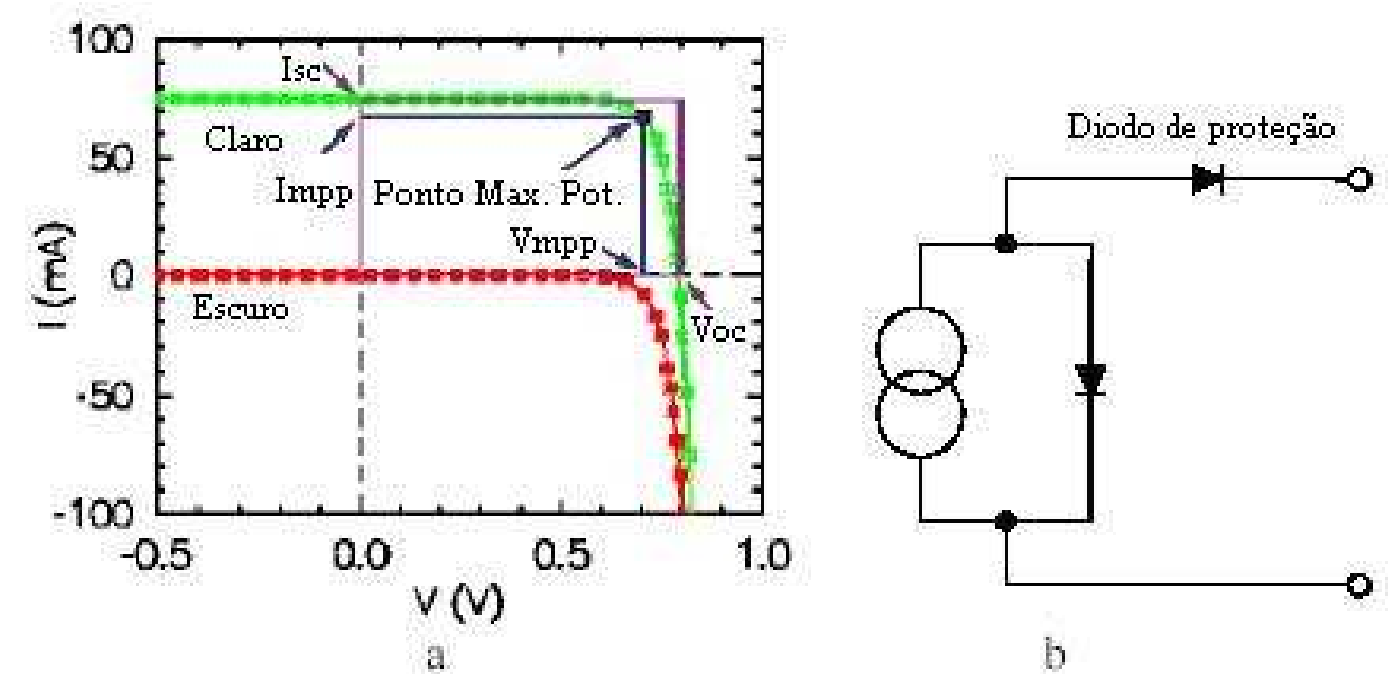

b

Figura 3.3 - a) Curvas I-V para as células solares b) Célula solar com o diodo

Na curva I-V são mostrados alguns pontos típicos para células solares. A tensão de circuito aberto Voc, a corrente de curto circuito Isc, a tensão que proporciona potência máxima Vmpp, a corrente que proporciona potência máxima Impp.

O Fator de preenchimento pode ser definido como uma razão da máxima potência e do produto da corrente de curto circuito e da tensão de circuito aberto e pode ser expresso por:

$$
F F=\frac{\mathrm{V}_{\mathrm{MPPP}} \cdot I_{M P P P}}{\mathrm{~V}_{\mathrm{OC}} \cdot I_{S C}}
$$

O Fator de preenchimento é sempre menor que a unidade; quanto mais próximo de 1 , melhor a qualidade da célula solar.

Uma das mais importantes características das células solares é a constante que mostra a eficiência da conversão de energia:

$$
\eta=\frac{\text { Máxima Potência Elétrica }}{\text { Potência da luz incidente }}
$$


3.2.2.2. Célula solar real - Influência da temperatura e da luz incidente na curva I-V [44]

$\mathrm{Na}$ figura 3.4 está sendo mostrado o circuito equivalente de uma célula solar real. Em células reais, podemos observar uma queda de tensão das células até os contatos externos. Esta queda de tensão pode ser expressa por um resistor Rs em série. Além disso, há uma corrente quiescente que pode ser representada por um resistor em paralelo, Rp.

Para a descrição deste circuito, podemos utilizar as relações mencionadas acima com algumas modificações que também envolvem influência da temperatura.

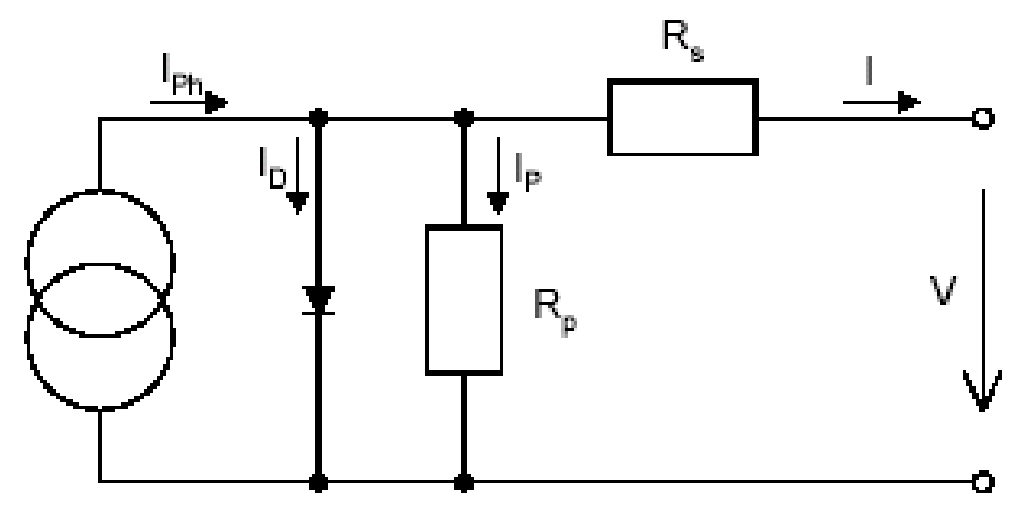

Figura 3.4 - Diagrama de circuito para uma célula solar real

A equação abaixo relaciona as características I-V de um diodo real com um número de parâmetros do dispositivo: 


$$
\begin{aligned}
& I=I_{P h}-I_{D}-I_{P}=\left(I_{S C}+k_{i} \cdot\left(T-T_{r e f}\right)\right) \cdot \frac{S}{100}- \\
& -I_{R R} \cdot\left(\frac{T}{T_{r e f}}\right)^{3} \cdot e^{\frac{q \cdot E_{G}}{A \cdot k}\left(\frac{1}{T_{r e f}}-\frac{1}{T}\right)} \cdot\left(e^{\frac{q \cdot\left(V+I \cdot R_{S}\right)}{A \cdot k \cdot T}}-1\right)- \\
& -\frac{V+I \cdot R_{S}}{R_{P}}
\end{aligned}
$$

Onde,

Isc é a corrente de curto circuito [A];

ki é o coeficiente da temperatura de curto circuito;

$\mathrm{T}$ é a temperatura da célula $[\mathrm{K}]$;

Tref é a temperatura de referência da célula $[\mathrm{K}]$;

$\mathrm{S}$ é a irradiação solar [mW/cm2];

Irr é a corrente de saturação reversa em Tref [A];

q é a carga de um elétron, 1.6 x 10-19 [eV];

Eg é a energia da banda de gap do semiconductor usado na célula [eV];

K é a constante de Boltzmann, 1.38 x 10-23 [J/K];

A é o fator de qualidade (1 a 5, 1 significa junção p-n ideal);

Rs é a resistência em série da célula [.];

RP é a resistência em paralelo da célula [.].

A maioria dos parâmetros da célula solar mostra uma dependência da temperatura. A equação geral para calcular o coeficiente Tc para um dado valor y é:

$$
T C(y)=\frac{1}{y} \cdot \frac{\partial y}{\partial T}
$$


No caso de uma relação linear entre y e a temperatura, então a equação acima pode ser reescrita:

$$
T C(y)=\frac{1}{y\left(T_{0}\right)} \cdot \frac{y\left(T_{1}\right)-y\left(T_{0}\right)}{T_{1}-T_{0}}
$$

A corrente de curto circuito aumenta um pouco em temperaturas maiores, enquanto que a tensão de circuito aberto fica menor (-0.4 $[\% / \mathrm{K}])$. Portanto, a potência de saída é menor para temperaturas maiores. A perda de potência é algo em torno de $0,3-0,5 \%$ por grau Celsius e um aumento de $30^{\circ} \mathrm{C}$ na temperatura faz a potência cair por volta de $9-15 \%$, conforme a figura 3.4 .

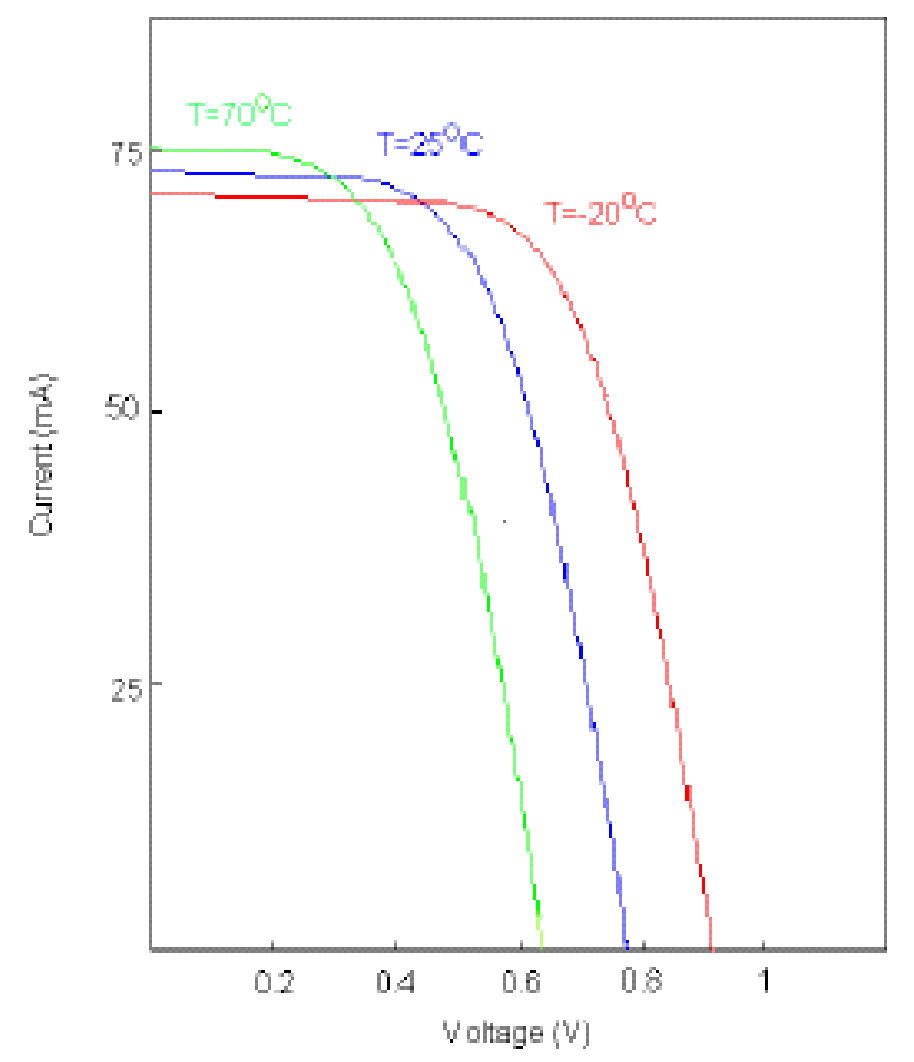

Figura 3.5 - Dependência da temperatura nas curvas I-V

A potência que é adquirida pela célula solar depende do ângulo de incidência da luz do sol. Na figura a seguir é ilustrada uma situação onde o ângulo é variado: 


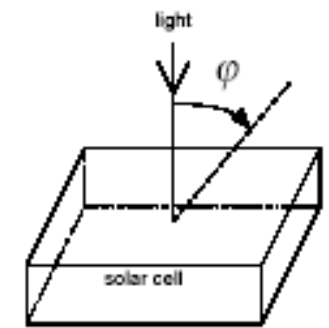

a
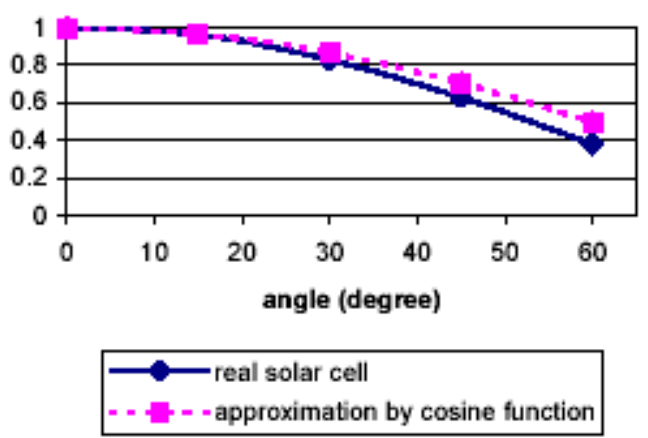

b

Figura 3.6 a) Mudança do ângulo da luz incidente b) Dependência da potência no ângulo de incidência solar

Para a descrição dessa situação é possível usar função matemática exata, porém, devido à sua complexidade, a função mais usada é a função co-seno. Na figura 3.6b está sendo mostrada por unidades de valor de potência a dependência da célula na incidência para aproximações reais e para a função co-seno.

\subsubsection{Cálculo da área de um painel solar}

O cálculo da área ideal de uma célula solar depende de três fatores: Radiação solar, eficiência da célula e potência de pico da célula. Todos estes fatores se relacionam pela seguinte fórmula:

$$
A=\frac{\text { Potência da Célula }(\mathrm{W})}{\text { Densidade de Potência }(\mathrm{W} / \mathrm{cm} 2) * \text { Eficiência }}
$$

Essa fórmula nos mostra que a área da célula é inversamente proporcional ao produto da densidade de potência pela eficiência, ou seja, quanto maior a eficiência ou a densidade, menor a área necessária para proporcionar uma mesma potência. 


\subsection{Escolha dos componentes}

\subsubsection{Escolha da bateria}

A nossa base para seleção da tecnologia da bateria foi capacidade de carga, faixa de operação de temperatura, segurança e preço. Nós optamos pelo uso do Níquel Cádmio (NiCd).

As baterias de Níquel Cádmio oferecem vantagens sobre as outras tecnologias pesquisadas. Possuem um custo menor, podem ser descarregadas com altas correntes, podem ser completamente carregadas em alguns minutos, têm faixas de temperatura de operação bastante grandes e, principalmente, não liberam hidrogênio em suas reações de Oxi-redução. Um acúmulo de hidrogênio dentro do nó remoto associado a altas temperaturas poderia causar uma explosão.

Há, entretanto, algumas desvantagens advindas da escolha da bateria. As baterias de NiCd têm uma tendência de apresentar efeito memória e queda de tensão. Isso nada mais é do que uma mudança na química da bateria que pode ser causada por sobrecarga. Portanto, é desejável que o carregador tenha meios de detectar carga completa na bateria ou carregá-la com uma corrente bem pequena, em torno de 5-10\% de sua carga nominal.

Foram pesquisados vários modelos de várias marcas de baterias, mas poucas se enquadram nas especificações de temperatura, conforme veremos a seguir.

Seguem abaixo as baterias que se enquadram nas especificações requeridas e um breve resumo sobre suas características.

$$
\text { 3.3.1.1. Sanyo [23] }
$$

A Sanyo apresenta vários modelos de baterias, mas para o nosso caso, só podemos aproveitar os modelos KR-AAH e N-600AAK. 
3.3.1.1.1 KR-AAH

\begin{tabular}{|c|c|}
\hline Capacidade Nominal & $600 \mathrm{mAh}$ \\
\hline Tensão Nominal & $1,2 \mathrm{~V}$ \\
\hline Temperatura para carga & $0^{\circ} \mathrm{C} \mathrm{a}+70^{\circ} \mathrm{C}\left(32^{\circ} \mathrm{F} \mathrm{a} 158^{\circ} \mathrm{F}\right)$ \\
\hline Temperatura para descarga & $-20^{\circ} \mathrm{C} \mathrm{a}+70^{\circ} \mathrm{C}\left(-4^{\circ} \mathrm{F} \mathrm{a} 158^{\circ} \mathrm{F}\right)$ \\
\hline Impedância interna & $18 \mathrm{~m} \Omega$ \\
\hline Peso & $23 \mathrm{~g}$ \\
\hline
\end{tabular}

Tabela 3.2- Principais características da bateria modelo KR-AAH

3.3.1.1.2 N-600AAK

\begin{tabular}{|c|c|}
\hline Capacidade Nominal & $600 \mathrm{mAh}$ \\
\hline Tensão Nominal & $1,2 \mathrm{~V}$ \\
\hline Temperatura para carga & $0^{\circ} \mathrm{C} \mathrm{a}+70^{\circ} \mathrm{C}\left(32^{\circ} \mathrm{F} \mathrm{a} 158^{\circ} \mathrm{F}\right)$ \\
\hline Temperatura para descarga & $-20^{\circ} \mathrm{C} \mathrm{a}+70^{\circ} \mathrm{C}\left(-4^{\circ} \mathrm{F} \mathrm{a} 158^{\circ} \mathrm{F}\right)$ \\
\hline Impedância interna & $12 \mathrm{~m} \Omega$ \\
\hline Peso & $23 \mathrm{~g}$ \\
\hline
\end{tabular}

Tabela 3.3- Principais características da bateria modelo $\mathrm{N}-600 A A K$

$$
\text { 3.3.1.2. Saft [27] }
$$

A Saft apresenta vários modelos, tamanhos e pesos para baterias de $\mathrm{NiCd}$, mas apenas um para altas temperaturas, o VT-AA.

3.3.1.2.1 VT-AA

\begin{tabular}{|c|c|}
\hline Capacidade Nominal & $700 \mathrm{mAh}$ \\
\hline Tensão Nominal & $1,2 \mathrm{~V}$ \\
\hline Temperatura para carga & $5^{\circ} \mathrm{C} \mathrm{a}+65^{\circ} \mathrm{C}\left(41^{\circ} \mathrm{F} \mathrm{a} 149^{\circ} \mathrm{F}\right)$ \\
\hline Temperatura para descarga & $-20^{\circ} \mathrm{C} \mathrm{a}+60^{\circ} \mathrm{C}\left(-4^{\circ} \mathrm{F} \mathrm{a} 140^{\circ} \mathrm{F}\right)$ \\
\hline Impedância interna & $16 \mathrm{~m} \Omega$ \\
\hline Peso & $20 \mathrm{~g}$ \\
\hline
\end{tabular}

Tabela 3.4- Principais características da bateria modelo VT-AA

\subsubsection{GP Batteries [21]}

A GP possui alguns modelos, mas apenas um se enquadra em nossas especificações, o GP70AAST.

$$
\text { 3.3.1.3.1 GP70AAST }
$$

\begin{tabular}{|c|c|}
\hline Capacidade Nominal & $700 \mathrm{mAh}$ \\
\hline Tensão Nominal & $1,2 \mathrm{~V}$ \\
\hline
\end{tabular}




\begin{tabular}{|c|c|}
\hline Temperatura para carga & $0^{\circ} \mathrm{C} \mathrm{a}+70^{\circ} \mathrm{C}\left(32^{\circ} \mathrm{F}\right.$ a $\left.158^{\circ} \mathrm{F}\right)$ \\
\hline Temperatura para descarga & Não Disponível \\
\hline Impedância interna & $20 \mathrm{~m} \Omega$ \\
\hline Peso & $21 \mathrm{~g}$ \\
\hline
\end{tabular}

Tabela 3.5 - Principais características da bateria modelo GP70AAST

\subsubsection{JJJ Battery Company [28]}

A marca chinesa JJJ Battery Co possui o seguinte modelo para altas temperaturas:

\subsection{AA-800H}

\begin{tabular}{|c|c|}
\hline Capacidade Nominal & $800 \mathrm{mAh}$ \\
\hline Tensão Nominal & $1,2 \mathrm{~V}$ \\
\hline Temperatura para carga & $-20^{\circ} \mathrm{C} \mathrm{a}+70^{\circ} \mathrm{C}\left(-4^{\circ} \mathrm{F} \mathrm{a} 158^{\circ} \mathrm{F}\right)$ \\
\hline Temperatura para descarga & $-20^{\circ} \mathrm{C} \mathrm{a}+70^{\circ} \mathrm{C}\left(-4^{\circ} \mathrm{F} \mathrm{a} 158^{\circ} \mathrm{F}\right)$ \\
\hline Impedância interna & $26 \mathrm{~m} \Omega$ \\
\hline Peso & $24 \mathrm{~g}$ \\
\hline
\end{tabular}

Tabela 3.6 - Principais características da bateria modelo AA-800H

\subsubsection{BYD Battery Company [29]}

Outra marca chinesa, a BYD Battery Co, possui o seguinte modelo para altas temperaturas:

$$
\text { 3.3.1.5.1 D-AA-700H }
$$

\begin{tabular}{|c|c|}
\hline Capacidade Nominal & $700 \mathrm{mAh}$ \\
\hline Tensão Nominal & $1,2 \mathrm{~V}$ \\
\hline Temperatura para carga & $0^{\circ} \mathrm{C} \mathrm{a}+60^{\circ} \mathrm{C}\left(32^{\circ} \mathrm{F} \mathrm{a} 140^{\circ} \mathrm{F}\right)$ \\
\hline Temperatura para descarga & $-20^{\circ} \mathrm{C} \mathrm{a}+70^{\circ} \mathrm{C}\left(-4^{\circ} \mathrm{F} \mathrm{a} 158^{\circ} \mathrm{F}\right)$ \\
\hline Impedância interna & $25 \mathrm{~m} \Omega$ \\
\hline Peso & $23 \mathrm{~g}$ \\
\hline
\end{tabular}

Tabela 3.7 - Principais características da bateria modelo D-AA-700H 


\subsubsection{Escolha do painel solar}

Num projeto como esse, o dimensionamento do painel solar é um dos primeiros passos que devem ser executados.

Como materiais semicondutores e dimensionamento de células solares foram temas abordados em detalhes na seção 3.2.2, nos atentaremos apenas a mostrar os cálculos feitos para o presente projeto.

Consideraremos a região sudeste como a região objeto do programa de dimensionamento, possuindo esta, características próprias de irradiação solar, qualidade de radiação e densidade de potência. Portanto, para a região sudeste, na altura da capital paulista, temos os seguintes dados, segundo informações do Instituto Nacional de Meteorologia (INMET) [17]:

\begin{tabular}{|c|c|}
\hline $\begin{array}{c}\text { Tempo médio de presença de sol } \\
\text { por ano (horas) }\end{array}$ & $\begin{array}{c}\text { Densidade de Potência } \\
\text { (W/cm2) }\end{array}$ \\
\hline 2000 & 0,043 \\
\hline
\end{tabular}

Tabela 3.8 - Dados para a cidade de São Paulo

Para a região em questão e considerando uma eficiência média de 17\% (para orientação e inclinação ótimas) [42], podemos calcular a área média necessária para o painel solar utilizando a fórmula mostrada na seção 3.2.2.4:

$$
A=\frac{\text { Potência da Célula }(\mathrm{W})}{\text { Densidade de Potência }(\mathrm{W} / \mathrm{cm} 2)^{*} \text { Eficiência }}
$$

$$
\begin{gathered}
A=\frac{0,25 \mathrm{~W}}{0,043 \mathrm{~W} / \mathrm{cm}^{2} * 0,17} \\
A=34,2 \mathrm{~cm}^{2}
\end{gathered}
$$

Há atualmente dezenas de tipos de painéis solares disponíveis no mercado que oferecem os requisitos de tensão, corrente e área para este projeto. Seguem abaixo as células solares pesquisadas. 


\subsubsection{Canrom Photovoltaics [30]}

A empresa apresenta apenas duas opções de células e suas especificações não são muito compreensíveis:

\begin{tabular}{|c|c|c|c|c|c|c|}
\hline Modelo & Potência & $\begin{array}{c}\text { Dimensão } \\
(\mathbf{m m x m m})\end{array}$ & Eficiência & $\begin{array}{c}\text { OCV } \\
(\mathbf{V})\end{array}$ & $\begin{array}{c}\mathbf{I}_{\mathbf{S C}} \\
(\mathbf{A})\end{array}$ & Custo (\$) \\
\hline $\begin{array}{c}\text { Quase } \\
\text { quadrado }\end{array}$ & $1,3 \mathrm{Wp}$ & $100 \times 100$ & - & 0,57 & $2,8-3,1$ & $0,42 /$ cut \\
\hline Redondo & $1,0 \mathrm{Wp}$ & $100 \mathrm{~mm}$ (diâmetro) & - & 0,57 & $1,9-2,6$ & $0,40 /$ cut \\
\hline
\end{tabular}

Tabela 3.9 - Especificações das células solares da Canrom Photovoltaics

\subsubsection{Plastecs [31]}

Apresenta maior número de opções, além de ter células pequenas (4cm2). Também apresenta células maiores.

\begin{tabular}{|c|c|c|c|c|c|c|}
\hline Modelo & Potência (W) & $\begin{array}{c}\text { Dimensão } \\
(\mathbf{m m x m m})\end{array}$ & $\begin{array}{c}\text { Eficiência } \\
(\%)\end{array}$ & $\begin{array}{c}\mathbf{V}_{\mathbf{O C}} \\
(\mathbf{V})\end{array}$ & $\begin{array}{c}\mathbf{I}_{\mathbf{S C}} \\
(\mathbf{A})\end{array}$ & $\begin{array}{c}\text { Custo (\$) } \\
\text { (unidade) }\end{array}$ \\
\hline Menores & - & $\begin{array}{c}20 \mathrm{x} 20 \mathrm{a} \\
114 \mathrm{x} 114\end{array}$ & $10-11$ & $0,4-0,5$ & 0,06 a 2,5 & $\begin{array}{c}0,52 \mathrm{a} \\
4,20\end{array}$ \\
\hline Quadrado & $\begin{array}{c}1,46 \\
\text { (máxima) }\end{array}$ & $100 \mathrm{x} 100$ & 14,6 & 0,617 & 3,07 & 6,50 \\
\hline $\begin{array}{c}\text { Quase } \\
\text { quadrado }\end{array}$ & $\begin{array}{c}1.80-2.0 \mathrm{~A} @ \\
0.57-0.60 \mathrm{~V}\end{array}$ & $84 \times 84$ & $12-12,9$ & - & - & 3,45 \\
\hline Redondo & $\begin{array}{c}2.0-2.25 \mathrm{~A} @ \\
0.57-0.60 \mathrm{~V}\end{array}$ & $\begin{array}{c}100 \mathrm{~mm} \\
\text { (diâmetro) }\end{array}$ & $12-12,9$ & - & - & 3,55 \\
\hline
\end{tabular}

Tabela 3.10 - Especificações das células solares da Plastecs

$$
\text { 3.3.2.3. Quark [32] }
$$

Não apresenta preços, apenas especificações.

\begin{tabular}{|c|c|c|c|c|c|c|}
\hline Modelo & Potência (W) & $\begin{array}{c}\text { Dimensão } \\
(\mathbf{m m x m m})\end{array}$ & $\begin{array}{c}\text { Eficiência } \\
(\mathbf{\%})\end{array}$ & $\begin{array}{c}\text { Tensão } \\
(\mathbf{V})\end{array}$ & $\begin{array}{c}\text { Corrente } \\
(\mathbf{A})\end{array}$ & $\begin{array}{c}\text { Custo (\$) } \\
\text { (unidade) }\end{array}$ \\
\hline- & $0,8-1,15$ & $83 \times 83$ & $13-17$ & $0,47-0,5$ & $1,9-2,2$ & - \\
\hline- & $1,0-1,25$ & $\begin{array}{c}100 \\
(\text { diâmetro) }\end{array}$ & $13-17$ & $0,47-0,5$ & $2,2-2,5$ & - \\
\hline- & $1,3-1,6$ & $103 \times 103$ & $13-17$ & $0,47-0,5$ & $2,8-3,2$ & - \\
\hline
\end{tabular}

Tabela 3.11 - Especificações das células solares da Quark

\subsubsection{Silicon Solar [11]}

Empresa com mais variedade de informações e com células pequenas e grandes. O preço varia pela quantidade de unidades compradas e oferece diferentes tecnologias de células. 


\begin{tabular}{|c|c|c|c|c|c|c|}
\hline $\begin{array}{c}\text { Modelo } \\
\text { (tecnologia) }\end{array}$ & $\begin{array}{c}\text { Potência } \\
\text { Máxima (W) }\end{array}$ & $\begin{array}{c}\text { Dimensão } \\
\text { (mmxmm) }\end{array}$ & Eficiência & $\begin{array}{c}\mathbf{V}_{\text {OC }} \\
\text { (V) }\end{array}$ & $\begin{array}{c}\mathbf{I}_{\text {SC }} \\
(\mathbf{A})\end{array}$ & $\begin{array}{c}\text { Custo (\$) (251- } \\
\mathbf{1 0 0 0} \text { unidades) }\end{array}$ \\
\hline Poli-cristalina & 0,12 a 2,14 & $\begin{array}{c}62,5 \times 17 \text { a } \\
125 \times 125\end{array}$ & - & - & - & 1,39 a 7,31 \\
\hline $\begin{array}{c}\text { Mono- } \\
\text { cristalina }\end{array}$ & 0,038 a 2,29 & $17 \times 26$ a $125 \times 125$ & - & - & - & 0,93 a 8,42 \\
\hline
\end{tabular}

Tabela 3.12 - Especificações das células solares da Silicon Solar

\subsubsection{Astro Power [33]}

Não apresenta preços, apenas especificações.

\begin{tabular}{|c|c|c|c|c|c|c|}
\hline $\begin{array}{c}\text { Modelo } \\
\text { tecnologia) }\end{array}$ & $\begin{array}{c}\text { Potência } \\
\text { Máxima (W) }\end{array}$ & $\begin{array}{c}\text { Dimensão } \\
(\mathbf{m m x m m})\end{array}$ & Eficiência & $\begin{array}{c}\mathbf{V}_{\text {OC }} \\
(\mathbf{V})\end{array}$ & $\begin{array}{c}\mathbf{I}_{\text {SC }} \\
(\mathbf{A})\end{array}$ & $\begin{array}{c}\text { Custo (\$) (251- } \\
\mathbf{1 0 0 0} \text { unidades) }\end{array}$ \\
\hline AP-4 (AP-104) & 1,4 & $10 \times 10$ & - & - & - & - \\
\hline AP-5 (AP-105) & 2,1 & $12,5 \times 12,5$ & - & - & - & - \\
\hline AP-6 (AP-106) & 3,3 & $15 \times 15$ & - & - & - & - \\
\hline AP-6/3BB & 3,3 & $<15 \times 15$ & - & - & - & - \\
\hline
\end{tabular}

Tabela 3.13 - Especificações das células solares da AstroPower

\subsubsection{EspectroLab [34]}

A empresa apresenta vários produtos com valores de eficiência diferentes. Apenas os menores valores foram colocados na tabela abaixo. Também parece que a empresa só vende em lotes de 50 ou mais.

\begin{tabular}{|c|c|c|c|c|c|c|}
\hline $\begin{array}{c}\text { Modelo } \\
\text { tecnologia) }\end{array}$ & $\begin{array}{c}\text { Potência } \\
\text { Máxima (W) }\end{array}$ & $\begin{array}{c}\text { Dimensão } \\
(\mathbf{m m x m m}\end{array}$ & Eficiência & $\begin{array}{c}\mathbf{V}_{\text {OC }} \\
(\mathbf{V})\end{array}$ & $\begin{array}{c}\mathbf{I}_{\text {SC }} \\
(\mathbf{A})\end{array}$ & $\begin{array}{c}\text { Custo (\$) } \\
\text { (unidade) }\end{array}$ \\
\hline Part \# 505000 & - & $1.55^{\prime \prime} \mathrm{x}$ & $15.75 \%-$ & - & $0,280-$ & 6 \\
& & $2.71^{\prime \prime}$ & $16.87 \%$ & & 0,300 & \\
\hline Part \# 505030 & - & $1.55^{\prime \prime} \mathrm{x}$ & $15.75 \%-$ & 2,050 & - & 12 \\
& & $2.71^{\prime \prime}$ & $16.87 \%$ & & & \\
\hline Part \# 505020 & - & $1.23^{\prime \prime} \mathrm{x}$ & $16.10 \%-$ & 2,050 & $0,230-$ & 6 \\
& & $2.72^{\prime \prime}$ & $17.15 \%$ & & 0,245 & \\
\hline
\end{tabular}

Tabela 3.14 - Especificações das células solares da EspectroLab

\subsubsection{Shell [35]}

A empresa apresenta grande variedade de modelos de células solares, aprofundando em especificações técnicas, mas sem dar preço.

\begin{tabular}{|c|c|c|c|c|c|c|}
\hline $\begin{array}{c}\text { Modelo } \\
\text { (tecnologia) }\end{array}$ & $\begin{array}{c}\text { Potência } \\
\text { Máxima } \\
(\mathbf{W})\end{array}$ & $\begin{array}{c}\text { Dimensão } \\
(\mathbf{m m x m m} \\
\text { ) }\end{array}$ & Eficiência & $\begin{array}{c}\mathbf{V}_{\mathbf{O C}} \\
(\mathbf{V})\end{array}$ & $\begin{array}{c}\mathbf{I}_{\mathbf{S C}} \\
(\mathbf{A})\end{array}$ & $\begin{array}{c}\text { Custo (\$) } \\
\text { (unidade) }\end{array}$ \\
\hline Shell ST5 & 5 & $\begin{array}{c}232,5 \mathrm{x} \\
302,5\end{array}$ & - & 22,9 & 0,39 & - \\
\hline Shell ST10 & 10 & $387 \times 328$ & - & 20,1 & 0,62 & - \\
\hline
\end{tabular}

Tabela 3.15 - Especificações das células solares da Shell 


\subsubsection{Atlantic Solar [36]}

Não apresenta preços, apenas especificações.

\begin{tabular}{|c|c|c|c|c|c|c|}
\hline $\begin{array}{c}\text { Modelo } \\
\text { (tecnologia) }\end{array}$ & $\begin{array}{c}\text { Potência } \\
\text { Máxima } \\
(\mathbf{W})\end{array}$ & $\begin{array}{c}\text { Dimensão } \\
(\mathbf{m m x m m})\end{array}$ & Eficiência & $\mathbf{V}_{\text {oc }}(\mathbf{V})$ & $\begin{array}{c}\mathbf{I}_{\mathbf{S C}} \\
(\mathbf{A})\end{array}$ & $\begin{array}{c}\text { Custo (\$) } \\
\text { (unidade) }\end{array}$ \\
\hline ASP112 & 1 & $234,5 \times 97$ & - & 21 & 0,09 & - \\
\hline ASP212 & 2,5 & $234,5 \times 153$ & - & 21 & 0,17 & - \\
\hline ASP512 & 5 & $234,5 \times 243$ & - & 21 & 0,33 & - \\
\hline
\end{tabular}

Tabela 3.16 - Especificações das células solares da Atlantic Solar

Apesar das várias opções largamente comercializadas, nós temos a oportunidade de encomendar um módulo de célula solar mono-cristalina fabricado especialmente para nós pela empresa Heliodinâmica. E dentre os módulos pesquisados, os de célula solar mono-cristalina são os mais baratos, duráveis e eficientes.

O arranjo final de células solares precisará, portanto, possuir as seguintes características:

\begin{tabular}{|c|c|}
\hline Tensão de circuito aberto (Voc) & $10 \mathrm{~V}$ \\
\hline Corrente de curto circuito (Isc) & $40 \mathrm{~mA}$ \\
\hline Área & $35 \mathrm{~cm} 2$ \\
\hline
\end{tabular}

Tabela 3.17 - Especificações do painel solar necessário

\subsubsection{Escolha do diodo de proteção}

O diodo de proteção é o dispositivo que evitará que as baterias descarreguem quando a tensão do painel solar for menor do que a das baterias. Isso acontecerá quando o nível de insolação for muito pequeno devido ao tempo nublado ou quando estiver no período da noite.

Embora o projeto não envolva o uso de grandes tensões, conversão AC-DC e uso de retificadores, optamos por escolher um diodo da família "Schottky" que possui um chaveamento mais rápido do que os diodos convencionais, suporta uma tensão reversa bastante adequada às nossas 
necessidades, tem uma baixa corrente de fuga e uma queda de tensão muito pequena.

Este diodo é comumente utilizado em aplicações que envolvem o uso de carregamento de pilhas de $\mathrm{NiCd}$ a partir da rede elétrica e de painéis solares. Escolhemos o modelo 1N5818 Schottky da STMicroelectronics [37], que possui as seguintes características:

\begin{tabular}{|c|c|}
\hline Tensão máxima reversa & $30 \mathrm{~V}$ \\
\hline Corrente direta máxima & $1 \mathrm{~A}$ \\
\hline Queda de tensão típica & $0,5 \mathrm{~V}$ \\
\hline Corrente reversa típica & $0,5 \mathrm{~mA}$ \\
\hline Temperatura máxima operação & $150^{\circ} \mathrm{C}$ \\
\hline
\end{tabular}

Tabela 3.18 - Principais características do diodo modelo 1 N5818

A utilização deste diodo no projeto pode ser ilustrada pela seguinte figura:

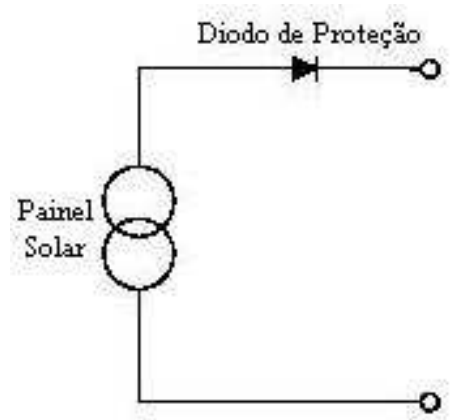

Figura 3.7 - Utilização do diodo de proteção

\subsubsection{Escolha dos reguladores}

A escolha dos reguladores a serem utilizados deve ser uma tarefa bastante cuidadosa, pois são eles que vão garantir a integridade e funcionabilidade do sistema. Para limitar a corrente provinda dos painéis solares, optamos pela utilização do regulador LM317 fabricado pela National Semiconductor, que também é um regulador de tensão, mas, no nosso caso, estará funcionando apenas no modo limitador de corrente.

Os reguladores que atuarão sobre os circuitos de sensor de pressão, circuito analógico/digital (processador e memória), RF e uma saída de 2,4 
V que poderá ser usada para futuras aplicações devem ter uma diferença entre Vin e Vout muito pequena para maximizar a eficiência do sistema. São os chamados "Low Dropout regulators". Os reguladores precisam ser escolhidos visando à minimização dos custos, mantendo sempre a eficiência e qualidade.

Foram pesquisadas algumas marcas de fabricantes de reguladores e os modelos que atendem às necessidades do projeto seguem abaixo:

\subsubsection{National Semiconductor [38]}

Esta empresa tem uma grande variedade de reguladores e circuitos integrados que atendem às necessidades. Abaixo estão alguns modelos escolhidos com um pequeno resumo de suas características:

$$
\text { 3.3.4.1.1. LP2986 }
$$

\begin{tabular}{|l|l|}
\hline Tensão de entrada mínima & $2,1 \mathrm{~V}$ \\
\hline Tensão de entrada máxima & $16 \mathrm{~V}$ \\
\hline Tensão de saída mínima & $1,23 \mathrm{~V}$ \\
\hline Tensão de saída máxima & $16 \mathrm{~V}$ \\
\hline Corrente de saída máxima & $200 \mathrm{~mA}$ \\
\hline Queda de tensão & $180 \mathrm{mV}$ \\
\hline Preço no site & $\$ 0,75$ \\
\hline
\end{tabular}

Tabela 3.19 - Principais características do regulador modelo LP2986

\subsubsection{2. $L P 2980$}

\begin{tabular}{|l|l|}
\hline Tensão de entrada mínima & $2,5 \mathrm{~V}$ \\
\hline Tensão de entrada máxima & $16 \mathrm{~V}$ \\
\hline Tensão de saída mínima & $1,23 \mathrm{~V}$ \\
\hline Tensão de saída máxima & $25 \mathrm{~V}$ \\
\hline Corrente de saída máxima & $50 \mathrm{~mA}$ \\
\hline Queda de tensão & $120 \mathrm{mV}$ \\
\hline Preço no site & Não Disponível \\
\hline
\end{tabular}

Tabela 3.20 - Principais características do regulador modelo LP2980 
3.3.4.1.3. LP2980-ADJ

\begin{tabular}{|l|l|}
\hline Tensão de entrada mínima & $2,5 \mathrm{~V}$ \\
\hline Tensão de entrada máxima & $16 \mathrm{~V}$ \\
\hline Tensão de saída mínima & $1,23 \mathrm{~V}$ \\
\hline Tensão de saída máxima & $25 \mathrm{~V}$ \\
\hline Corrente de saída máxima & $50 \mathrm{~mA}$ \\
\hline Queda de tensão & $120 \mathrm{mV}$ \\
\hline Preço no site & $\$ 0,29$ \\
\hline
\end{tabular}

Tabela 3.21 - Principais características do regulador modelo LP2980-ADJ

3.3.4.1.4. $L P 2951$

\begin{tabular}{|l|l|}
\hline Tensão de entrada mínima & $-0,3 \mathrm{~V}$ \\
\hline Tensão de entrada máxima & $30 \mathrm{~V}$ \\
\hline Tensão de saída mínima & $1,24 \mathrm{~V}$ \\
\hline Tensão de saída máxima & $29 \mathrm{~V}$ \\
\hline Corrente de saída máxima & $100 \mathrm{~mA}$ \\
\hline Queda de tensão & $380 \mathrm{mV}$ \\
\hline Preço no site & $\$ 0,28$ \\
\hline
\end{tabular}

Tabela 3.22 - Principais características do regulador modelo LP2951

\subsection{LP2983}

\begin{tabular}{|l|l|}
\hline Tensão de entrada mínima & $2,2 \mathrm{~V}$ \\
\hline Tensão de entrada máxima & $16 \mathrm{~V}$ \\
\hline Tensão de saída fixa & $0,9 \mathrm{~V}, 1 \mathrm{~V}, 1,2 \mathrm{~V}$ \\
\hline Corrente de saída máxima & $150 \mathrm{~mA}$ \\
\hline Queda de tensão & Não Disponível \\
\hline Preço no site & $\$ 0,49$ \\
\hline
\end{tabular}

Tabela 3.23 - Principais características do regulador modelo LP2983

\subsubsection{6. $L P 2985$}

\begin{tabular}{|l|l|}
\hline Tensão de entrada mínima & $2,5 \mathrm{~V}$ \\
\hline Tensão de entrada máxima & $16 \mathrm{~V}$ \\
\hline Tensão de saída fixa & $2,4 \mathrm{~V}, 3,6 \mathrm{~V}, 4,8 \mathrm{~V}$ \\
\hline Corrente de saída máxima & $150 \mathrm{~mA}$ \\
\hline Queda de tensão & $260 \mathrm{mV}$ \\
\hline Preço no site & $\$ 0,25$ \\
\hline
\end{tabular}

Tabela 3.24 - Principais características do regulador modelo LP2985 


\subsubsection{Analog Devices [39]}

Esta empresa também possui uma grande variedade de produtos, mas poucos que atendem às necessidades do projeto. De fato, apenas dois produtos servem para o projeto, sendo que um foi parado de fabricar. Além disso, ela não oferece produtos para a regulação da saída de 1,2 V. O produto encontrado segue na tabela abaixo:

3.3.4.2.1. ADP3308

\begin{tabular}{|l|l|}
\hline Tensão de entrada mínima & $3 \mathrm{~V}$ \\
\hline Tensão de entrada máxima & $12 \mathrm{~V}$ \\
\hline Tensão de saída mínima & $2,7 \mathrm{~V}$ \\
\hline Tensão de saída máxima & $3,6 \mathrm{~V}$ \\
\hline Corrente de saída máxima & $50 \mathrm{~mA}$ \\
\hline Queda de tensão & $80 \mathrm{mV}$ \\
\hline Preço no site & Não Disponível \\
\hline
\end{tabular}

Tabela 3.25 - Principais características do regulador modelo ADP3308

\subsection{Topologias de circuito}

Ao longo do semestre, alguns modelos foram idealizados ou encontrados e analisados. Houve a oportunidade de verificar as características, as vantagens e as desvantagens de cada modelo, para que, finalmente, identificássemos o modelo que melhor nos serviria.

\subsubsection{Modelo usando um LM317 e um regulador multisaída}

Este circuito mostra um arranjo de 11 células solares em série ligadas a um regulador de tensão LM317 que converterá a tensão de entrada para uma tensão de saída condizente com a das baterias mais a queda no diodo. Logo depois temos o diodo que impedirá que a corrente flua no sentido contrário quando não houver tensão nas células solares, ou seja, durante a noite ou em tempo muito nublado. Em seguida há um segundo regulador de tensão que contém 3 saídas. A primeira delas deverá estar regulada para fornecer a tensão necessária para 
funcionamento do sensor de pressão, a segunda para o digital/analógico do projeto e a terceira para o circuito de RF.

Observa-se que o esquema é bastante simples e não requer investimento alto. Entretanto, possui algumas desvantagens como não possuir limitador de corrente (se a corrente proveniente do painel for alta, poderá haver sobrecarga nas baterias) e usar um regulador de tensão multisaída extremamente difícil de se encontrar no mercado. E, quando encontrado, por um valor muito alto que não compensa seu uso.

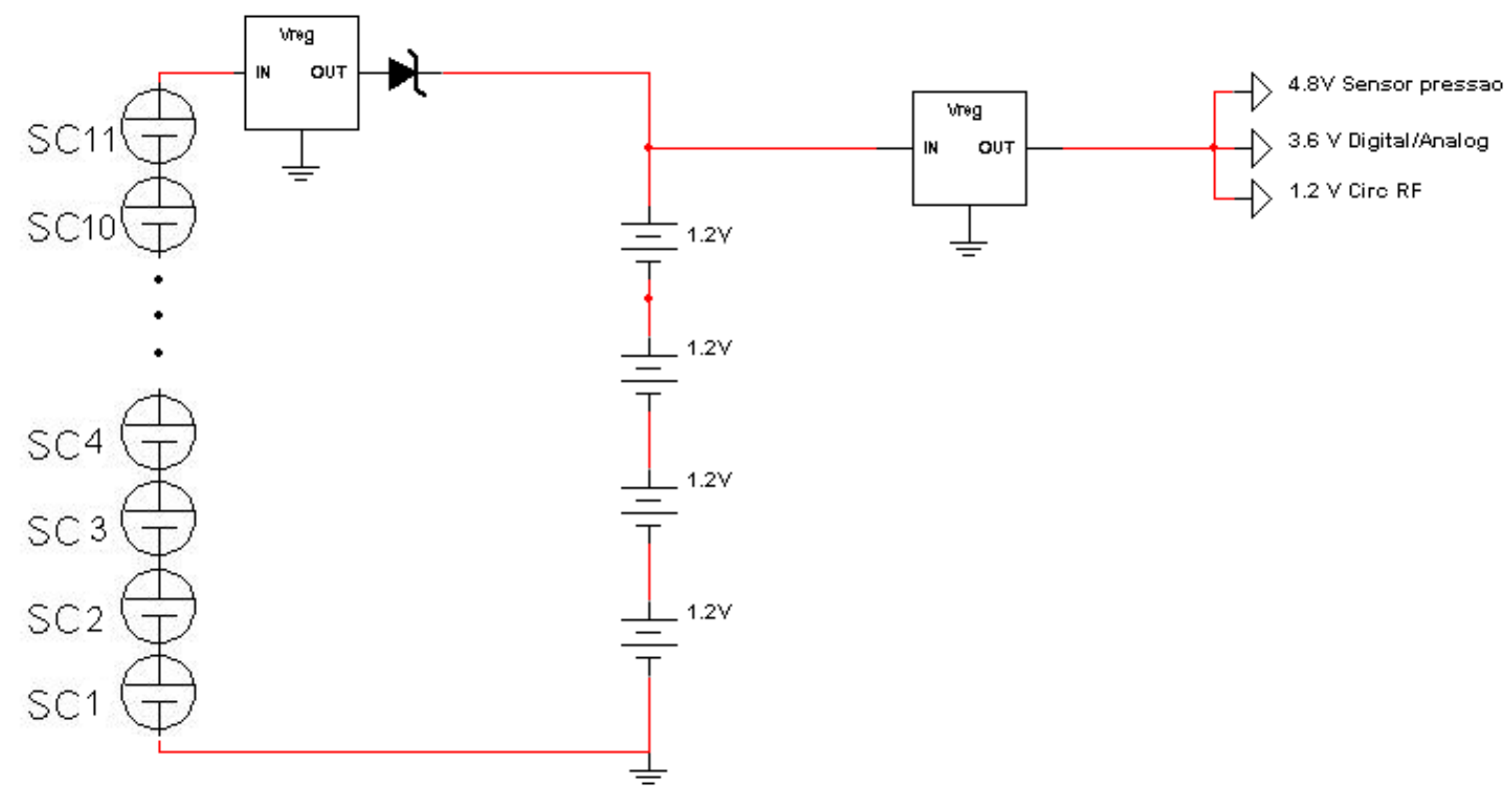

Figura 3.8 - Modelo utilizando um LM317 e um regulador multisaída

\subsubsection{Modelo usando microprocessador MAX639 [40]}

Esse modelo é o idealizado pela fabricante de microprocessadores MAXIM. A vantagem que ele apresenta é o controle inteligente de carga das baterias, entretanto, ele tem a grande desvantagem de possuir um custo muito alto. Se a idéia do projeto de irrigação é colocar tudo num único chip, não se justifica a utilização de um outro microprocessador só para controle de baterias. Provavelmente ele custará mais que o projeto em desenvolvimento. Além disso, ele não opera em temperaturas acima de $80^{\circ} \mathrm{C}$, o que já o exclui das nossas possibilidades. 


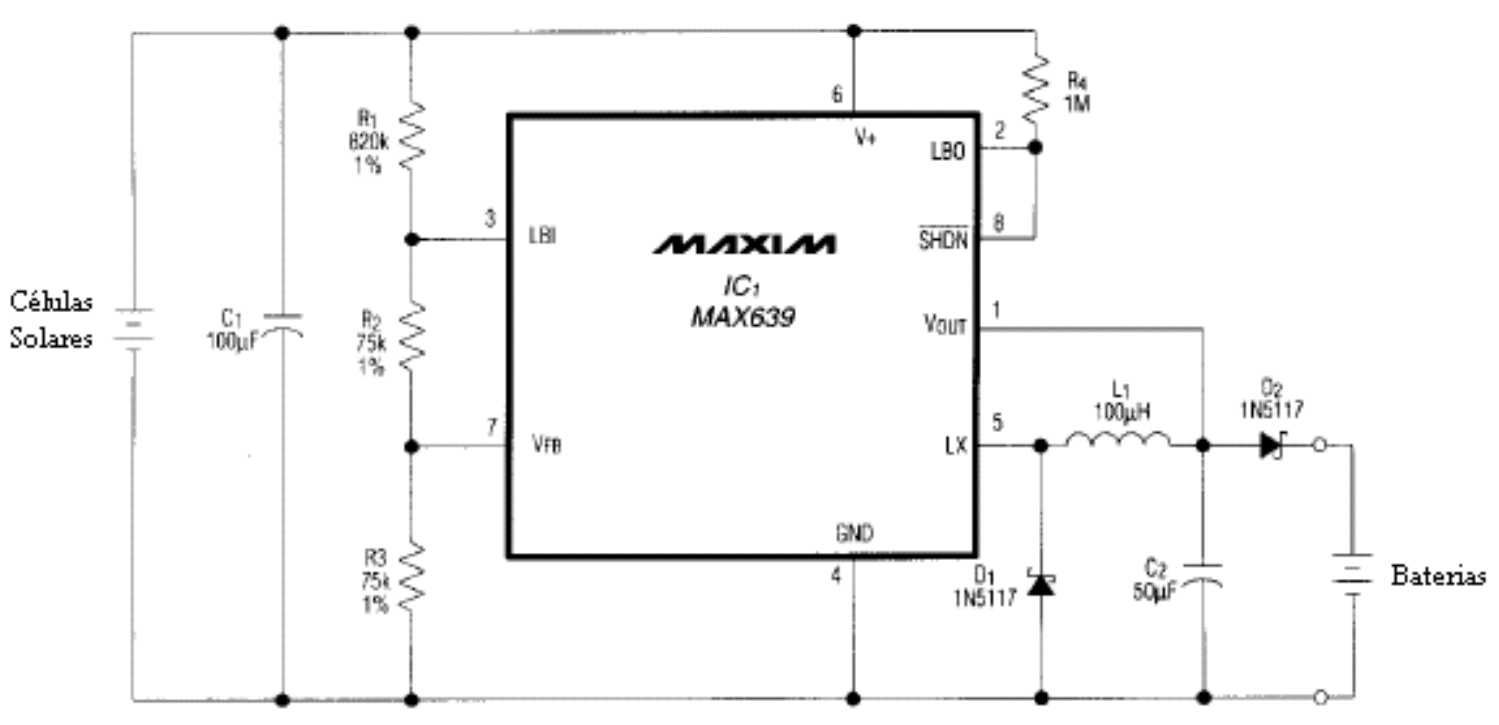

Figura 3.9 - Modelo utilizando um microprocessador MAX639

\subsubsection{Modelo usando microprocessador PIC16C711 [8]}

Este modelo não foge muito do usado pelo MAX639. O PIC é um microprocessador que está muito além das nossas necessidades. Teríamos de dispor de um regulador de tensão, um regulador de corrente, um cristal de $4 \mathrm{MHz}$, um transistor e um PIC16C711, dentre outros componentes. Percebemos que é uma implementação um pouco complexa com o intuito de funcionar apenas como carregador de baterias, tornando o modelo bastante ineficaz do ponto de vista econômico. Ele também sofre dos problemas de temperatura acima dos $80^{\circ} \mathrm{C}$, assim como o MAX639. 


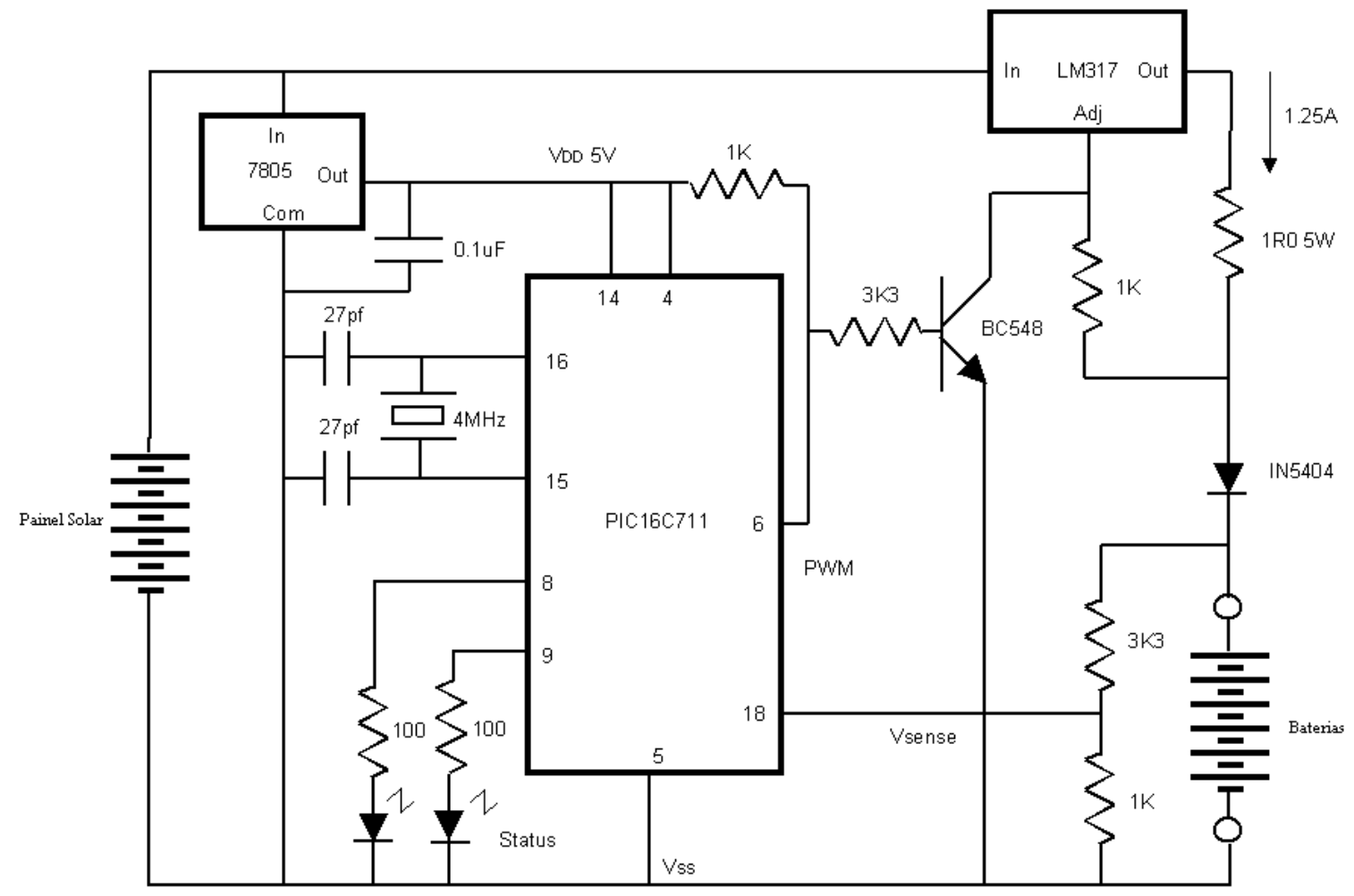

Figura 3.10 - Modelo utilizando um microprocessador PIC16C711

\subsubsection{Modelo usando um LM317 e três LP3982}

O circuito do modelo abaixo é bem parecido com o mostrado na figura 3.8, com a diferença de utilizar um regulador de tensão para cada circuito que será alimentado. Esse modelo é mais vantajoso do ponto de vista econômico, visto que possui 3 reguladores LP3982 amplamente disponíveis no mercado. Esses reguladores são um pouco diferentes do LM317, na medida em que permitem uma pequena diferença entre a tensão de entrada e a tensão de saída (algo em torno de $80 \mathrm{mV}$ para 200 $\mathrm{mA})$. No LM317 essa diferença é por volta de 3V. O tamanho do circuito pode aumentar um pouco de tamanho, mas certamente o custo não subirá. Ele também não possui um limitador de corrente para que ocorra uma carga lenta eficaz sobre as baterias. 


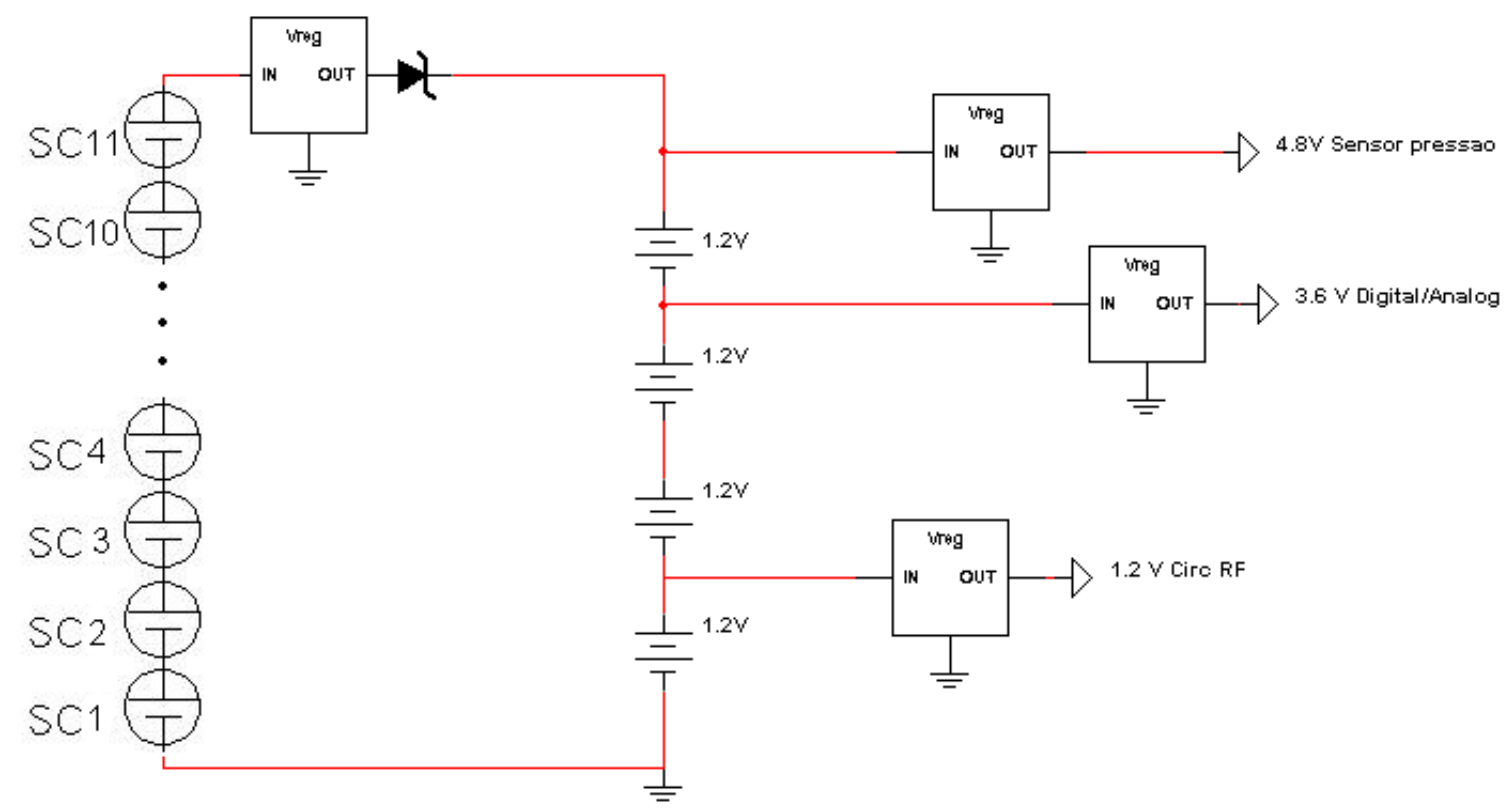

Figura 3.11 - Modelo utilizando um LM317 e três LP3982

\subsubsection{Modelo usando um LM317, três reguladores LP2985 saída}

\section{fixa e um regulador $L P 2983$ saída fixa}

Este é o modelo possui grandes vantagens como baixo custo, boa eficiência energética, baixo consumo e limitador de corrente. Os reguladores empregados são de baixo custo e largamente utilizados em aplicações que necessitam um valor de tensão estático em suas saídas.

O LM317 ainda continua sendo empregado, só que neste modelo ele assume a configuração de limitador de corrente com o auxílio de um resistor. Dessa maneira, uma baixa corrente permite que as baterias sejam constantemente carregadas sem que haja necessidade de um dispositivo que monitore a tensão e o tempo de carga delas.

O diodo de proteção continua sendo utilizado visando à proteção contra o descarregamento das pilhas sobre o painel solar.

O circuito idealizado pode ser conferido na figura abaixo: 


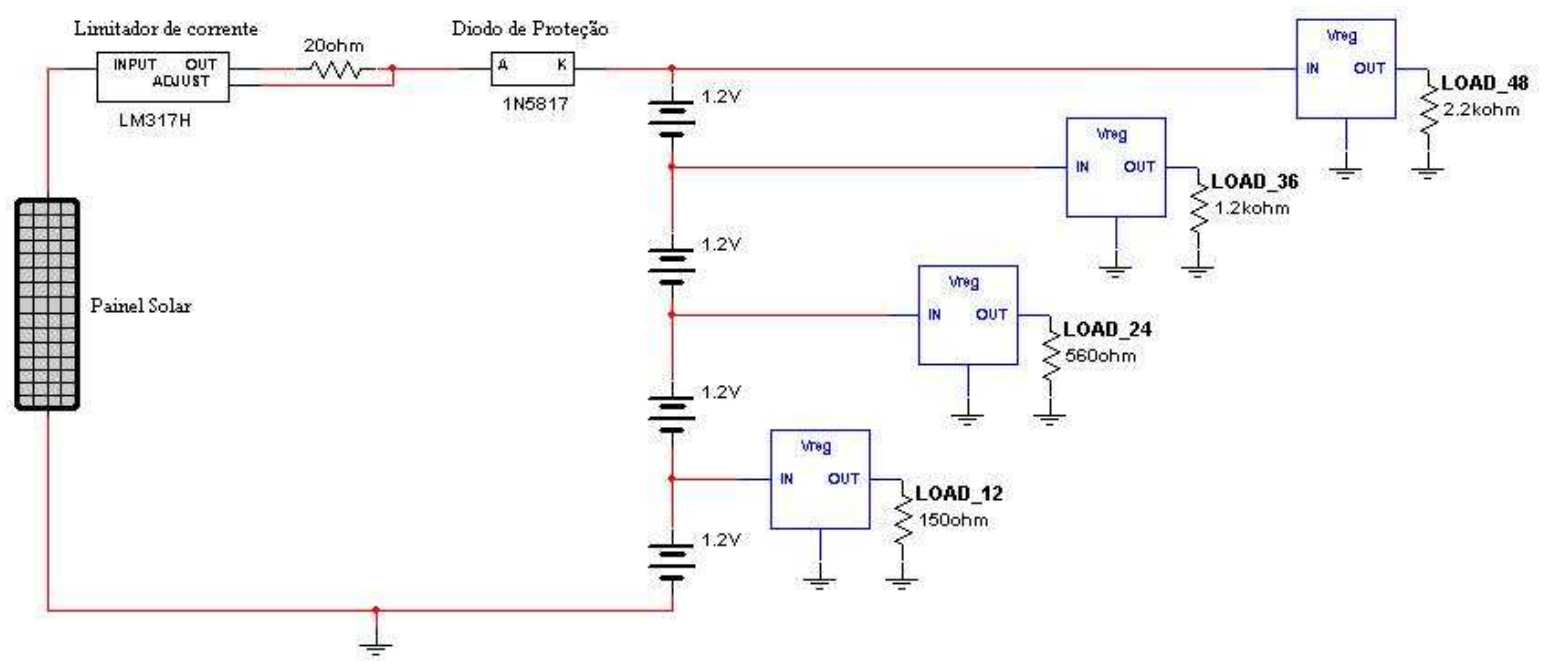

Figura 3.12 - Modelo utilizando um LM317 e quatro reguladores de saída fixa

Podemos colocar numa tabela comparativa as características, vantagens e desvantagens de cada um dos modelos de modo a justificar a proposta escolhida:

\begin{tabular}{|l|c|c|c|c|c|}
\hline \multicolumn{1}{|c|}{ Característica } & $\begin{array}{c}\text { Reg. } \\
\text { Multisaída }\end{array}$ & MAX639 & $\begin{array}{c}\text { PIC16C7 } \\
\mathbf{1 1}\end{array}$ & PL3982 & $\begin{array}{c}\text { Saída } \\
\text { Fixa }\end{array}$ \\
\hline Facilidade de Implementação & Média & Baixa & Baixa & Alta & Alta \\
\hline Custo & Médio & Alto & Alto & Baixo & Baixo \\
\hline Eficiência & Média & Alta & Alta & Média & Média \\
\hline Faixa de operação & $0^{\circ} \mathrm{C}$ a $85^{\circ} \mathrm{C}$ & $0^{\circ} \mathrm{C}$ a & $0^{\circ} \mathrm{C} \mathrm{a}$ & $-40^{\circ} \mathrm{C}$ a & $-40^{\circ} \mathrm{C}$ a \\
& & $70^{\circ} \mathrm{C}$ & $70^{\circ} \mathrm{C}$ & $85^{\circ} \mathrm{C}$ & $125^{\circ} \mathrm{C}$ \\
\hline Consumo & Alto & Médio & Médio & Alto & Baixo \\
\hline Disponibilidade no mercado & Baixa & Média & Média & Alta & Alta \\
\hline Circuito inteligente & Não & Sim & Sim & Não & Não \\
\hline Controle de corrente & Não & Sim & Sim & Não & Sim \\
\hline
\end{tabular}

Tabela 3.26 - Principais diferenças entre os principais modelos 


\section{Projeto do sistema de alimentação}

Após a análise das especificações, a pesquisa e a escolha dos componentes é hora de montar uma topologia de circuito que maximize a eficiência do modelo, levando em conta a especificação dos reguladores e das células solares.

Não nos atentaremos a tecer mais comentários sobre os cálculos, a escolha e a utilização do painel solar, pois isto se encontra bem explicado na seção 3.2.2 deste documento.

Devido às condições encontradas para a realização deste projeto, houve a necessidade de se dividir esta seção em duas partes: uma para o projeto idealizado para o nó remoto do projeto de irrigação e outra para o projeto que foi posto em prática no laboratório, onde foram feitos todos os testes de autonomia, eficiência energética, consumo, etc.

\subsection{Projeto idealizado}

O modelo do projeto da fonte de alimentação para o nó remoto que foi idealizado pode ser visto na figura 3.12. Optou-se por utilizar reguladores de saída fixa devido ao seu baixo custo em relação à solução oferecida por aqueles de saída ajustável, ou seja, estes necessitam de resistores auxiliares que fazem o papel de divisores de tensão para atingir o valor de tensão desejado. Na soma dos custos os de saída fixa são mais baratos.

Portanto, os reguladores analisados que foram escolhidos estão ilustrados na tabela abaixo:

\begin{tabular}{|c|c|c|}
\hline Modelo do Regulador & Circuito a regular & Tensão de saída \\
\hline LP2985AIM5-4,8 & Sensor de Pressão & $4,8 \mathrm{~V}$ \\
\hline LP2985AIM5-3,6 & Circuito analógico/digital & $3,6 \mathrm{~V}$ \\
\hline LP2985AIBP-2,4 & Circuito previsto futuramente & $2,4 \mathrm{~V}$ \\
\hline LP2983AIM5-1,2 & Circuito de RF & $1,2 \mathrm{~V}$ \\
\hline
\end{tabular}

Tabela 4.1 - Reguladores escolhidos para o projeto 
Quando houver alguma referência ao datasheet dos reguladores, ou então seja de vontade do leitor consultar algum parâmetro que não esteja constado neste documento, os dados fornecidos pelo fabricante encontram-se no anexo 9.3 para o LP2985, no anexo 9.4 para o LP2983 e no anexo 9.1 para o LM317.

A escolha desses reguladores é justificada pela facilidade de implementação, disponibilidade no mercado, baixo custo, baixo consumo e baixa queda de tensão.

A implementação dos reguladores acima expostos é basicamente a mesma da ilustrada pela figura 3.12, com algumas pequenas modificações para poder seguir as especificações de tensão mínima de entrada.

Nesta configuração justifica-se a necessidade de um painel solar que possa fornecer $10 \mathrm{~V}$, porque considerando uma queda de tensão de 3 $\mathrm{V}$ no limitador de corrente e uma queda de $0,5 \mathrm{~V}$ no diodo, resta $6,5 \mathrm{~V}$ para o carregamento das baterias. Considerando que cada bateria deva ser carregada com uma tensão de $1,5 \mathrm{~V}$, o jogo de 4 baterias deve, por conseguinte, ser alimentado com uma tensão mínima de $6 \mathrm{~V}$.

O limitador de corrente, por sua vez, deverá estar configurado para fornecer uma corrente de, aproximadamente, 0,1 vezes a capacidade nominal da bateria utilizada. Portanto, se a bateria possuir uma capacidade típica de $800 \mathrm{mAh}$, o resistor deverá ser convenientemente escolhido de modo a deixar passar uma corrente de $80 \mathrm{~mA}$. Da mesma maneira, se a bateria for de $700 \mathrm{mAh}$, o regulador deverá deixar passar 70 $\mathrm{mA}$.

Esse fator de 0,1C (Onde C é a capacidade nominal da bateria) é a corrente máxima recomendada para um carregamento sem meios de detectar seu fim [22]. Dessa maneira, as baterias podem ser carregadas sem a preocupação de sobrecarga. E como o painel estará atuando, na melhor das hipóteses, por 13 ou 14 horas ininterruptas (que é o maior 
tempo possível com a presença de luz solar), não deverá haver preocupação com nenhum tipo de sobrecarga.

A figura da topologia final do circuito idealizado pode ser encontrada abaixo:

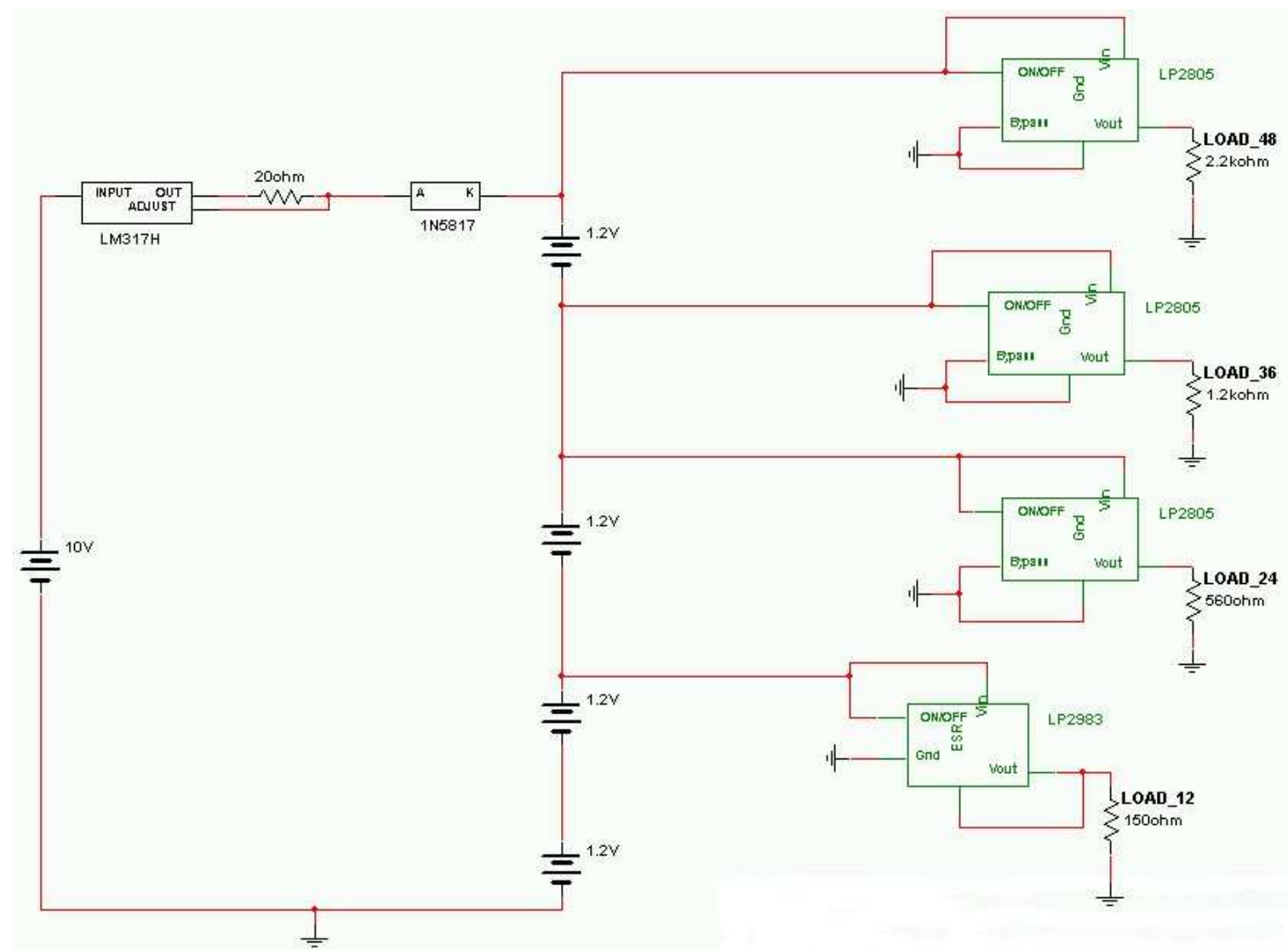

Figura 4.1 - Circuito idealizado para o projeto de irrigação

\subsection{Projeto realizado}

O projeto realizado é essencialmente o ilustrado na figura 3.12, com algumas pequenas modificações nos reguladores para incluir os resistores que atuam como divisores de tensão, a substituição do painel solar por uma fonte de tensão e a mudança da tensão de entrada.

O limitador de corrente está configurado com um resistor de $20 \Omega$ para deixar passar uma corrente de $60 \mathrm{~mA}$, que são exatamente os $10 \%$ da capacidade nominal da bateria de $600 \mathrm{mAh}$ utilizada. A fórmula utilizada para achar esse valor foi: 


$$
I_{\text {out }}=\frac{1,25}{R}
$$

Onde,

Iout é a corrente que passa pelo regulador;

$\mathrm{R}$ é o resistor acoplado entre as saídas Vout e Adj.

$\mathrm{O}$ diodo utilizado tem uma queda de tensão de $1,1 \mathrm{~V}$ a $1 \mathrm{~A}$, segundo informações do fabricante [41].

O LM317 utilizado como regulador de tensão para as saídas de $4,8 \mathrm{~V}, 3,6 \mathrm{~V}, 2,4 \mathrm{~V}$ e $1,2 \mathrm{~V}$ precisa do auxílio de dois resistores convenientemente acoplados para fornecer a tensão desejada. Essa tensão de saída pode ser representada pela seguinte fórmula:

$$
V_{\text {out }}=1,25\left(1+\frac{R 2}{R 1}\right)+I_{A D J}(R 2)
$$

Onde,

Vout é a tensão de saída;

R1 é o resistor que está entre a saída Vout e Adj;

R2 é o resistor que está entre a saída Adj e o terra;

Iadj é a corrente quiescente

Como o valor de Iadj é da ordem de microamperes, o segundo termo da equação pode ser desprezado.

Os valores de R1 e R2 devem ser escolhidos de forma a manter uma proporção que forneça a tensão desejada. Por facilidade, fixou-se R1 com $100 \Omega$ para todos os reguladores. Assim, de posse do valor de R1 e da fórmula 4.2, os valores de R2 puderam ser calculados para chegar às tensões desejadas, segundo a tabela abaixo: 


\begin{tabular}{|c|c|}
\hline 280 & 4,75 \\
\hline 180 & 3,5 \\
\hline 92 & 2,4 \\
\hline 0 & 1,25 \\
\hline
\end{tabular}

Tabela 4.2 - Valores de R2 para fornecer a tensão de saída

O resistor de carga representa o circuito a ser alimentado por aquela saída de tensão. Seus valores foram calculados com base nas estimativas de consumo de cada um dos circuitos, segundo a tabela abaixo:

\begin{tabular}{|c|c|c|c|}
\hline Circuito & Tensão $(\mathbf{V})$ & Potência $(\mathbf{m W})$ & Carga $(\mathbf{\Omega})$ \\
\hline Sensor de Pressão & 4,8 & 10 & $2 \mathrm{~K} 2$ \\
\hline Processador/Memória & 3.6 & 10 & $1 \mathrm{~K} 2$ \\
\hline Previsto futuramente & 2,4 & 10 & 560 \\
\hline Transceptor de RF & 1,2 & 10 & 150 \\
\hline
\end{tabular}

Tabela 4.3 - Valores da carga para cada um dos reguladores

Os valores de carga fora calculados baseando-se na lei de Ohm, onde a potência é a tensão ao quadrado sobre a resistência, ou melhor:

$$
P=\frac{V^{2}}{R}
$$

Com essa configuração de carga assumimos que os quatro circuitos estão consumindo $10 \mathrm{~mW}$ de potência o tempo todo, ou seja, os testes de autonomia e performance refletirão os resultados do pior caso possível.

Dessa maneira, a figura do circuito final realizado pode ser observada abaixo: 


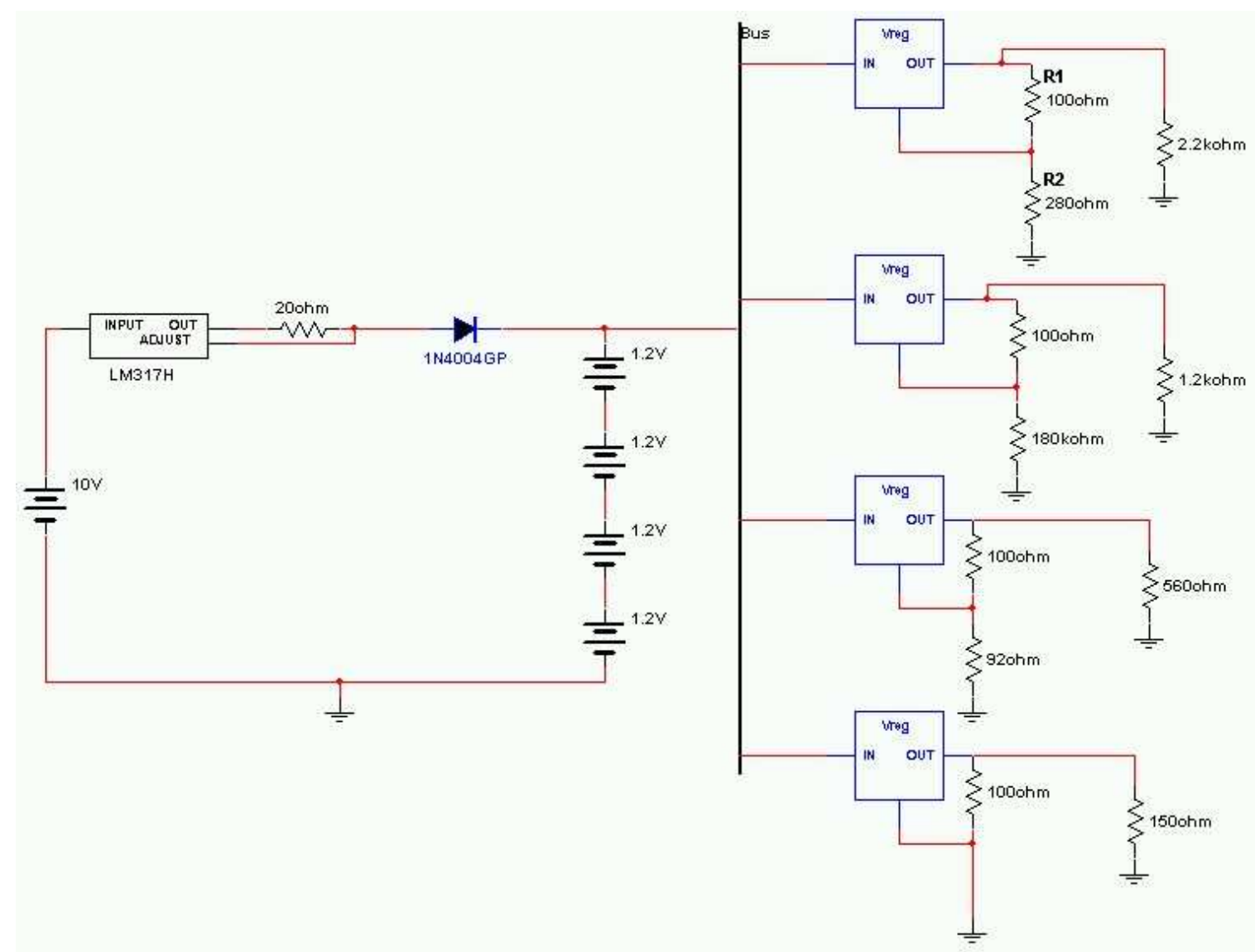

Figura 4.2 - Circuito realizado para testes

A foto do sistema efetivamente realizado segue abaixo: 


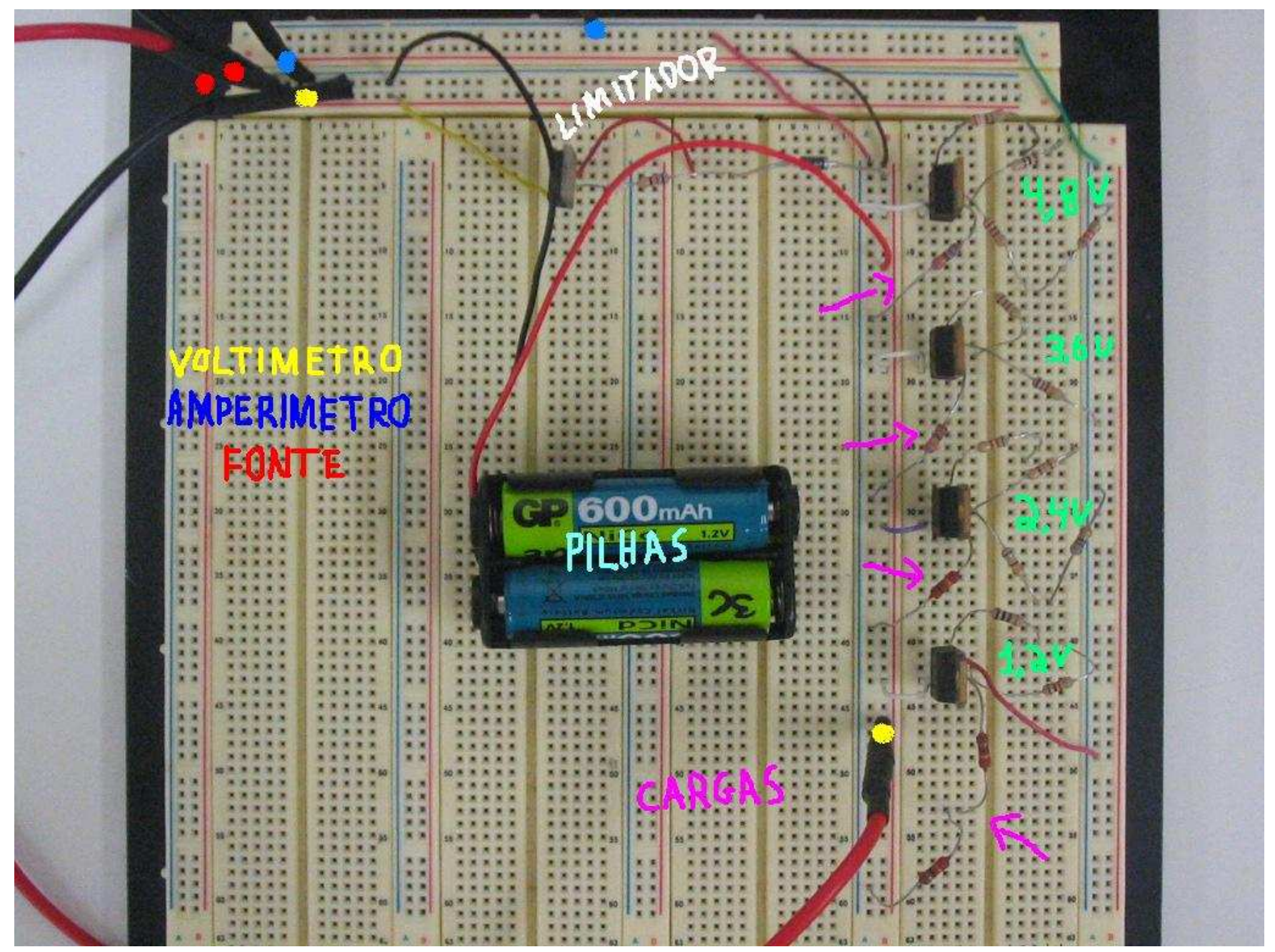

Figura 4.3 - Circuito implementado no laboratório 


\section{Testes Realizados}

Para a realização dos experimentos foram utilizados os seguintes equipamentos e dispositivos:

- 3 Jogos de pilha de NiCd 600 mAh GPBatteries GP600AAS;

- Resistores de 1R3, 3R9, 10, 12, 15, 68, 82, 100, 120, 150, 180, $1 \mathrm{~K} 2,2 \mathrm{~K} 2,15 \mathrm{~K} 2$, todos com tolerância de $10 \%$;

- 3 Diodos 1N4004;

- 1 Protoboard Jameco Electronics JE27;

- 2 Multímetros HP 34401A;

- 1 Multímetro Minipa Modelo ET-1000;

- 1 Calibrador HP 6920B;

- 1 Fonte de tensão PHILIPS PE 4819;

- 1 Computador PC DX2-66 com software Benchlink versão 1.01 da HP;

- 1 Termômetro infravermelho ICEL TD-960;

- 2 Décadas resistivas DEKABOX DB52;

- 1 Relógio analógico de parede comum;

- 1 Timer de energia elétrica FLASH PRATIC Typ 867.

Segue abaixo uma foto geral dos equipamentos utilizados: 


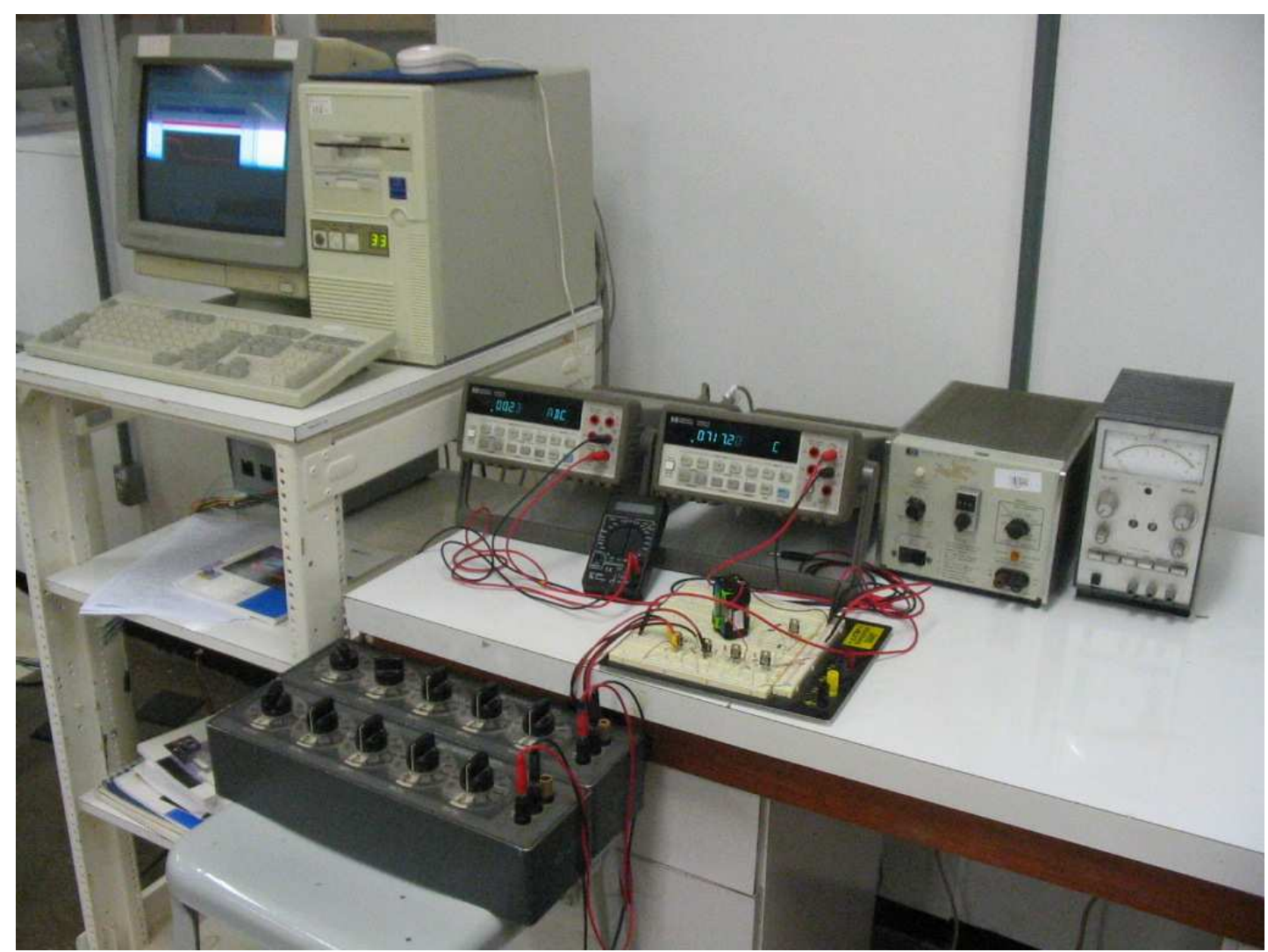

Figura 5.1 - Equipamentos utilizados no laboratório

\subsection{Instrumentação}

Dada a oportunidade de poder utilizar um calibrador como fonte de tensão/corrente pôde-se verificar a acurácia e os erros apresentados pelos multímetros, pelas décadas e pela fonte de tensão da Philips.

Os testes foram basicamente realizados conectando-se o calibrador ao equipamento a ser testado e verificando se o que o calibrador estava mandando era o que realmente estava sendo lido pelos equipamentos, segundo as figuras abaixo: 


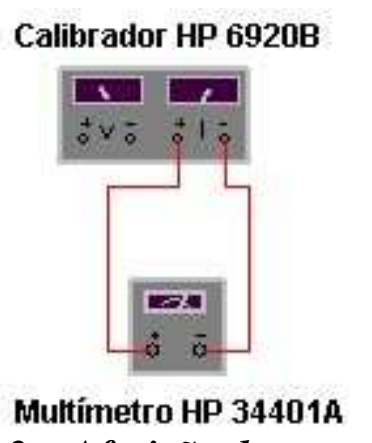

Figura 5.2 - Aferição do amperímetro

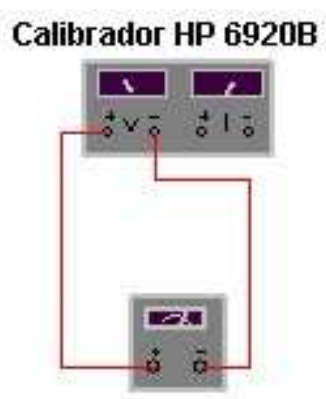

Multímetro HP $34401 \mathrm{~A}$

Figura 5.3 - Aferição do voltímetro

Multímetro HP 34401A

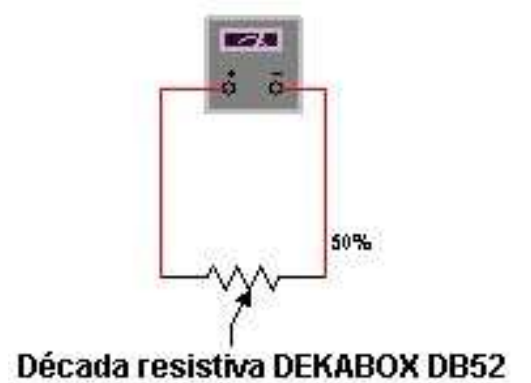

Figura 5.4 - Aferição da década resistiva

As Décadas foram aferidas pelos multímetros, após estes terem sido testados e calibrados. Com o uso do computador e a configuração do software "Benchlink" foi possível fazer com que o computador lesse a cada 10 minutos os valores indicados no multímetro e os guardasse numa tabela com informações de data, hora e valores. 


\subsection{Componentes}

\subsubsection{Pilhas}

O teste da pilhas tem como objetivo verificar a confiabilidade e autonomia que elas podem oferecer para a performance de todo o sistema. Além disso, os teste foram utilizados para verificar as curvas de carga e descarga descritas pelo fabricante, de modo a comprovar se o lote adquirido estava em conformidade com as especificações.

Foram realizados, basicamente, os seguintes testes com as baterias isoladas (sem estarem acopladas ao resto do sistema), a saber:

\subsubsection{Carga lenta a $60 \mathrm{~mA}$}

O teste de carga lenta é um processo que leva de 16 a 20 horas para se completar e tem como objetivo tentar reproduzir as curvas oferecidas pelo fabricante. Os primeiros testes foram realizados anotando-se apenas as tensões inicial e final das pilhas, enquanto que nos últimos houve a oportunidade de usar o computador para coletar os dados. O teste de carga a $60 \mathrm{~mA}$ foi montado segundo as seguintes topologias:

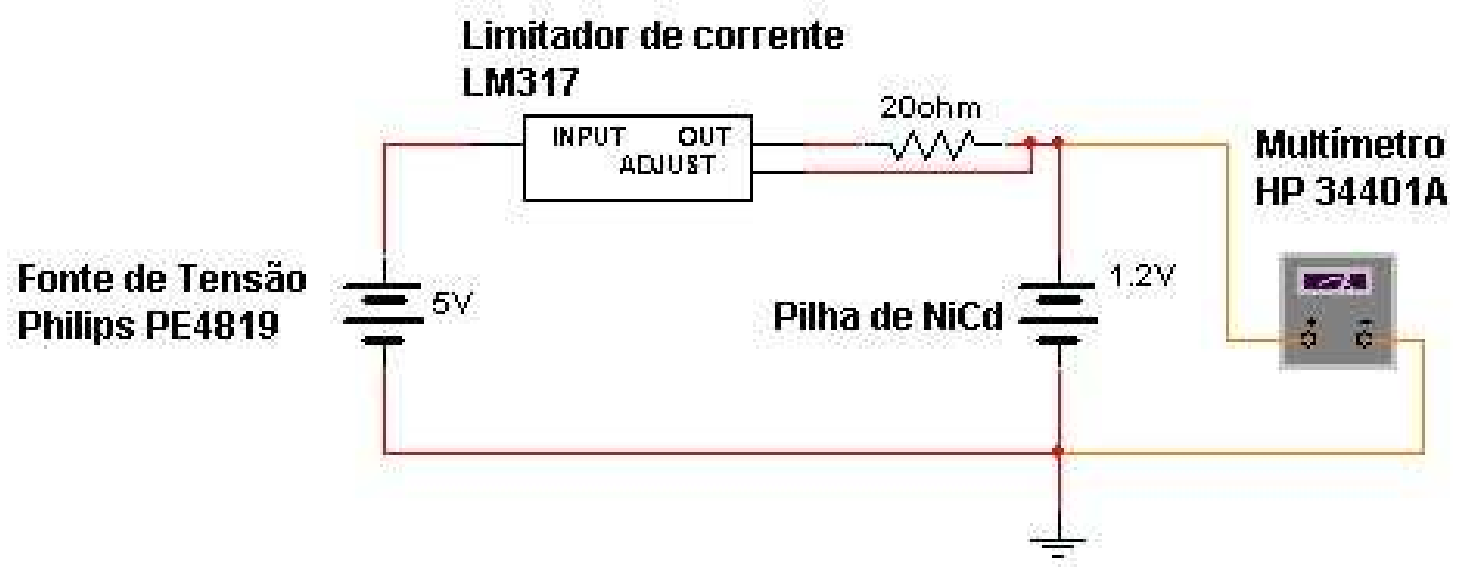

Figura 5.5 - Teste de carga a $60 \mathrm{~mA}$ para uma pilha 


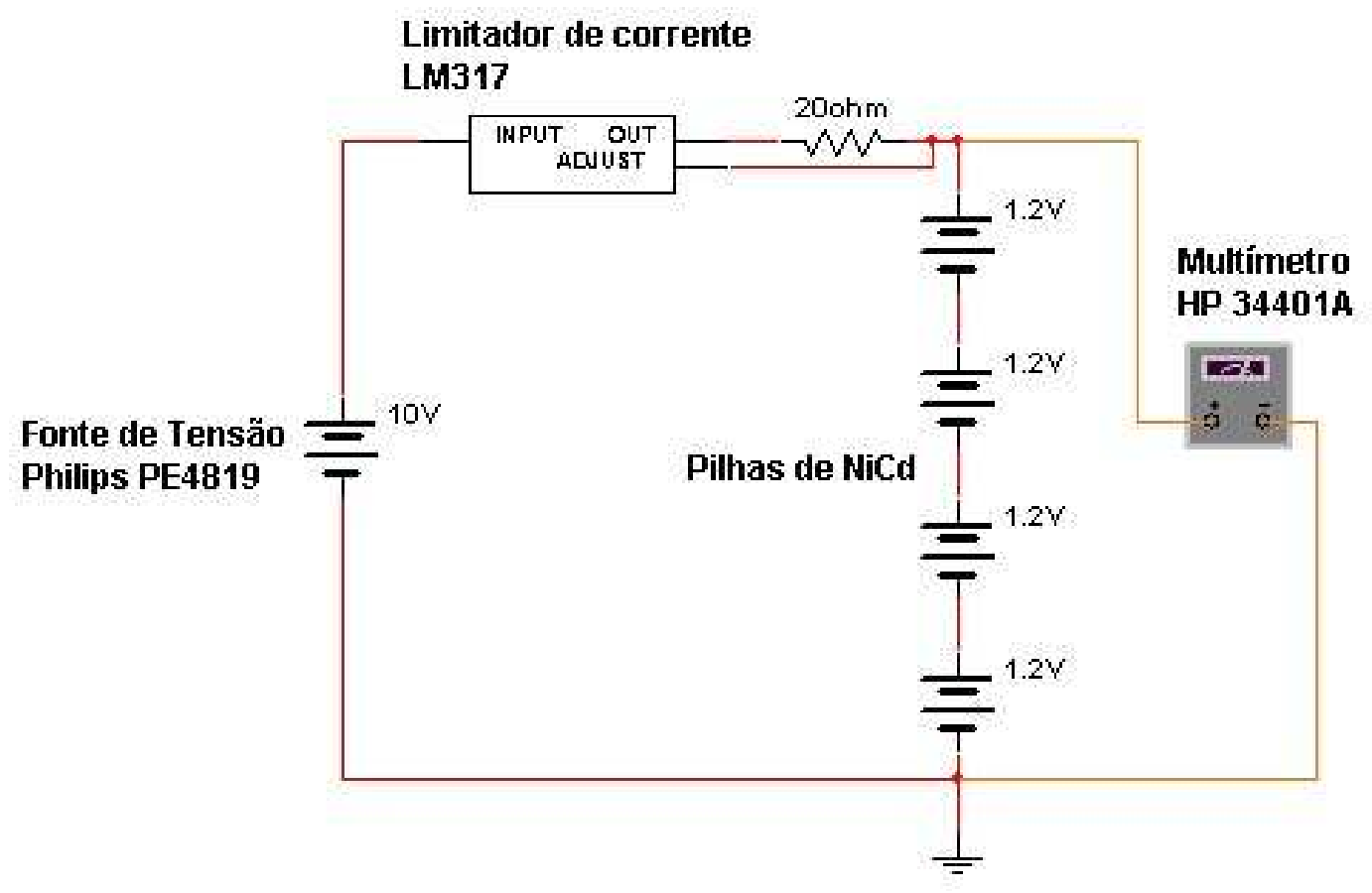

Figura 5.6 - Teste de carga a $60 \mathrm{~mA}$ para quatro pilhas

\subsubsection{Carga lenta a $30 \mathrm{~mA}$;}

Este teste foi realizado para mostrar o comportamento das pilhas em condições parecidas com as do circuito final, onde a corrente de carga será de aproximadamente $30 \mathrm{~mA}$. O circuito montado segue abaixo:

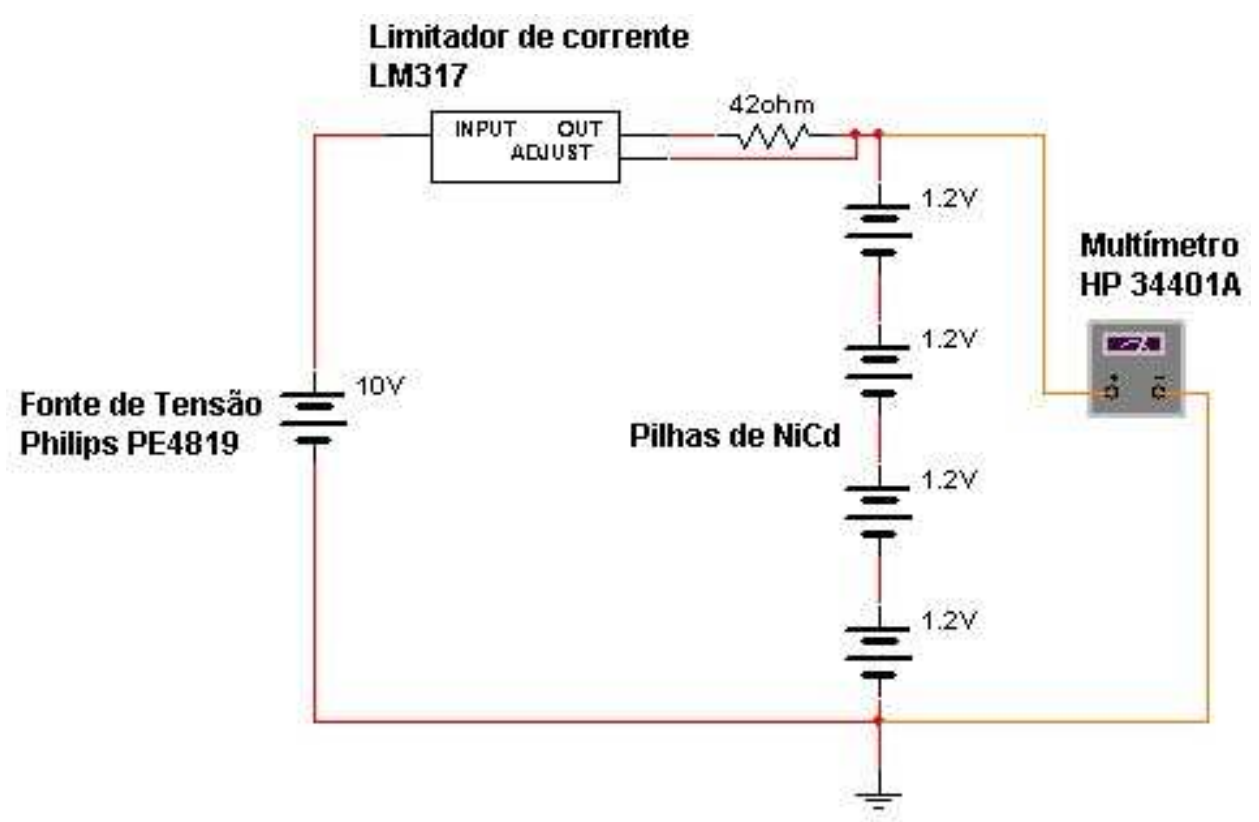

Figura 5.7 - Teste de carga a $30 \mathrm{~mA}$ para quatro pilhas 
5.2.1.3. Descarga lenta a $60 \mathrm{~mA}$;

Assim como a carga lenta a $60 \mathrm{~mA}$, este teste tem como objetivo verificar a conformidade das pilhas adquiridas com os dados do fabricante. Os circuitos utilizados seguem abaixo:

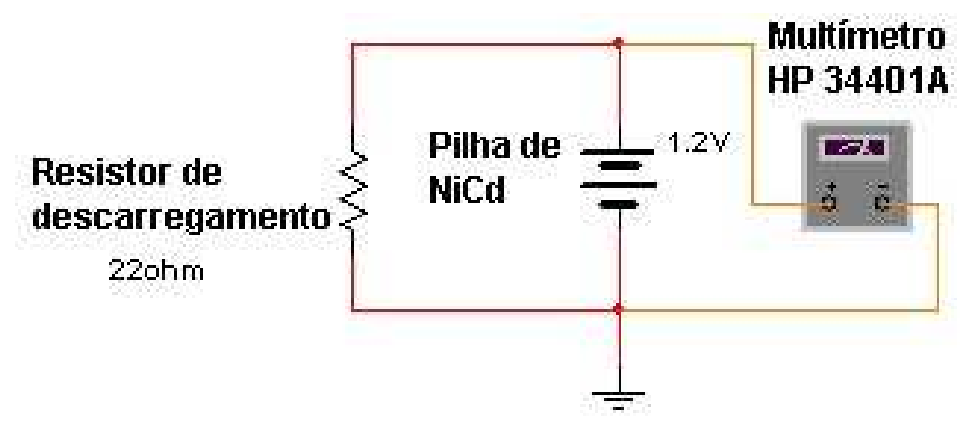

Figura 5.8 - Teste de descarga a 60 mA para uma pilha

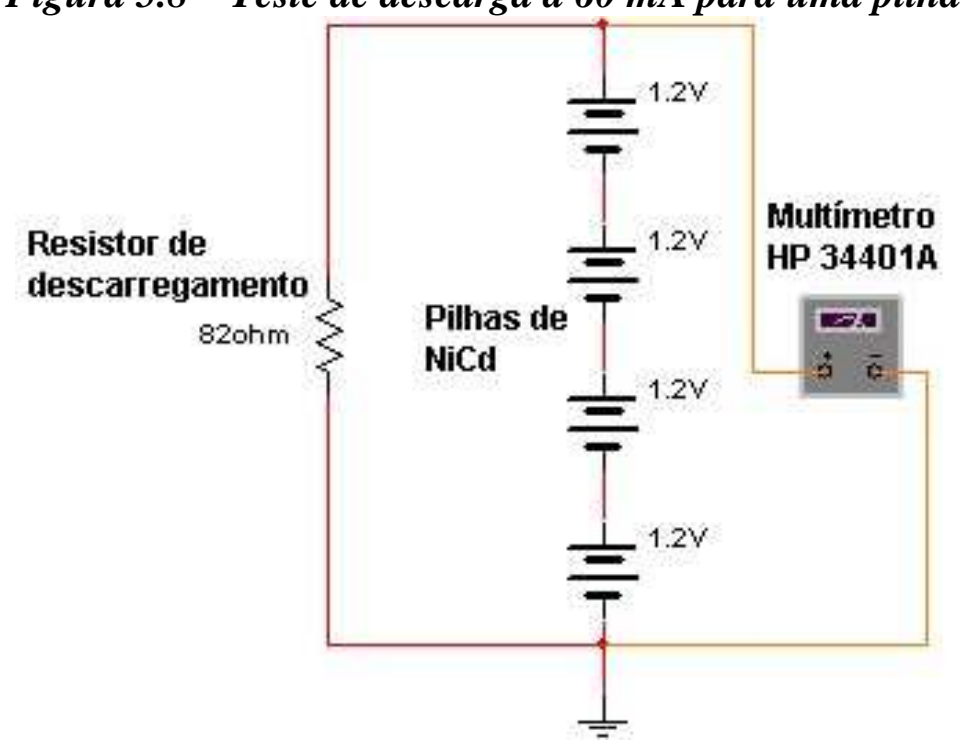

Figura 5.9 - Teste de descarga a $60 \mathrm{~mA}$ para quatro pilhas

5.2.1.4. Carga rápida a $600 \mathrm{~mA}$;

O teste de carga rápida pode demorar até 2 horas para se realizar e também foi concebido para corroborar as curvas do fabricante. Os dados foram coletados e intervalos de 5 e 10 minutos e as topologias seguem abaixo: 


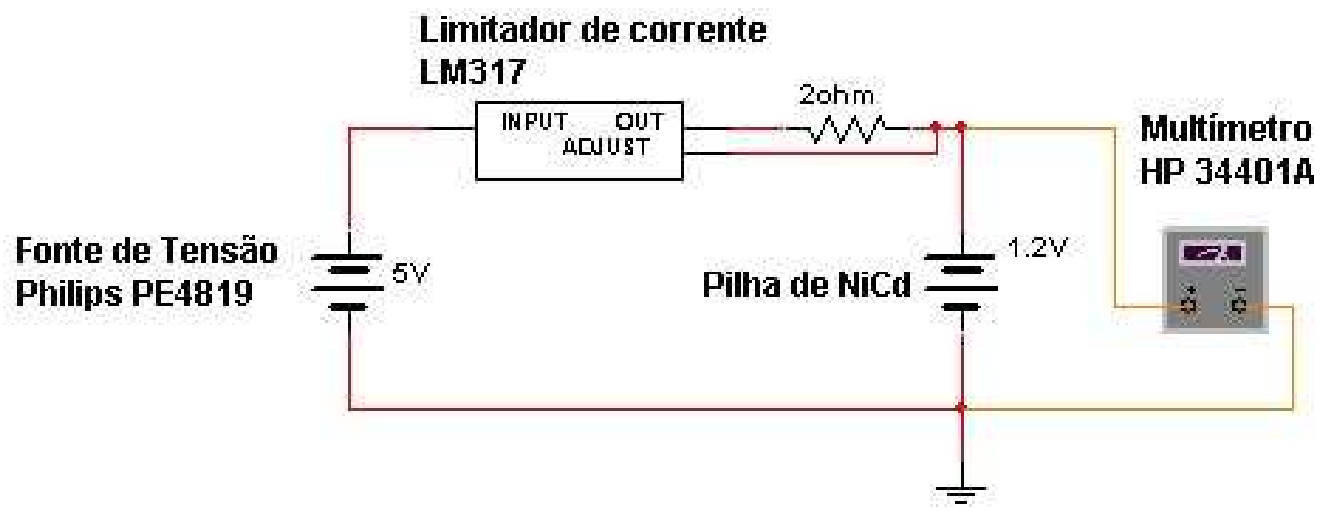

Figura 5.10 - Teste de carga a $600 \mathrm{~mA}$ para uma pilha

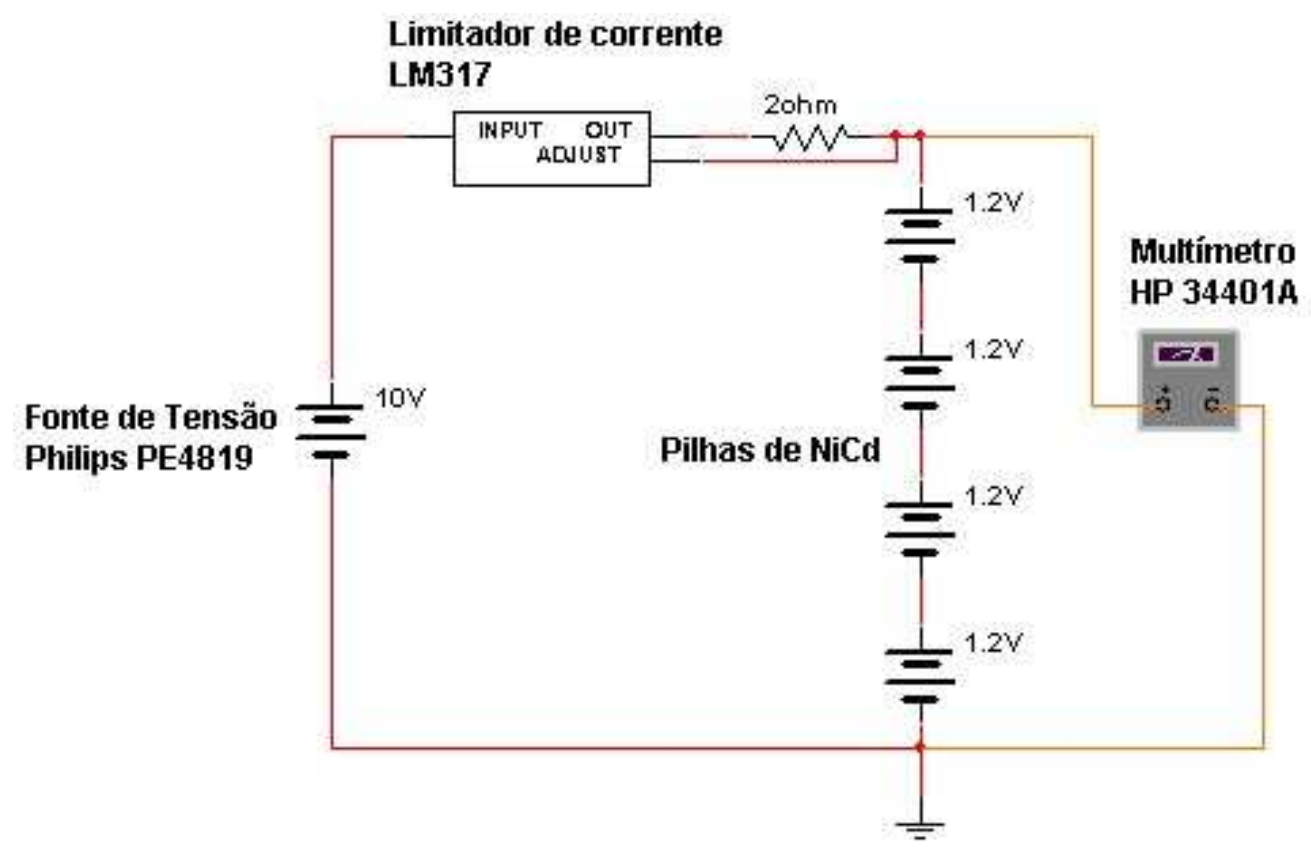

Figura 5.11 - Teste de carga a $600 \mathrm{~mA}$ para quatro pilhas

\subsubsection{Resistores e diodos}

Neste teste verificou-se se os resistores estavam dentro de sua faixa de tolerância e se o diodo estava conduzindo no sentido correto, cortando no sentido contrário e qual a sua queda de tensão.

O multímetro utilizado possuía uma precisão bastante grande, permitindo avaliar os valores de resistência com grande eficácia. Ele também possuía uma função especial que permite testar a funcionalidade dos diodos e a queda de tensão sobre eles, restando apenas anotar os valores indicados. 
Os testes podem ser visualizados conforme as seguintes figuras:

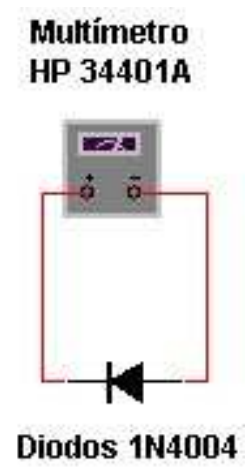

Figura 5.12 - Teste dos diodos

Multímetro

HP 34401A

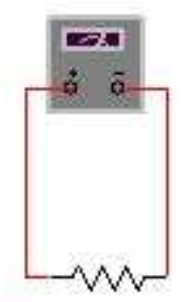

Resistores

Figura 5.13 - Teste dos resistores

\subsubsection{Reguladores}

O teste dos reguladores foi concebido verificar os itens mais importantes constados no datasheet do fabricante, como, por exemplo, corrente quiescente, corrente de saída, tensão de saída, variação de tensão e variação de corrente.

Foram realizados dois grupos de testes diferentes para o LM317, pois num deles a configuração estava como regulador de tensão e no outro era de limitador de corrente.

Inicialmente foi realizado o teste de limitação da corrente utilizando um LM317, o calibrador, um resistor de $20 \Omega$ e um multímetro no modo amperímetro, segundo a topologia a seguir: 


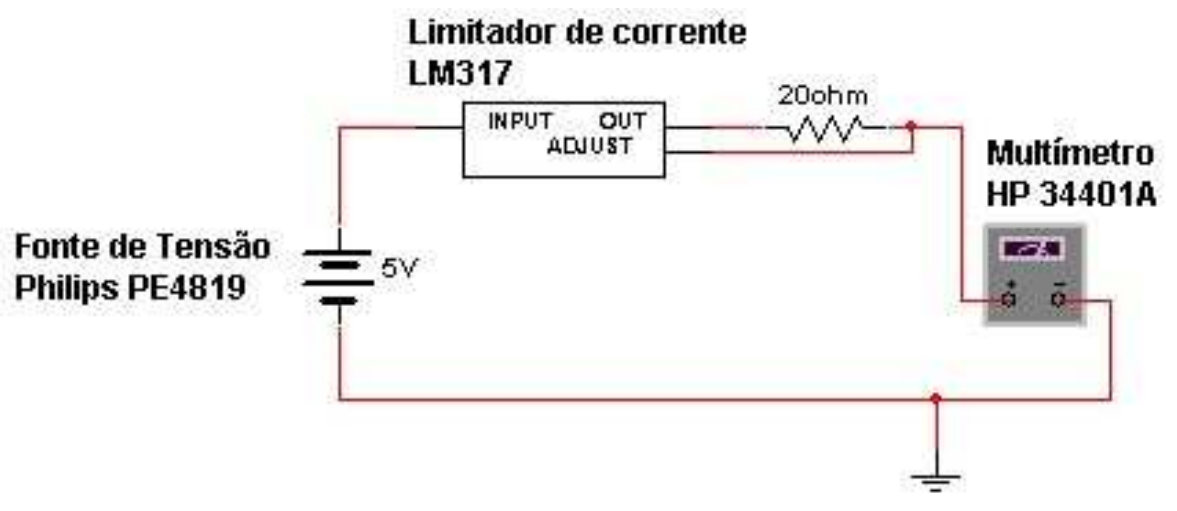

Figura 5.14 - Teste da corrente do regulador

A tensão foi variada entre $5 \mathrm{~V}$ e $10 \mathrm{~V}$ e foram observados os valores indicados pelos multímetros, bem como a variação da corrente para uma dada tensão fixa. Os valores foram comparados com os dados fornecidos pelo fabricante.

O segundo teste consistiu em verificar a tensão de saída do LM317 no modo regulador de tensão. Para verificar isso, foram utilizados um voltímetro e três resistores de valores $2 \mathrm{~K} 2 \Omega, 100 \Omega$ e 280 $\Omega$, que foram montados segundo a seguinte topologia:

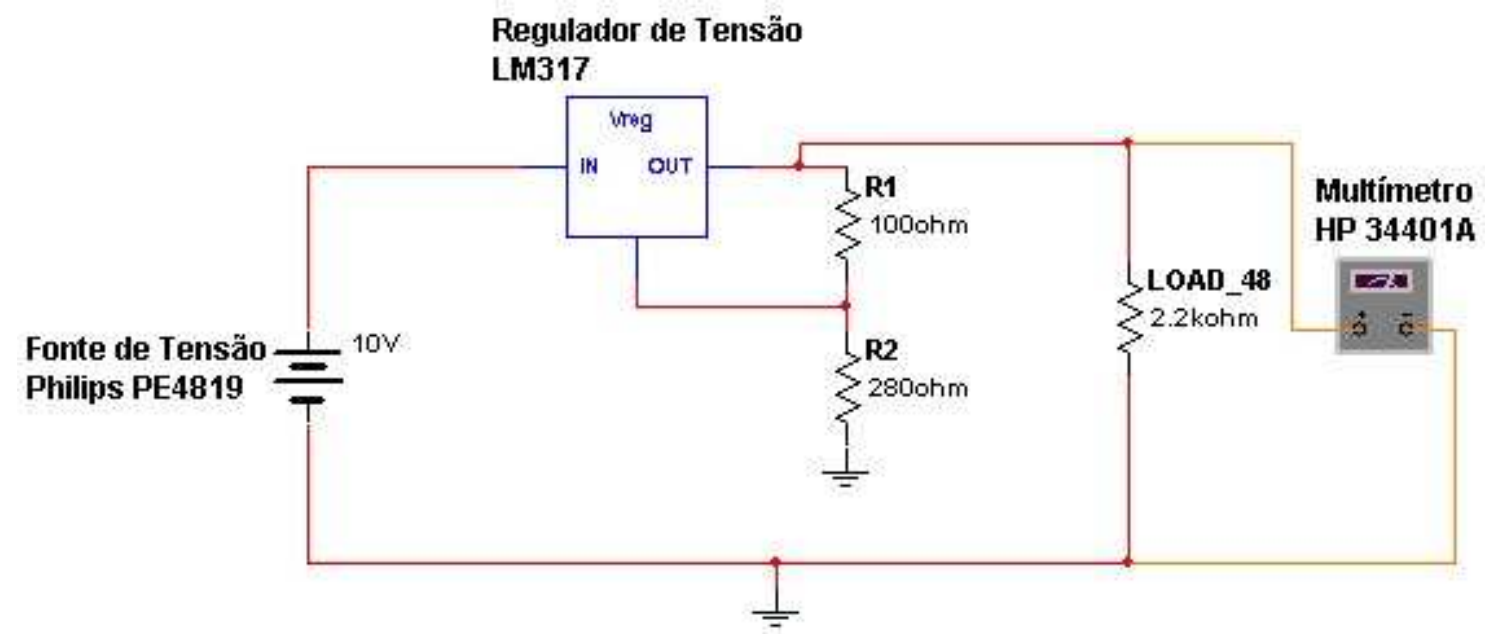

Figura 5.15 - Teste da tensão de saída do regulador

Os resistores de $100 \Omega$ e $280 \Omega$ fazem um divisor de tensão, enquanto que o resistor de $2 \mathrm{~K} 2 \Omega$ atua como carga. Os valores de tensão 
de saída, bem como variação, foram anotados e comparados com os dados do fabricante.

Para achar a corrente quiescente adicionaram-se dois voltímetros para calcular a tensão em cima dos resistores R1 e R2. De posse dos valores de tensão e utilizando a lei de Ohm, a diferença entre as correntes que passam por R1 e R2 é a corrente quiescente. A seguinte topologia foi estruturada:

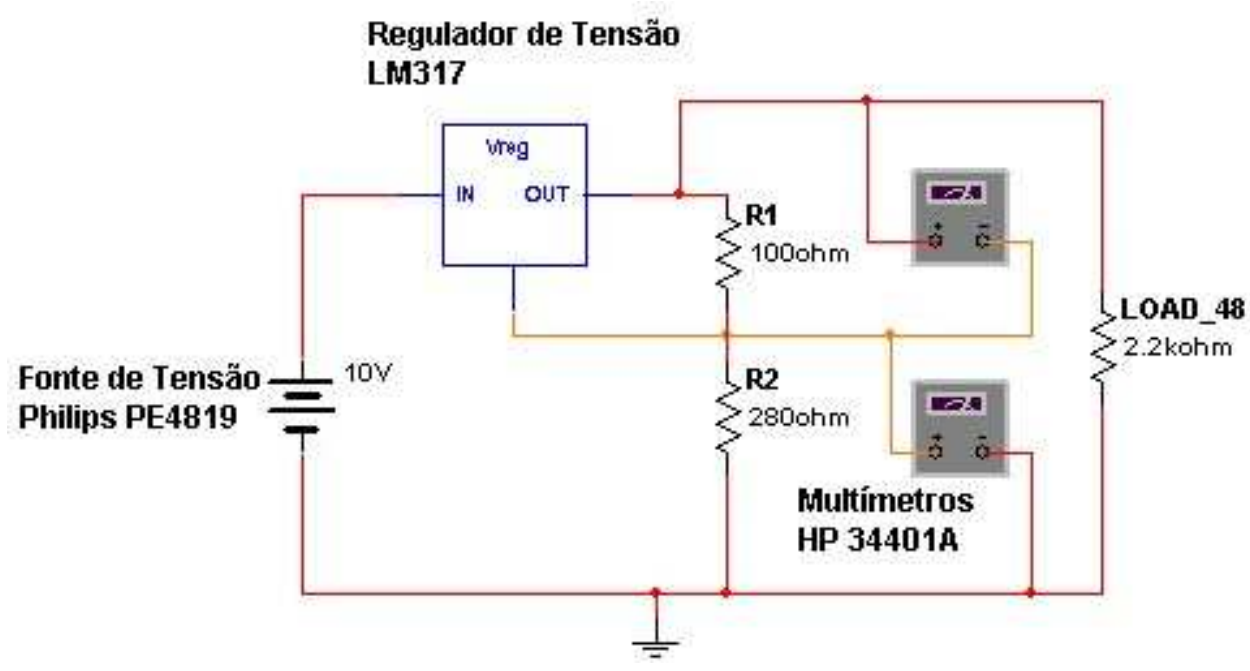

Figura 5.16 - Teste da corrente quiescente do regulador

O último teste visou diminuir a corrente de fuga dos reguladores de modo que a duração das baterias em cima do circuito seja maior. A topologia utilizada segue abaixo: 


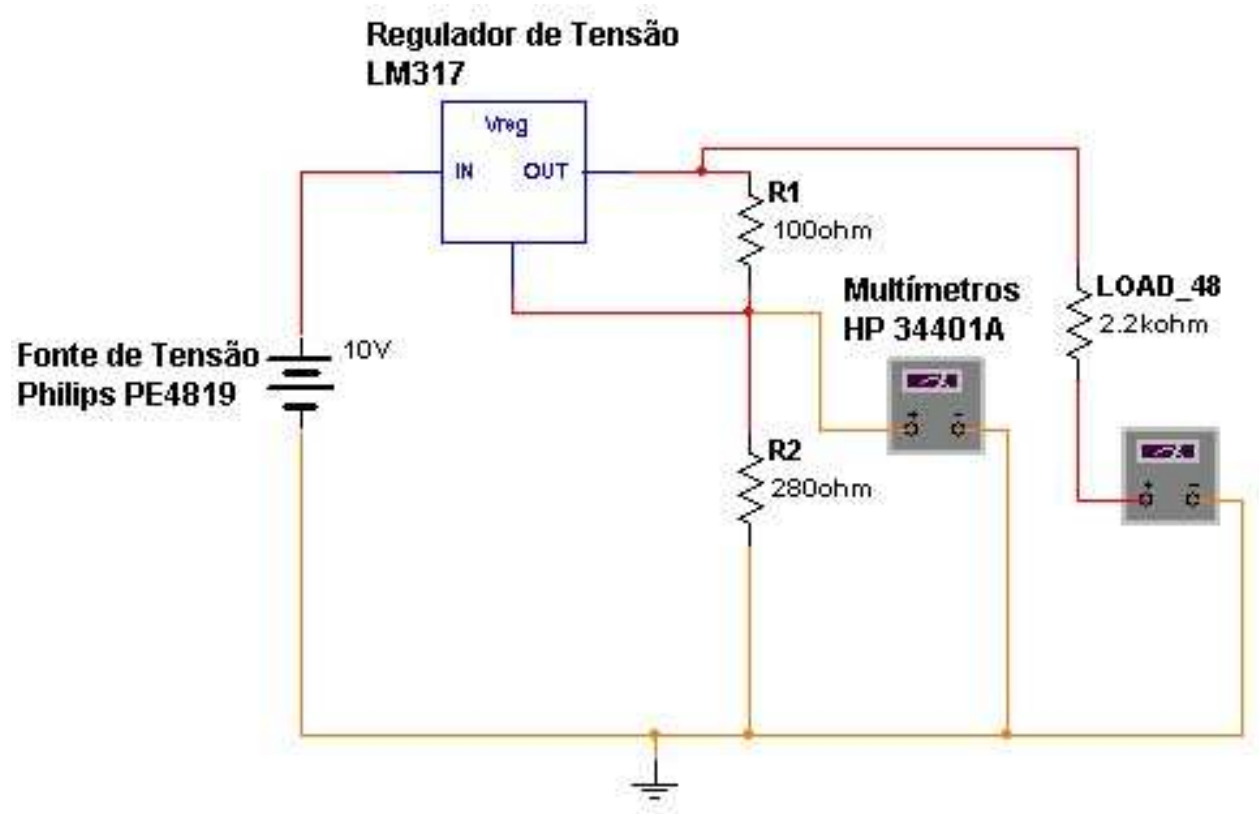

Figura 5.17 - Teste de minimização da corrente de fuga

\subsection{Sistema}

É natural que aconteça um teste prático de todo o sistema a fim de verificar a funcionalidade e eficiência do modelo que foi idealizado. Procurou-se ao máximo simular o ambiente em que o circuito se encontrará dentro do projeto Milênio, e isso inclui grandes variações de tensão no painel solar, várias horas sem a ajuda do painel, diferentes temperaturas, etc.

Os teste realizados foram basicamente os seguintes:

\subsubsection{Autonomia do circuito}

Neste teste o conjunto de baterias foi conectado ao sistema e os valores de tempo, tensões em cada um dos reguladores e tensão na bateria foram anotadas. $\mathrm{O}$ esquema do circuito utilizado segue abaixo: 


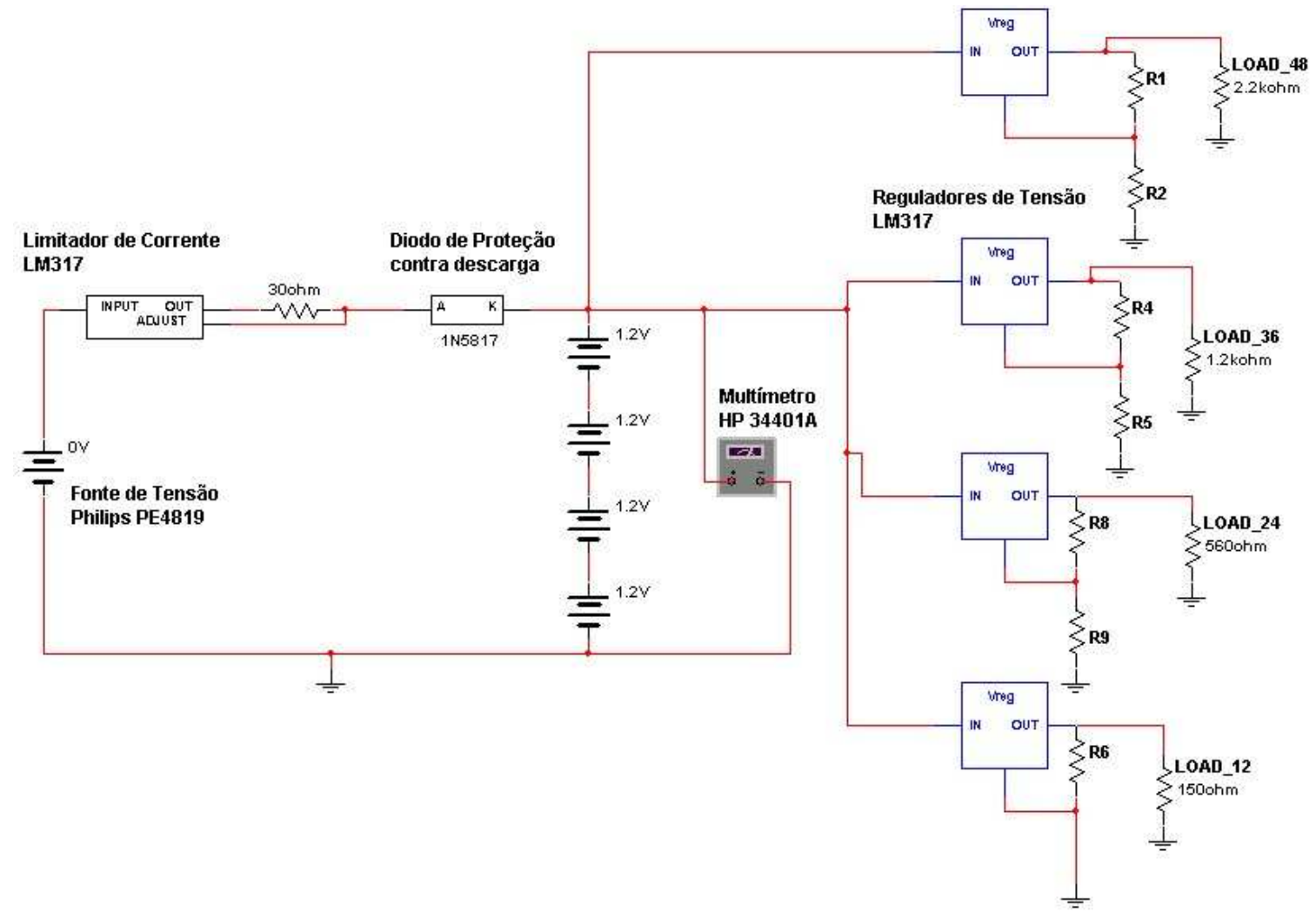

Figura 5.18 - Teste de autonomia do circuito

\subsubsection{Simulação de dia e noite}

Essa simulação nada mais é do que a ausência e a presença de tensão da fonte em cima do sistema. Foram testados regimes de 12 horas ininterruptas de energia intercalados por um período de 12 horas sem a atuação da fonte de alimentação. O timer utilizado no teste foi ajustado para ligar durante doze horas e depois permanecer desligado por mais 12 , fazendo isso por 10 ciclos seguidos, totalizando 5 dias de teste. Todos os dados foram colhidos pelo computador e o teste foi realizado seguindo a seguinte topologia: 


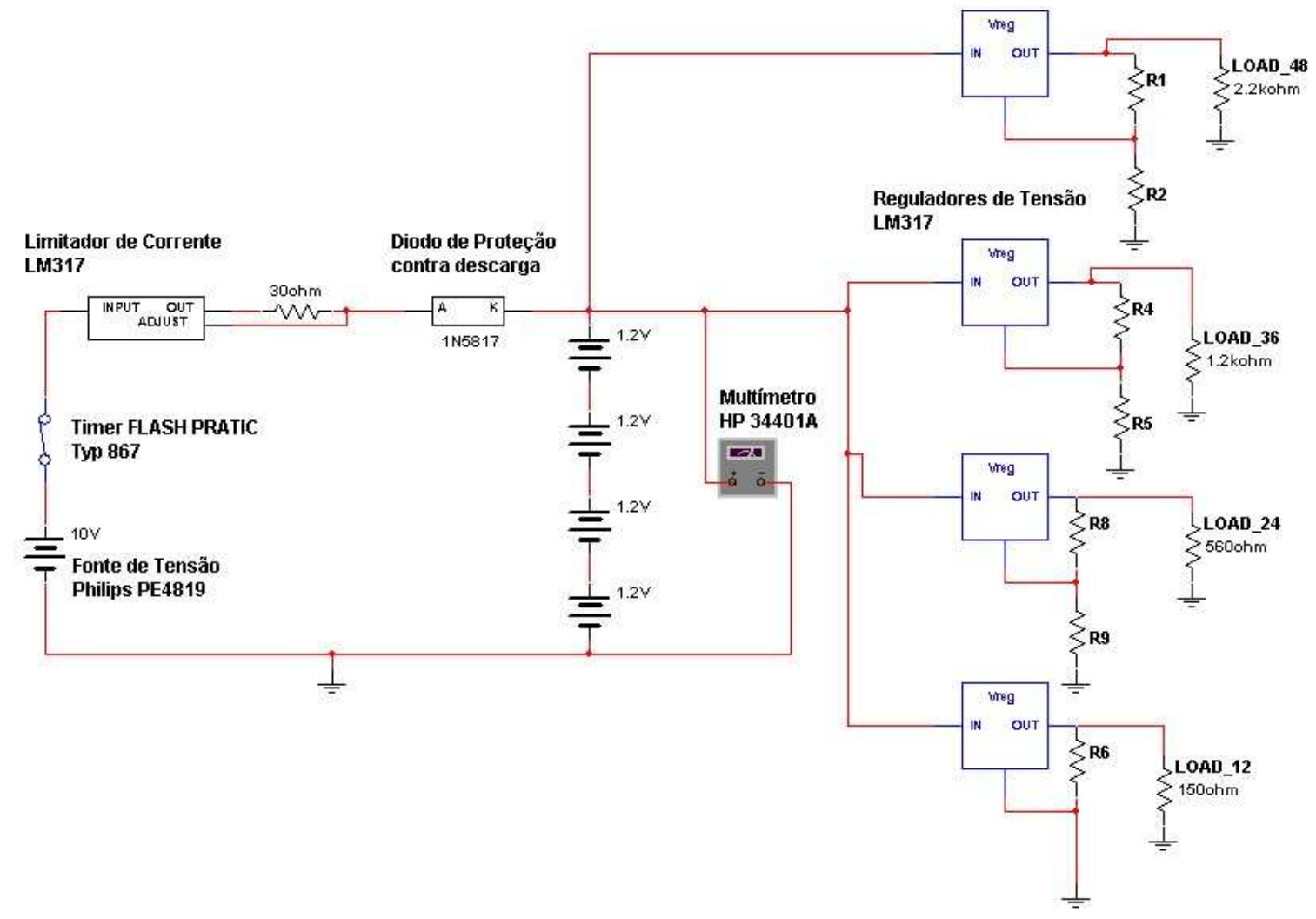

Figura 5.19 - Simulação de "dia" e "noite" 


\section{Resultados e Discussão}

Para os testes que seguem iremos nos referir à corrente de carga e descarga como múltiplos de "C", onde "C" indica a capacidade nominal da pilha. Sendo assim, uma pilha de $600 \mathrm{mAh}$ tem seu "C" igual a 600 mA e $0,1 C$ é igual a $60 \mathrm{~mA}$.

Os testes com os dispositivos duraram aproximadamente 2 semanas e seus resultados não serão apresentados na ordem cronológica, mas, sim, em 4 grandes grupos de testes.

Quando necessária, a fórmula utilizada para o cálculo da corrente que passa pelo LM317 é:

$$
I_{\text {out }}=\frac{1,25}{R}
$$

Onde,

Iout é a corrente de saída em A;

$\mathrm{R}$ é o resistor limitador em $\Omega$.

\subsection{Resultado do teste de instrumentação}

Os resultados dos testes de instrumentação serão divididos em três pequenas categorias: Teste dos multímetros, teste das décadas e teste da fonte de alimentação.

\subsubsection{Teste dos multímetros}

O teste dos multímetros foi realizado segundo a topologia indicada nas figuras 5.2 e 5.3. Com o calibrador conectado no modo voltímetro, o multímetro indicava exatamente o que estava sendo enviado pelo calibrador. A precisão do calibrador era de apenas 2 casas decimais, enquanto que o multímetro tinha condições fazer medidas de micro volt. Segue abaixo a tabela com os resultados da medição: 


\begin{tabular}{|c|c|}
\hline Valor indicado pela fonte (V) & Valor indicado pelo voltímetro (V) \\
\hline 8,00 & 8,00352 \\
\hline
\end{tabular}

Tabela 6.1 - Leitura indicada pelo voltímetro

O mesmo aconteceu com o multímetro no modo amperímetro. Segue abaixo a tabela correspondente:

\begin{tabular}{|c|c|}
\hline Valor indicado pela fonte (mA) & Valor indicado pelo amperímetro (mA) \\
\hline 8,00 & 8,00199 \\
\hline
\end{tabular}

Tabela 6.2 - Leitura indicada pelo amperímetro

\subsubsection{Teste das décadas resistivas}

O teste das décadas resistivas está ilustrado pela figura 5.4 e o resultado pode ser conferido pela tabela abaixo:

\begin{tabular}{|c|c|c|}
\hline Valor selecionado $(\boldsymbol{\Omega})$ & $\begin{array}{c}\text { Valor indicado pelo } \\
\text { Década } \mathbf{(}(\mathbf{\Omega})\end{array}$ & $\begin{array}{c}\text { Valor indicado pelo } \\
\text { Década } \mathbf{(}(\mathbf{\Omega})\end{array}$ \\
\hline 10 & 10,352 & 10,521 \\
\hline 50 & 50,352 & 50,521 \\
\hline 100 & 100,352 & 100,521 \\
\hline 500 & 500,352 & 500,521 \\
\hline 1000 & 1000,352 & 1000,521 \\
\hline 10000 & 10000,352 & 10000,521 \\
\hline 100000 & 100000,352 & 100000,521 \\
\hline
\end{tabular}

Tabela 6.3 - Resistências aferidas pelo multímetro

Os resultados nos mostram que há um offset diferente em cada uma das décadas resistivas, independente do valor de resistência escolhido. Quando as décadas foram utilizadas foi necessário recordar o valor do offset.

\subsection{Resultados dos testes das pilhas}

Para os testes com as pilhas as subdividimos em 3 grupos com 4 pilhas cada grupo. Os grupos foram numerados de 1 a 3 e as pilhas de cada grupo receberam as letras do alfabeto, A, B, C e D. Assim, uma pilha caracterizada como 2D é a pilha D do grupo 2 . 
Dessa maneira, a forma de identificar as pilhas e os testes que foram feitos com cada uma delas torna-se mais fácil.

Todas as topologias utilizadas estão ilustradas na seção 5.2.1, sendo que faremos referência apenas ao número da figura quando quisermos mostrar a topologia.

\subsubsection{Primeiro teste de descarga lenta a $60 \mathrm{~mA}$}

O presente teste foi realizado segundo a topologia indicada pela figura 5.9 e possui as seguintes condições iniciais:

\begin{tabular}{|c|c|}
\hline Pilhas & $1 \mathrm{~A}, 1 \mathrm{~B}, 1 \mathrm{C} \mathrm{e} \mathrm{1D}$ \\
\hline Tensão inicial 1A & $1,2454 \mathrm{~V}$ \\
\hline Tensão inicial 1B & $1,2443 \mathrm{~V}$ \\
\hline Tensão inicial 1C & $1,2356 \mathrm{~V}$ \\
\hline Tensão inicial 1D & $1,2370 \mathrm{~V}$ \\
\hline Tensão Inicial total & $4,9622 \mathrm{~V}$ \\
\hline Temperatura ambiente & $26^{\circ} \mathrm{C}$ \\
\hline Resistor de descarregamento & $82 \Omega$ \\
\hline Corrente teórica inicial & $60,5 \mathrm{~mA}$ \\
\hline
\end{tabular}

Tabela 6.4 - Condições do primeiro teste de descarga lenta a $60 \mathrm{~mA}$

Os resultados obtidos podem ser observados na seguinte tabela:

\begin{tabular}{|c|c|c|c|}
\hline Tempo (min) & Tensão (V) & Corrente (mA) & Temperatura $\left({ }^{\mathbf{}} \mathbf{C}\right)$ \\
\hline 0 & 4,77 & 58 & 26,2 \\
\hline 20 & 4,57 & 56 & 26 \\
\hline 65 & 4,52 & 55 & 26 \\
\hline 90 & 4,49 & 54 & 26,1 \\
\hline $900(15 \mathrm{hr})$ & $34 \mathrm{mV}$ & 0 & 26,5 \\
\hline
\end{tabular}

Tabela 6.5 - Resultados do primeiro teste de descarga lenta a $60 \mathrm{~mA}$

O teste que foi concebido para durar mais de 16 horas acabou por ter tido algum problema com alguma das baterias, pois depois de 15 horas de teste a tensão final estava por volta de $34 \mathrm{mV}$. De fato, seguem abaixo os valores de tensão individual e total depois de 4 horas desconectadas da carga: 


\begin{tabular}{|c|c|}
\hline Tensão final 1A & $1,2162 \mathrm{~V}$ \\
\hline Tensão final 1B & $1,17 \mathrm{~V}$ \\
\hline Tensão final 1C & $1,164 \mathrm{~V}$ \\
\hline Tensão final 1D & $19 \mathrm{mV}$ \\
\hline Tensão final total & $3,53 \mathrm{~V}$ \\
\hline
\end{tabular}

Tabela 6.6 - Tensões nas baterias

Com estes dados identificamos claramente que a bateria 1D teve um comportamento de descarga fora do normal. Depois deste teste a bateria foi colocada em observação.

\subsubsection{Segundo teste de descarga lenta a $60 \mathrm{~mA}$}

Para este teste utilizamos a mesma topologia usada no primeiro teste de descarga lenta a $60 \mathrm{~mA}$ ilustrada na figura 5.9. Substituiu-se a bateria que estava com suspeita de falha, a $1 \mathrm{D}$, pela bateria $2 \mathrm{~A}$. As condições do teste podem ser observadas a seguir:

\begin{tabular}{|c|c|}
\hline Pilhas & $1 \mathrm{~A}, 1 \mathrm{~B}, 1 \mathrm{C}$ e 2A \\
\hline Tensão inicial 1A & $1,22 \mathrm{~V}$ \\
\hline Tensão inicial 1B & $1,193 \mathrm{~V}$ \\
\hline Tensão inicial 1C & $1,177 \mathrm{~V}$ \\
\hline Tensão inicial 2A & $1,236 \mathrm{~V}$ \\
\hline Tensão Inicial total & $4,8236 \mathrm{~V}$ \\
\hline Temperatura ambiente & $26^{\circ} \mathrm{C}$ \\
\hline Resistor de descarregamento & $82 \Omega$ \\
\hline Corrente teórica inicial & $58,8 \mathrm{~mA}$ \\
\hline
\end{tabular}

Tabela 6.7 - Condições do segundo teste de descarga lenta a $60 \mathrm{~mA}$

Os resultados podem ser verificados pela seguinte tabela:

\begin{tabular}{|c|c|c|c|}
\hline Tempo (min) & Tensão (V) & Corrente (mA) & Temperatura $\left({ }^{\circ} \mathbf{C}\right)$ \\
\hline 0 & 2,5 & 30,5 & 26,2 \\
\hline 5 & 0,408 & 5 & 26 \\
\hline 15 & 0,227 & 2,7 & 26 \\
\hline 25 & 0,193 & 2,3 & 26,1 \\
\hline
\end{tabular}

Tabela 6.8 - Resultados do segundo teste de descarga lenta a $60 \mathrm{~mA}$ 
A tensão quando tiramos a carga foi para $250 \mathrm{mV}$ e depois de duas horas estabilizou em $3,945 \mathrm{~V}$

\subsubsection{Primeiro teste de carga lenta a $60 \mathrm{~mA}$}

$\mathrm{Na}$ terceira tentativa de carregar as baterias com uma pequena corrente de $60 \mathrm{~mA}$ utilizou-se a topologia da figura 5.6 e anotaram-se as seguintes condições iniciais:

\begin{tabular}{|c|c|}
\hline Pilhas & $3 \mathrm{~A}, 3 \mathrm{~B}, 3 \mathrm{C} \mathrm{e} \mathrm{3A}$ \\
\hline Tensão inicial 1A & $1,228 \mathrm{~V}$ \\
\hline Tensão inicial 1B & $1,245 \mathrm{~V}$ \\
\hline Tensão inicial 1C & $1,227 \mathrm{~V}$ \\
\hline Tensão inicial 2A & $1,245 \mathrm{~V}$ \\
\hline Tensão Inicial total & $4,956 \mathrm{~V}$ \\
\hline Temperatura ambiente & $26^{\circ} \mathrm{C}$ \\
\hline Tensão da fonte & $10 \mathrm{~V}$ \\
\hline Resistor limitador & $20 \Omega$ \\
\hline Corrente máxima teórica & $62,5 \mathrm{~mA}$ \\
\hline
\end{tabular}

Tabela 6.9 - Condições do primeiro teste de carga lenta a $60 \mathrm{~mA}$

Este teste foi realizado exatamente segundo as informações pesquisadas para carga de uma célula de NiCd. Uma fonte de tensão com um limitador de corrente.

Apenas os dados inicial e final foram coletados, segundo a tabela abaixo:

\begin{tabular}{|c|c|}
\hline Tempo (horas) & Tensão (V) \\
\hline 0 & 5,195 \\
\hline 16 & 6,005 \\
\hline
\end{tabular}

Tabela 6.10 - Resultado do primeiro teste de carga lenta a $60 \mathrm{~mA}$

Assim que a fonte foi desligada, a tensão total caiu para 5,65 V. Depois de 2 horas, as baterias assumiram as seguintes configurações de tensão: 


\begin{tabular}{|c|c|}
\hline Tensão final 3A & $1,375 \mathrm{~V}$ \\
\hline Tensão final 3B & $1,375 \mathrm{~V}$ \\
\hline Tensão final 3C & $1,374 \mathrm{~V}$ \\
\hline Tensão final 3D & $1,375 \mathrm{~V}$ \\
\hline Tensão final total & $5,498 \mathrm{~V}$ \\
\hline
\end{tabular}

Tabela 6.11 - Tensão final das baterias $3 A, 3 B, 3 C$ e $3 D$

Pode-se perceber que este tipo de topologia permitiu o carregamento igual das 4 baterias, fato esse não havia acontecido nos testes anteriores.

\subsubsection{Primeiro teste de carga rápida a $600 \mathrm{~mA}$}

Este é um dos testes realizados para corroborar as curvas de carga fornecidas pelo fabricante. $\mathrm{O}$ circuito foi montado segundo a topologia da figura 5.11 e as condições do teste eram as seguintes:

\begin{tabular}{|c|c|}
\hline Pilhas & $1 \mathrm{~A}, 1 \mathrm{~B}, 1 \mathrm{C} \mathrm{e} \mathrm{2 \textrm {A }}$ \\
\hline Tensão inicial 1A & $1,270 \mathrm{~V}$ \\
\hline Tensão inicial 1B & $1,265 \mathrm{~V}$ \\
\hline Tensão inicial 1C & $1,265 \mathrm{~V}$ \\
\hline Tensão inicial 2A & $1,274 \mathrm{~V}$ \\
\hline Tensão Inicial total & $5,074 \mathrm{~V}$ \\
\hline Temperatura ambiente & $26^{\circ} \mathrm{C}$ \\
\hline Tensão da fonte & $10 \mathrm{~V}$ \\
\hline Resistor limitador & $2 \Omega$ \\
\hline Corrente máxima teórica & $625 \mathrm{~mA}$ \\
\hline
\end{tabular}

Tabela 6.12 - Condições do primeiro teste de carga rápida a $600 \mathrm{~mA}$

Os resultados foram de acordo com o esperado e os dados seguem na tabela abaixo:

\begin{tabular}{|c|c|c|}
\hline Tempo (min) & Tensão $(\mathbf{V})$ & Temperatura $\left({ }^{\mathbf{0}} \mathbf{C}\right)$ \\
\hline 0 & 7,16 & 26,7 \\
\hline 10 & 7,192 & 28 \\
\hline 20 & 7,212 & 31 \\
\hline 30 & 7,197 & 32,6 \\
\hline 40 & 7,203 & 33,5 \\
\hline 50 & 7,252 & 34,8 \\
\hline 60 & 7,336 & 36,3 \\
\hline
\end{tabular}




\begin{tabular}{|c|c|c|}
\hline 65 & 7,603 & 37,4 \\
\hline 70 & 7,622 & 39 \\
\hline 75 & 7,660 & 41,3 \\
\hline 80 & 7,685 & 43 \\
\hline
\end{tabular}

Tabela 6.13 - Resultados do primeiro teste de carga rápida a $600 \mathrm{~mA}$

O gráfico da tabela acima segue abaixo:

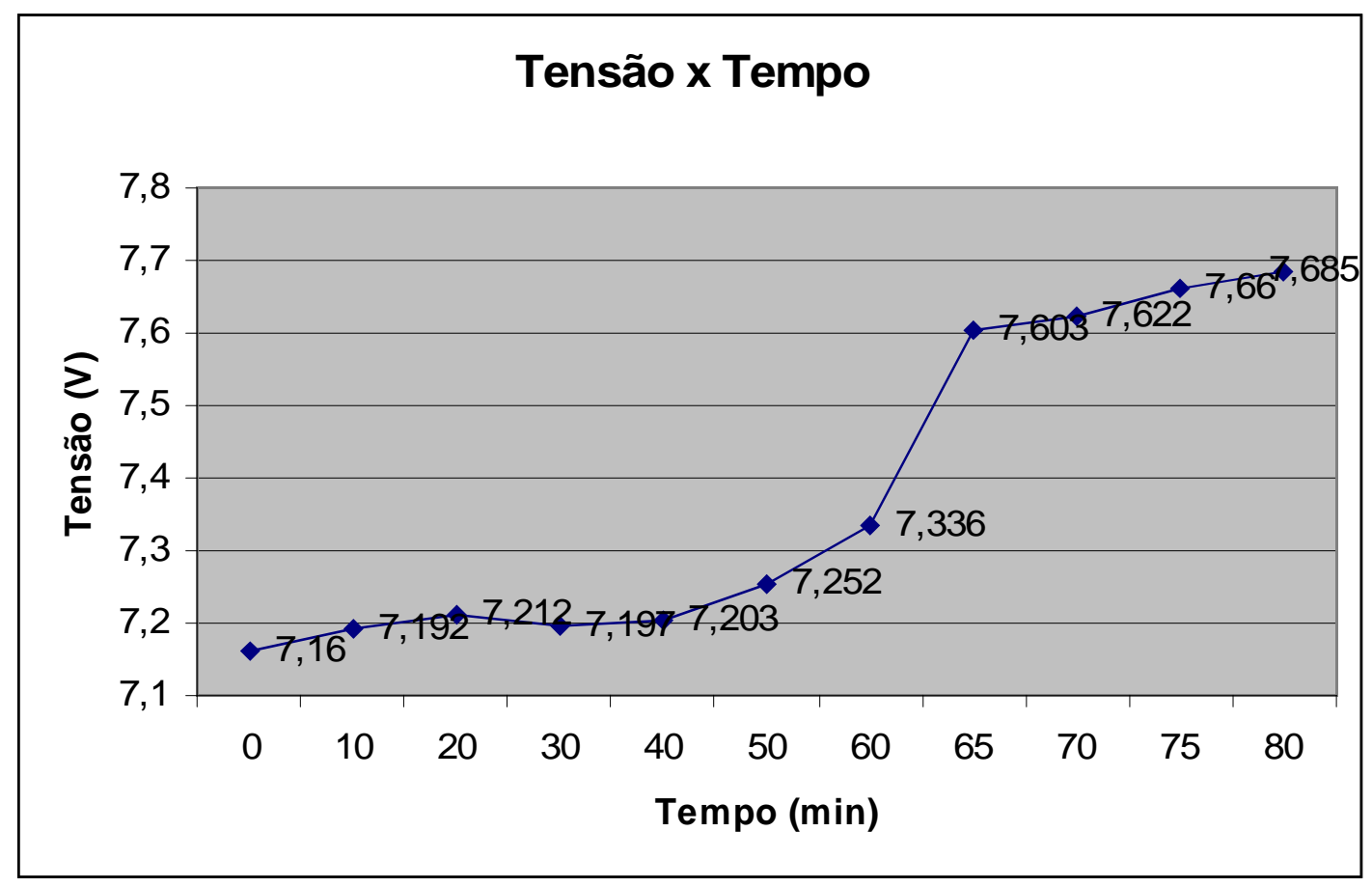

Gráfico 6.1 - Resultado do primeiro teste de carga rápida a $600 \mathrm{~mA}$

Como um teste de carga rápida pode danificar a bateria, caso ocorra uma sobrecarga, optou-se por colher dados de apenas 80 minutos, visto que neste momento a temperatura das baterias já estava em $43^{\circ} \mathrm{C}$ e a tensão total estava por volta de 7,685, o que dá uma média de $1,92 \mathrm{~V}$ por bateria.

Depois de retirada a fonte de tensão e passadas 2 horas, as tensões das pilhas ficaram da seguinte maneira: 


\begin{tabular}{|c|c|}
\hline Tensão final 1A & $1,4 \mathrm{~V}$ \\
\hline Tensão final 1B & $1,405 \mathrm{~V}$ \\
\hline Tensão final 1C & $1,402 \mathrm{~V}$ \\
\hline Tensão final 2A & $1,394 \mathrm{~V}$ \\
\hline Tensão final total & $5,69 \mathrm{~V}$ \\
\hline
\end{tabular}

Tabela 6.14 - Tensão final das baterias $1 \mathrm{~A}, 1 \mathrm{~B}, 1 \mathrm{C}$ e $2 \mathrm{~A}$

Analisando o gráfico, podemos observar uma grande inclinação a partir de 60 minutos e, a partir dos 65, uma tendência à estabilidade. De fato, se o procedimento fosse continuado por mais algumas dezenas de minutos, a tendência era que se pudesse observar uma pequena queda da tensão com relação ao seu valor anterior, ou seja, um $\Delta \mathrm{V}$ negativo.

\subsubsection{Segundo teste de carga rápida a $600 \mathrm{~mA}$}

Este teste foi feito com apenas uma pilha, segundo a topologia indicada na figura 5.10. As condições iniciais do circuito eram:

\begin{tabular}{|c|c|}
\hline Pilha & 2B \\
\hline Tensão total & $1,2397 \mathrm{~V}$ \\
\hline Temperatura ambiente & $26^{\circ} \mathrm{C}$ \\
\hline Tensão da fonte & $7 \mathrm{~V}$ \\
\hline Resistor limitador & $2 \Omega$ \\
\hline Corrente máxima teórica & $625 \mathrm{~mA}$ \\
\hline
\end{tabular}

Tabela 6.15 - Condições do segundo teste de carga rápida a $600 \mathrm{~mA}$

Os dados colhidos podem ser verificados na tabela abaixo:

\begin{tabular}{|c|c|c|}
\hline Tempo (min) & Tensão $(\mathbf{V})$ & Temperatura $\left({ }^{\mathbf{0}} \mathbf{C}\right)$ \\
\hline 0 & 1,95 & 26,3 \\
\hline 5 & 2,068 & 26,7 \\
\hline 15 & 2,076 & 27,2 \\
\hline 25 & 2,106 & 27,8 \\
\hline 35 & 2,143 & 28,3 \\
\hline 45 & 2,169 & 29,8 \\
\hline 55 & 2,181 & 31,5 \\
\hline 65 & 2,291 & 33,2 \\
\hline
\end{tabular}

Tabela 6.16 - Resultados do segundo teste de carga rápida a $600 \mathrm{~mA}$ 
Quando a fonte foi retirada, a tensão caiu para 1,46V e estabilizou em 1,377V, denotando carga completa.

Segue abaixo o gráfico da tensão da pilha pelo tempo:

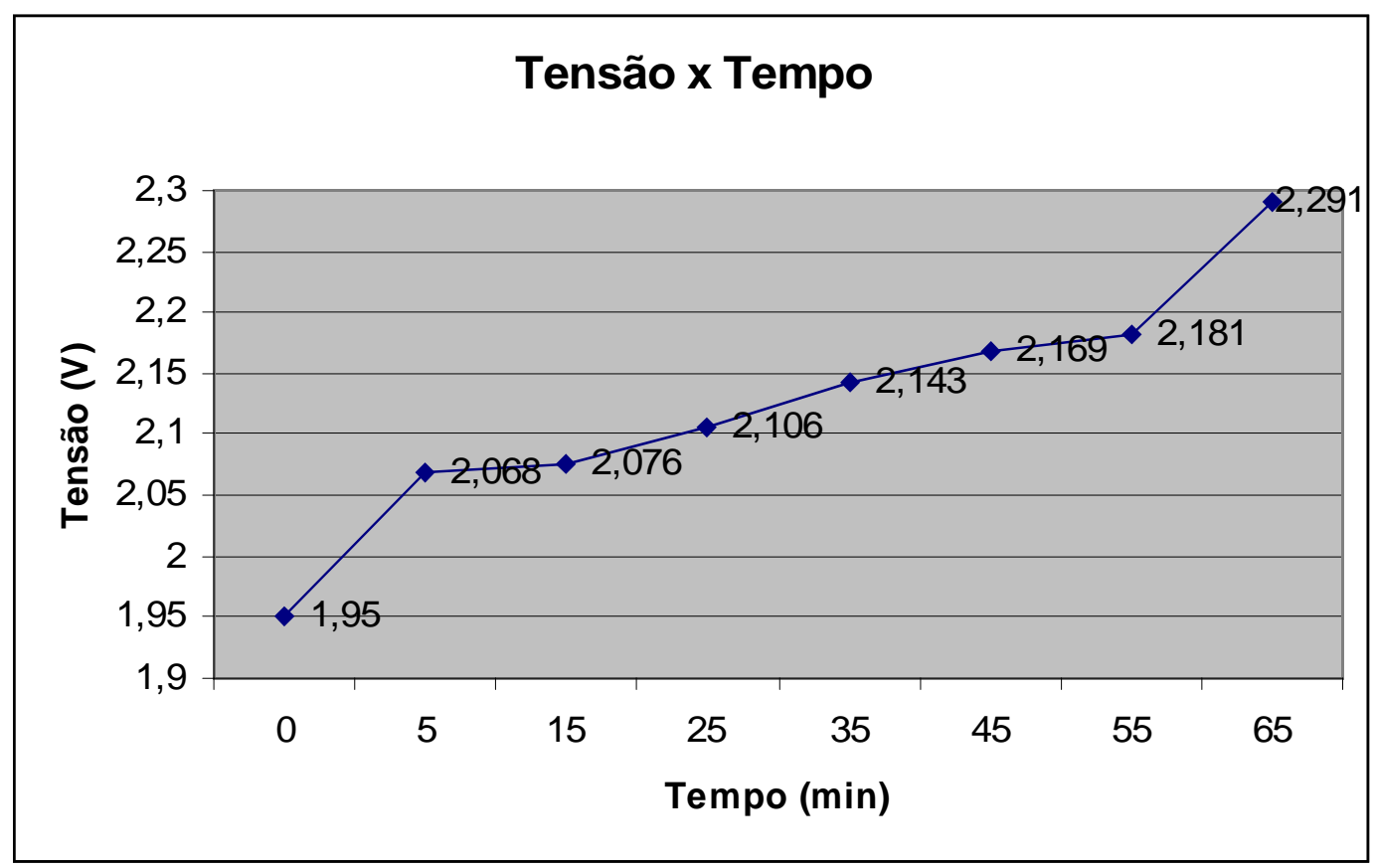

Gráfico 6.2 - Resultado do segundo teste de carga rápida a $600 \mathrm{~mA}$

Já neste gráfico não é possível prever o comportamento da pilha além dos 65 minutos já relatados. A tendência é que haja uma pequena queda, ou seja, um $\Delta \mathrm{V}$ negativo.

\subsubsection{Terceiro teste de descarga lenta a $60 \mathrm{~mA}$}

Este foi o primeiro teste em que houve a oportunidade de se usar o computador como auxílio para a captura dos dados. O circuito foi montado segundo a topologia indicada na figura 5.8 e os dados foram capturados a cada 10 minutos durante 17 horas, gerando uma tabela com mais de 100 valores.

As condições iniciais do teste eram as seguintes: 


\begin{tabular}{|c|c|}
\hline Pilha & $2 \mathrm{D}$ \\
\hline Tensão total & $1,363 \mathrm{~V}$ \\
\hline Temperatura ambiente & $26^{\circ} \mathrm{C}$ \\
\hline Resistor de descarregamento & $22 \Omega$ \\
\hline Corrente máxima teórica & $56,8 \mathrm{~mA}$ \\
\hline
\end{tabular}

Tabela 6.17 - Condições do terceiro teste de descarga lenta a $60 \mathrm{~mA}$

O gráfico dos resultados obtidos segue abaixo:

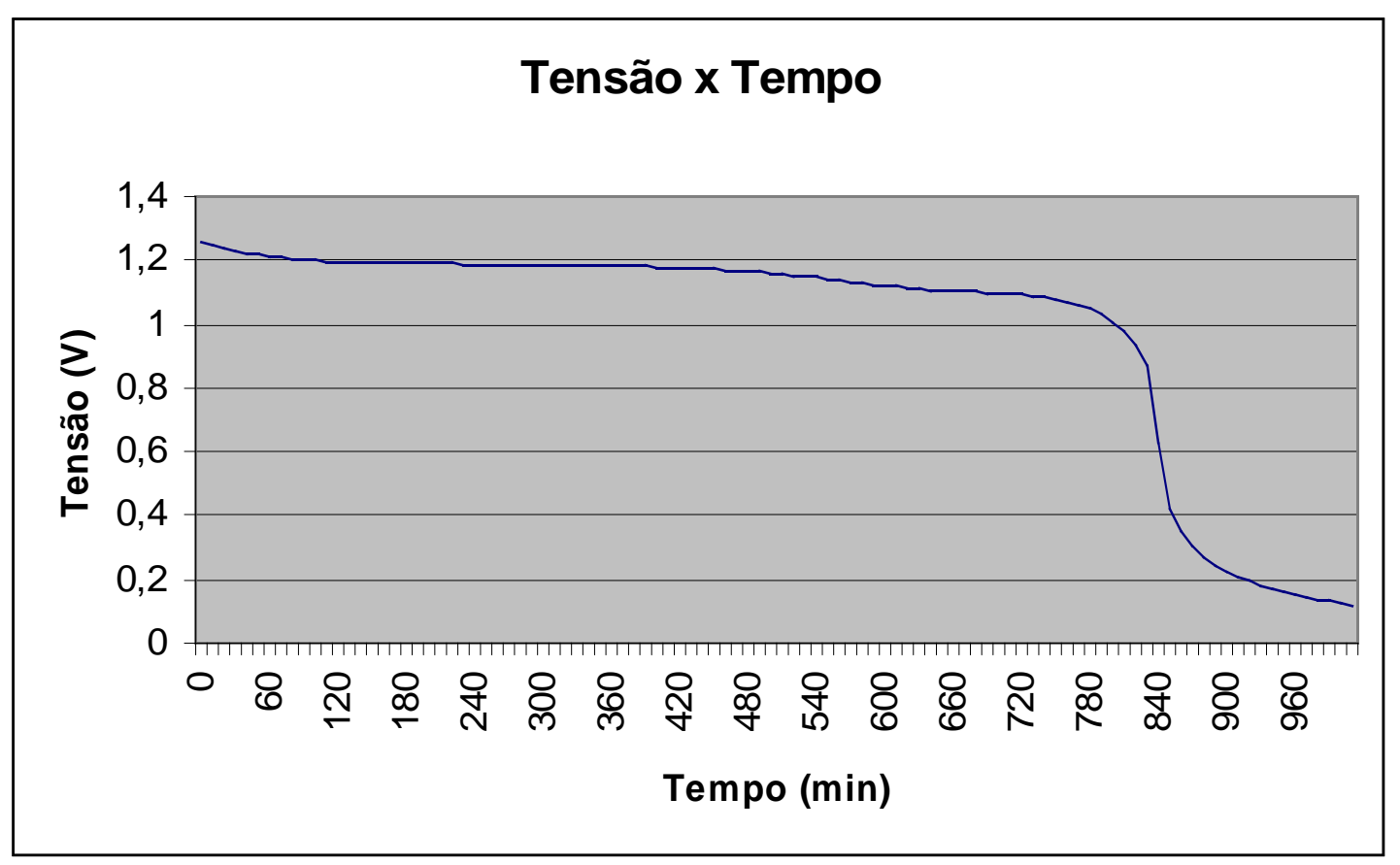

Gráfico 6.3 - Resultado do terceiro teste de descarga lenta a $60 \mathrm{~mA}$

Percebe-se claramente que a ajuda computacional permite que se chegue mais próximo das curvas fornecidas pelo fabricante.

Conforme ilustrado no anexo 9.2, a figura de descarga a $60 \mathrm{~mA}$ se assemelha bastante à curva encontrada no experimento.

\subsubsection{Quarto teste de descarga lenta a $60 \mathrm{~mA}$}

Este teste segue os mesmos padrões do teste anterior, só que agora é para quatro pilhas. As condições iniciais são as seguintes: 


\begin{tabular}{|c|c|}
\hline Pilhas & 3A, 3B, 3C e 3D \\
\hline Tensão total & $5,341 \mathrm{~V}$ \\
\hline Temperatura ambiente & $26^{\circ} \mathrm{C}$ \\
\hline Resistor de descarregamento & $82 \Omega$ \\
\hline Corrente máxima teórica & $65,1 \mathrm{~mA}$ \\
\hline
\end{tabular}

Tabela 6.18 - Condições do quarto teste de descarga lenta a $60 \mathrm{~mA}$

Os dados foram coletados em intervalos de 10 minutos durante 23 horas. Devido ao grande número de valores da tabela, será exibido apenas o gráfico correspondente.

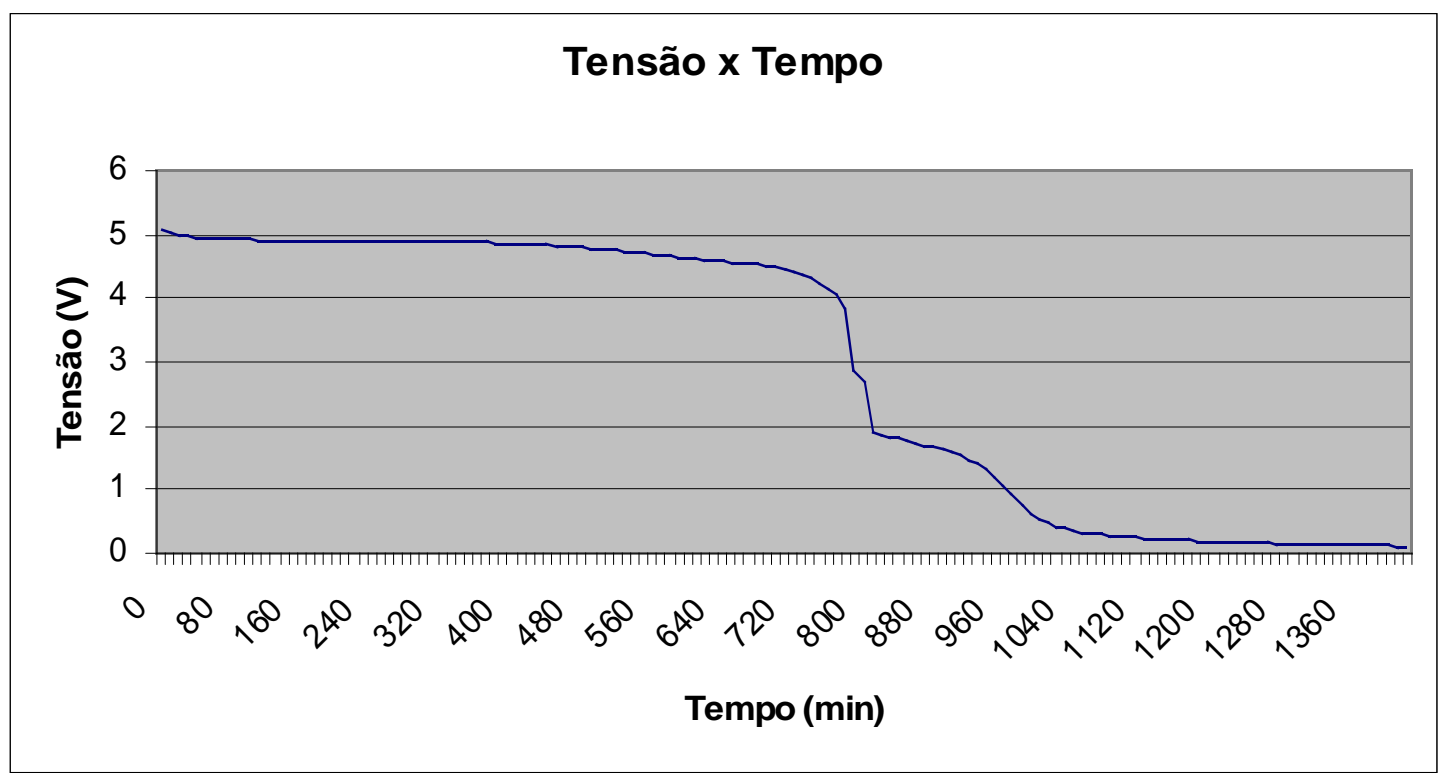

Gráfico 6.4- Resultado do quarto teste de descarga lenta a $60 \mathrm{~mA}$

Percebe-se uma pequena anomalia no gráfico, provavelmente causada pelo descarregamento desigual das pilhas. Enquanto que era para ser observada uma curva parecida com a do teste para apenas 1 pilha, há uma pequena "quebra" por volta da $13^{\mathrm{a}}$ hora de teste.

\subsubsection{Teste de carga lenta a $30 \mathrm{~mA}$}

Este teste foi terminado propositadamente com 48 horas de experimento devido ao tempo que precisava ser alocado para os outros testes. Ele está indicado pela topologia da figura 5.7. Como os dados foram coletados a cada 10 minutos durante 48 horas, a tabela de valores 
ficou bastante grande, e, portanto, exibiremos apenas o gráfico correspondente. As condições iniciais eram as seguintes:

\begin{tabular}{|c|c|}
\hline Pilhas & 3A, 3B, 3C e 3D \\
\hline Tensão total & $4,818 \mathrm{~V}$ \\
\hline Temperatura ambiente & $26^{\circ} \mathrm{C}$ \\
\hline Tensão da fonte & $10 \mathrm{~V}$ \\
\hline Resistor limitador & $40 \Omega$ \\
\hline Corrente máxima teórica & $31,25 \mathrm{~mA}$ \\
\hline
\end{tabular}

Tabela 6.19 - Condições iniciais do teste de carga lenta a $30 \mathrm{~mA}$

O gráfico dos resultados do teste de carga segue abaixo:

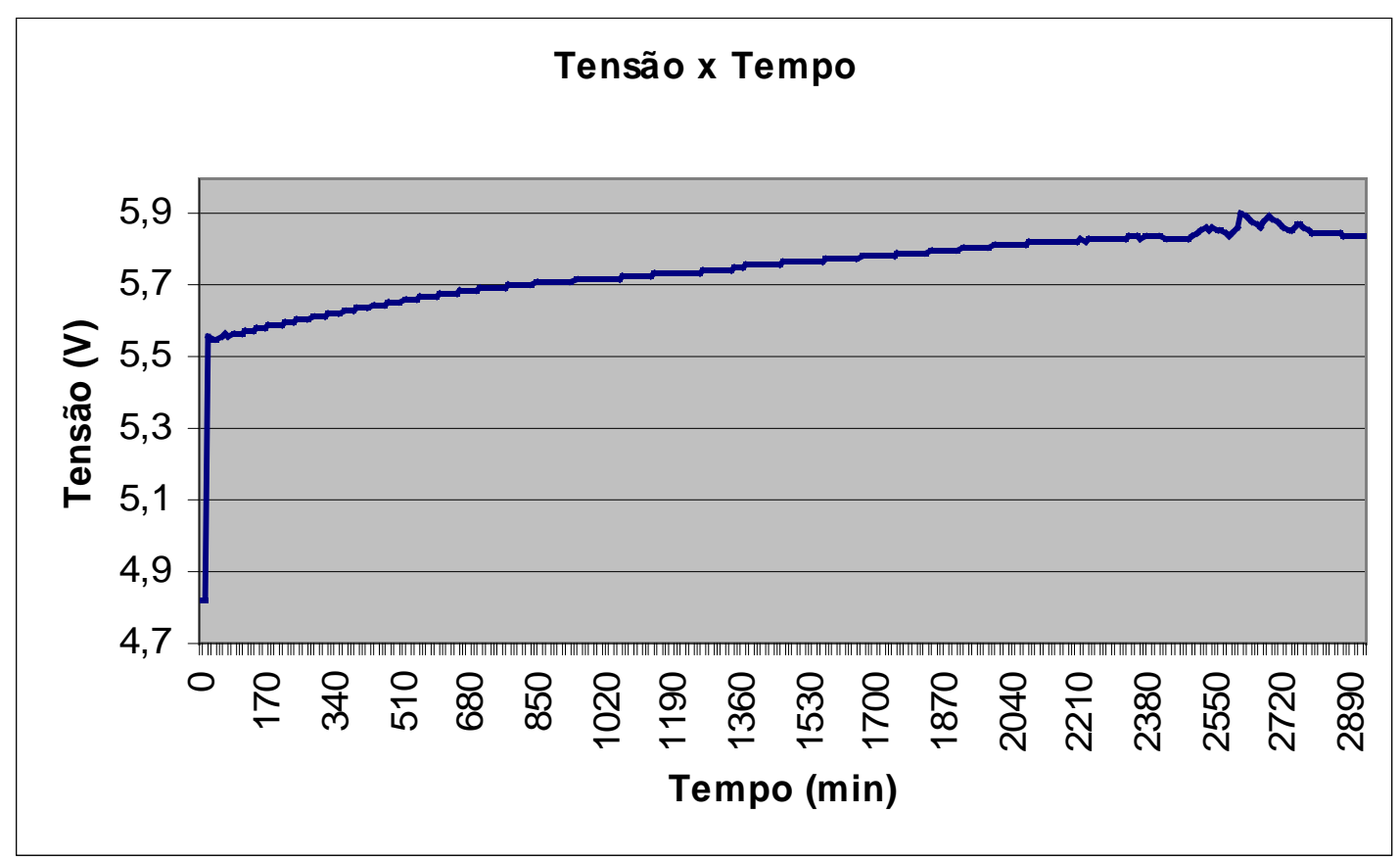

Gráfico 6.5 - Resultado do teste de carga lenta a $30 \mathrm{~mA}$

Pode-se verificar uma variação na tensão quando se atinge por volta de 41 horas de carga. Esta variação permanece grande até a hora 46 e depois a tensão começa a cair, denotando um fim de carga.

\subsection{Resultados dos testes dos resistores e diodos}

A topologia dos testes realizados com os diodos pode ser vista na figura 5.12 e apresentou os seguintes resultados: 
- Todos os diodos estavam conduzindo positivamente e cortando no sentido contrário;

- Todos os diodos tinham uma queda de tensão entre 700 e $800 \mathrm{mV}$ a $60 \mathrm{~mA}$.

A topologia dos testes com os resistores pode ser vista na figura 5.13 e o resultado é que todos os resistores estavam dentro da faixa de tolerância de $10 \%$, conforme garantia do fabricante.

\subsection{Resultados dos testes dos reguladores}

Todos os testes realizados com os reguladores foram feitos segundo a topologia indicada nas figuras 5.14 e 5.15. Além disso, os reguladores foram identificados e permaneceram fixos para cada valor de tensão.

Para o cálculo da tensão de saída utilizou-se a seguinte fórmula fornecida pelo fabricante:

$$
V_{\text {out }}=1,25\left(1+\frac{R 2}{R 1}\right)
$$

\subsubsection{Verificação dos parâmetros dos reguladores}

Este teste tem como objetivo verificar a tensão de referência de cada um dos reguladores, bem como a tensão de saída, corrente de carga e corrente de fuga. Os resultados obtidos podem ser visualizados utilizando-se as tabelas abaixo: 
6.4.1.1. Regulador de tensão de $4,8 \mathrm{~V}$

\begin{tabular}{|c|c|}
\hline Parâmetro & Valor \\
\hline Regulador & Configurado para 4,8 V \\
\hline Tensão de referência (Vref) & $1,2639 \mathrm{~V}$ \\
\hline Resistência 1 (R1) & $100 \Omega$ \\
\hline Resistência 2 (R2) & $280,2 \Omega$ \\
\hline Resistência de carga (Rc) & $2196 \Omega$ \\
\hline Tensão de saída teórica (Vot) & $4,805 \mathrm{~V}$ \\
\hline Tensão de saída prática (Vop) & $4,8202 \mathrm{~V}$ \\
\hline Diferença & $+0,3 \%$ \\
\hline Corrente de carga (Ic) & $2,191 \mathrm{~mA}$ \\
\hline Corrente de fuga (If) & $12,46 \mathrm{~mA}$ \\
\hline Corrente Quiescente (Iadj) & $3,101 \mathrm{~mA}$ \\
\hline
\end{tabular}

Tabela 6.20 - Principais parâmetros do regulador de 4,8V

6.4.1.2. Regulador de tensão de 3,6 V

\begin{tabular}{|c|c|}
\hline Parâmetro & Valor \\
\hline Regulador & Configurado para 3,6 V \\
\hline Tensão de referência (Vref) & $1,2579 \mathrm{~V}$ \\
\hline Resistência 1 (R1) & $101,8 \Omega$ \\
\hline Resistência 2 (R2) & $179,54 \Omega$ \\
\hline Resistência de carga (Rc) & $1180 \Omega$ \\
\hline Tensão de saída teórica (Vot) & $3,47 \mathrm{~V}$ \\
\hline Tensão de saída prática (Vop) & $3,543 \mathrm{~V}$ \\
\hline Diferença & $+2,1 \%$ \\
\hline Corrente de carga (Ic) & $3,008 \mathrm{~mA}$ \\
\hline Corrente de fuga (If) & $12,478 \mathrm{~mA}$ \\
\hline Corrente Quiescente (Iadj) & $1,273 \mathrm{~mA}$ \\
\hline
\end{tabular}

Tabela 6.21 - Principais parâmetros do regulador de 3,6V

6.4.1.3. Regulador de tensão de $2,4 \mathrm{~V}$

\begin{tabular}{|c|c|}
\hline Parâmetro & Valor \\
\hline Regulador & Configurado para 2,4 V \\
\hline Tensão de referência (Vref) & $1,2592 \mathrm{~V}$ \\
\hline Resistência 1 (R1) & $100,0 \Omega$ \\
\hline Resistência 2 (R2) & $92 \Omega$ \\
\hline Resistência de carga (Rc) & $555 \Omega$ \\
\hline Tensão de saída teórica (Vot) & $2,418 \mathrm{~V}$ \\
\hline Tensão de saída prática (Vop) & $2,422 \mathrm{~V}$ \\
\hline Diferença & $+0,16 \%$ \\
\hline
\end{tabular}




\begin{tabular}{|c|c|}
\hline Corrente de carga (Ic) & $4,364 \mathrm{~mA}$ \\
\hline Corrente de fuga (If) & $12,386 \mathrm{~mA}$ \\
\hline Corrente Quiescente (Iadj) & $1,569 \mathrm{~mA}$ \\
\hline
\end{tabular}

Tabela 6.22 - Principais parâmetros do regulador de 2,4V

6.4.1.4. Regulador de tensão de $1,2 \mathrm{~V}$

\begin{tabular}{|c|c|}
\hline Parâmetro & Valor \\
\hline Regulador & Configurado para 1,2 V \\
\hline Tensão de referência (Vref) & $1,2452 \mathrm{~V}$ \\
\hline Resistência 1 (R1) & $0 \Omega=$ curto \\
\hline Resistência 2 (R2) & $100 \Omega$ \\
\hline Resistência de carga (Rc) & $149 \Omega$ \\
\hline Tensão de saída teórica (Vot) & $1,2452 \mathrm{~V}$ \\
\hline Tensão de saída prática (Vop) & $1,273 \mathrm{~V}$ \\
\hline Diferença & $+2,2 \%$ \\
\hline Corrente de carga (Ic) & $8,543 \mathrm{~mA}$ \\
\hline Corrente de fuga (If) & $12,448 \mathrm{~mA}$ \\
\hline Corrente Quiescente (Iadj) & $1,15 \mathrm{~mA}$ \\
\hline
\end{tabular}

Tabela 6.23 - Principais parâmetros do regulador de 1,2V

Verifica-se que a tensão de referência varia entre $1,2452 \mathrm{~V}$ até $1,2639 \mathrm{~V}$, confirmando as informações do fabricante que diz que este valor pode variar entre $1,2 \mathrm{~V}$ e 1,3 $\mathrm{V}$.

Observa-se também que as os valores calculados para tensão de saída e os obtidos na prática não são muito diferentes. Essa diferença varia entre $0,16 \%$ chegando até $2,2 \%$. Isso denota que os reguladores estão em boas condições e operando conforme o esperado.

\subsubsection{Diferença entre Vin e Vout}

Como o LM317 não é um regular com baixa queda de tensão, a diferença entre a tensão de entrada e a tensão de saída deve ser maior do que $3 \mathrm{~V}$, segundo o datasheet do fabricante.

Este teste tem como intuito verificar se esta queda é realmente de 3 $\mathrm{V}$ e como o regulador se comporta para diferentes entradas. Os resultados podem ser vistos na tabela abaixo: 


\begin{tabular}{|c|c|c|c|}
\hline $\begin{array}{c}\text { Tensão de } \\
\text { entrada (V) }\end{array}$ & $\begin{array}{c}\text { Tensão de Saída } \\
(\mathbf{V})\end{array}$ & Vin - Vout (V) & $\begin{array}{c}\text { Queda na tensão } \\
\text { original (\%) }\end{array}$ \\
\hline 10 & 4,768 & 5,232 & - \\
\hline 9,5 & 4,768 & 5,232 & 0 \\
\hline 9 & 4,7678 & 4,2322 & 0,004 \\
\hline 8,5 & 4,7676 & 3,7324 & 0,008 \\
\hline 8 & 4,7673 & 3,2327 & 0,014 \\
\hline 7,5 & 4,7670 & 2,733 & 0,021 \\
\hline 7 & 4,7626 & 2,2374 & 0,11 \\
\hline 6,5 & 4,7295 & 1,7705 & 0,8 \\
\hline 6 & 4,405 & 1,595 & 8 \\
\hline 5,5 & 3,917 & 1,583 & 22 \\
\hline 5 & 3,445 & 1,555 & 38 \\
\hline
\end{tabular}

Tabela 6.24 - Queda de tensão do LM317

Observa-se que a diferença entre a tensão de entrada e a tensão de saída, para a corrente utilizada, pode ser menor do que $3 \mathrm{~V}$. De fato, esta diferença pode baixar até $1,77 \mathrm{~V}$ sem que haja uma grande diferença na tensão de saída, com relação à tensão original. Neste caso, esta diferença fica por volta de $0,8 \%$, que ainda é aceitável. A partir daí a diferença começa a se tornar muito grande e a tensão de saída começa a cair muito.

Mesmo com uma diferença de $1,77 \mathrm{~V}$, o uso do LM317 não pode ser validado com para o uso como regulador de $4,8 \mathrm{~V}$, porque a tensão total nas baterias dificilmente será maior do que $6,5 \mathrm{~V}$.

\subsubsection{Minimizando a corrente de fuga}

Depois de realizados alguns testes com as pilhas, nas configurações de reguladores descritas no item 6.4.1, percebeu-se que a corrente de fuga estava muito alta e que poderia ser mais baixa aumentando-se os valores dos resistores do divisor de tensão proporcionalmente.

O terceiro teste dos reguladores foi, portanto, achar um ponto ideal de aumento dos resistores sem que o regulador pare de funcionar e sem que a tensão de saída seja prejudicada por esse aumento. 
Os testes foram realizados substituindo-se os resistores do divisor de tensão pelas décadas resistivas. Dessa maneira, os valores de resistência poderiam ser modificados sem que se precisasse mexer no circuito. Os resultados desta análise podem ser conferidos nas tabelas e nos gráficos que seguem a partir do item 6.4.3.1.

6.4.3.1. Regulador de 4,8V

\begin{tabular}{|c|c|c|c|c|}
\hline $\mathbf{R 1}(\mathbf{\Omega})$ & $\mathbf{R 2}(\mathbf{\Omega})$ & $\begin{array}{c}\text { Corrente de } \\
\text { Carga }(\mathbf{m A})\end{array}$ & $\begin{array}{c}\text { Corrente de } \\
\text { Fuga }(\mathbf{m A})\end{array}$ & $\begin{array}{c}\text { Tensão na } \\
\text { Carga }(\mathbf{V})\end{array}$ \\
\hline 100 & 280 & 2,191 & 12,46 & 4,8202 \\
\hline 200 & 560 & 2,184 & 6,277 & 4,8048 \\
\hline 300 & 840 & 2,187 & 4,21 & 4,8114 \\
\hline $\mathbf{4 0 0}$ & $\mathbf{1 1 2 0}$ & $\mathbf{2 , 1 9 2}$ & $\mathbf{3 , 1 7 2}$ & $\mathbf{4 , 8 2 2 4}$ \\
\hline 500 & 140 & 2,198 & 2,55 & 4,8356 \\
\hline 600 & 1680 & 2,204 & 2,135 & 4,849 \\
\hline 700 & 1960 & 2,211 & 1,839 & 4,8642 \\
\hline 800 & 2240 & 2,218 & 1,616 & 4,8796 \\
\hline 900 & 2520 & 2,225 & 1,443 & 4,895 \\
\hline 1000 & 2800 & 2,232 & 1,305 & 4,9104 \\
\hline
\end{tabular}

Tabela 6.25 - Teste de resistores no regulador de 4,8V

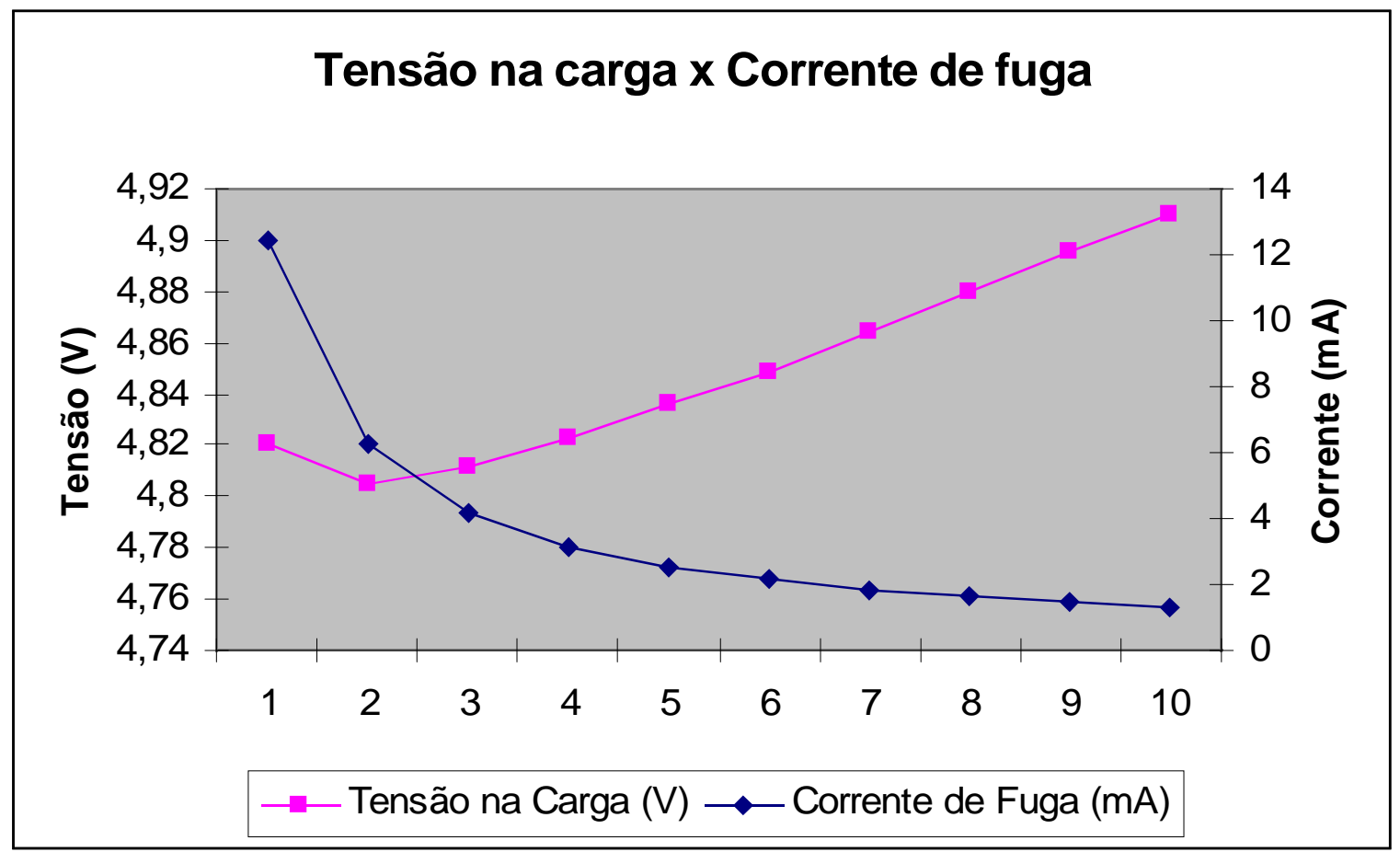

Gráfico 6.6 - Corrente de Fuga versus Tensão na carga no regulador de 4,8V 
A partir do gráfico acima podemos perceber o quanto a corrente de fuga pode diminuir sem que haja um aumento significativo na tensão. Pode-se inferir, também, uma condição ideal de resistência que é dada pelo ponto 4 do gráfico acima. Neste ponto a tensão está em $4,8224 \mathrm{~V}$ enquanto que a corrente caiu para 3,172 mA, ou seja, a tensão aumentou apenas $0,04 \%$ ao passo que a corrente caiu $393 \%$.

6.4.3.2. Regulador de 3,6V

\begin{tabular}{|c|c|c|c|c|}
\hline R1 ( $\mathbf{\Omega})$ & $\mathbf{R 2}(\mathbf{\Omega})$ & $\begin{array}{c}\text { Corrente de } \\
\text { Carga }(\mathbf{m A})\end{array}$ & $\begin{array}{c}\text { Corrente de } \\
\text { Fuga }(\mathbf{m A})\end{array}$ & $\begin{array}{c}\text { Tensão na } \\
\text { Carga }(\mathbf{V})\end{array}$ \\
\hline 100 & 180 & 3,008 & 12,478 & 3,543 \\
\hline 200 & 360 & 2,989 & 6,276 & 3,521 \\
\hline 300 & 540 & 2,987 & 4,204 & 3,518 \\
\hline 400 & 720 & 2,990 & 3,166 & 3,522 \\
\hline 500 & 900 & 2,995 & 2,544 & 3,528 \\
\hline 600 & 1080 & 3,001 & 2,128 & 3,535 \\
\hline 700 & 1260 & 3,007 & 1,832 & 3,54 \\
\hline 800 & 1440 & 3,014 & 1,609 & 3,55 \\
\hline 900 & 1620 & 3,021 & 1,436 & 3,558 \\
\hline $\mathbf{1 0 0 0}$ & $\mathbf{1 8 0 0}$ & $\mathbf{3 , 0 2 8}$ & $\mathbf{1 , 2 9 7}$ & $\mathbf{3 , 5 6 7}$ \\
\hline
\end{tabular}

Tabela 6.26 - Teste de resistores no regulador de $3,6 \mathrm{~V}$ 


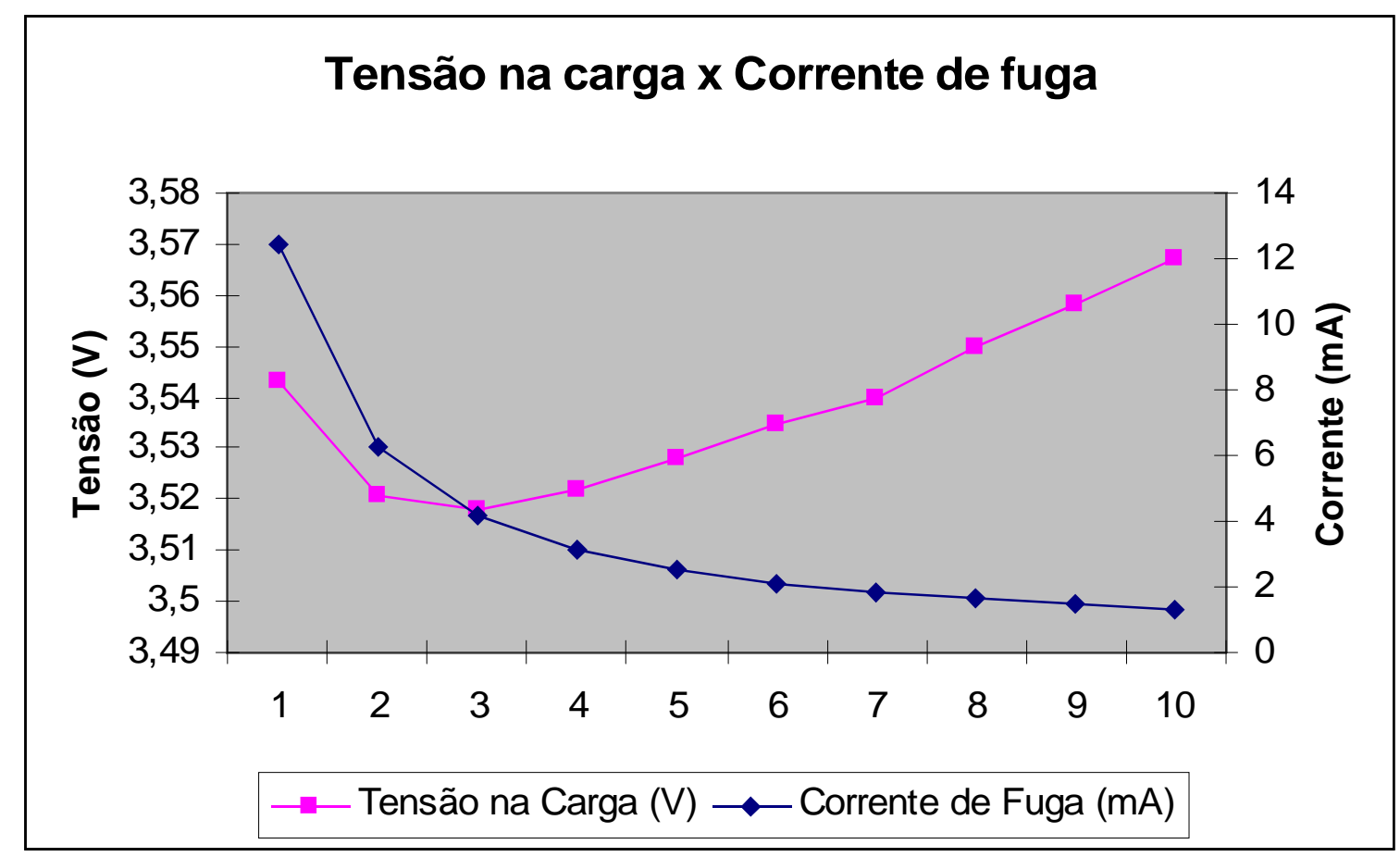

Gráfico 6.7 - Corrente de Fuga versus Tensão na carga no regulador de 3,6V

Este gráfico nos mostra que, mesmo com valores de resistência 10 vezes maiores, o valor de tensão ainda não chegou em 3,6 V. Por esse motivo optou-se por utilizar essas resistências, visto que a tensão aumentou apenas $0,6 \%$ enquanto que a corrente caiu $962 \%$.

\subsubsection{Regulador de $2,4 \mathrm{~V}$}

Como na década utilizada não havia precisão para selecionar valores de unidade, os valores apresentados estão aproximados para baixo. A cada 5 medições, o erro era descontado e o valor da resistência corrigido.

\begin{tabular}{|c|c|c|c|c|}
\hline $\mathbf{R 1}(\mathbf{\Omega})$ & $\mathbf{R 2}(\mathbf{\Omega})$ & $\begin{array}{c}\text { Corrente de } \\
\text { Carga }(\mathbf{m A})\end{array}$ & $\begin{array}{c}\text { Corrente de } \\
\text { Fuga }(\mathbf{m A})\end{array}$ & $\begin{array}{c}\text { Tensão na } \\
\text { Carga }(\mathbf{V})\end{array}$ \\
\hline 100 & 90 & 4,364 & 12,386 & 2,422 \\
\hline 200 & 180 & 4,33 & 6,291 & 2,403 \\
\hline 300 & 270 & 4,319 & 4,218 & 2,397 \\
\hline 400 & 260 & 4,18 & 3,179 & 2,396 \\
\hline 500 & 460 & 4,366 & 2,555 & 2,423 \\
\hline 600 & 550 & 4,363 & 2,138 & 2,421 \\
\hline 700 & 640 & 4,363 & 1,841 & 2,421 \\
\hline
\end{tabular}




\begin{tabular}{|c|c|c|c|c|}
\hline $\mathbf{8 0 0}$ & $\mathbf{7 3 0}$ & $\mathbf{4 , 3 6 5}$ & $\mathbf{1 , 6 1 7}$ & $\mathbf{2 , 4 2 3}$ \\
\hline 900 & 820 & 4,370 & 1,444 & 2,425 \\
\hline 1000 & 920 & 4,398 & 1,305 & 2,44 \\
\hline
\end{tabular}

Tabela 6.27 - Teste de resistores no regulador de $2,4 \mathrm{~V}$

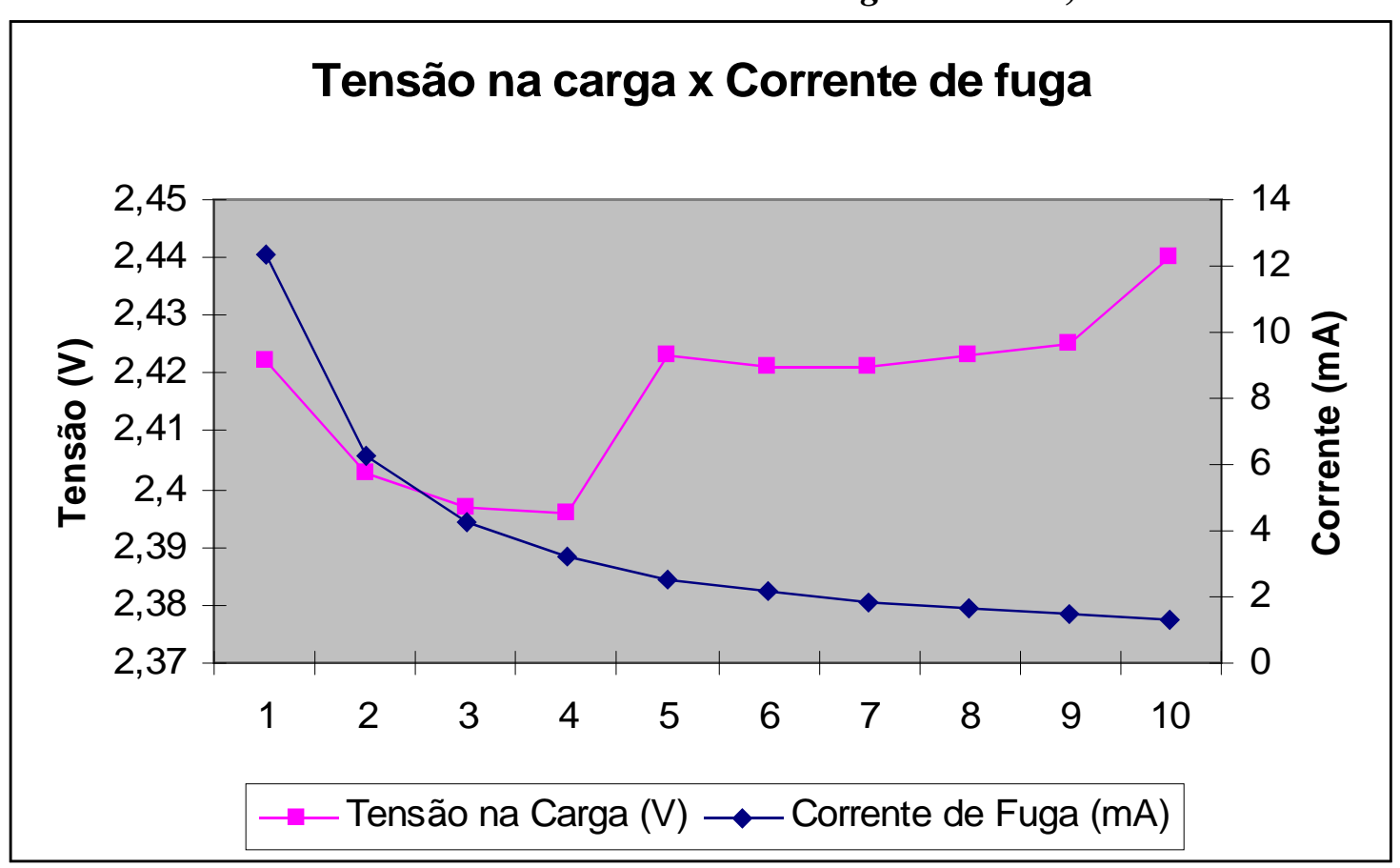

Gráfico 6.8 - Corrente de Fuga versus Tensão na carga no regulador de $2,4 \mathrm{~V}$

Já neste teste podemos perceber a variação que ocorre na corrente quando se passa de 4 para 5 vezes o valor da resistência inicial. A resistência escolhida está no passo 8 , pois lá há aumento de tensão de apenas $0,04 \%$ enquanto que a corrente cai $766 \%$.

\subsubsection{Regulador de $1,2 \mathrm{~V}$}

Para o regulador de 1,2V não há necessidade de alterar o valor de $\mathrm{R} 2$, visto que ele é um curto e deve permanecer como tal para os valores de tensão permanecerem coerentes. 


\begin{tabular}{|c|c|c|c|}
\hline R1 $(\mathbf{\Omega})$ & $\begin{array}{c}\text { Corrente de } \\
\text { Carga }(\mathbf{m A})\end{array}$ & $\begin{array}{c}\text { Corrente de } \\
\text { Fuga }(\mathbf{m A})\end{array}$ & $\begin{array}{c}\text { Tensão na } \\
\text { Carga (V) }\end{array}$ \\
\hline 100 & 8,543 & 12,448 & 1,273 \\
\hline 200 & 8,309 & 6,266 & 1,238 \\
\hline 300 & 7,661 & 3,905 & 1,141 \\
\hline 400 & 7,578 & 2,924 & 1,129 \\
\hline 500 & 7,555 & 2,348 & 1,125 \\
\hline 600 & 7,563 & 1,971 & 1,127 \\
\hline 700 & 7,578 & 1,702 & 1,129 \\
\hline 800 & 7,582 & 1,498 & 1,13 \\
\hline 900 & 7,586 & 1,338 & 1,13 \\
\hline 1000 & 7,606 & 1,213 & 1,133 \\
\hline $\mathbf{1 1 0 0}$ & $\mathbf{7 , 7 2 7}$ & $\mathbf{1 , 1 2 6}$ & $\mathbf{1 , 1 5}$ \\
\hline 1200 & 7,718 & 1,036 & 1,149 \\
\hline
\end{tabular}

Tabela 6.28 - Teste de resistores no regulador de $1,2 \mathrm{~V}$

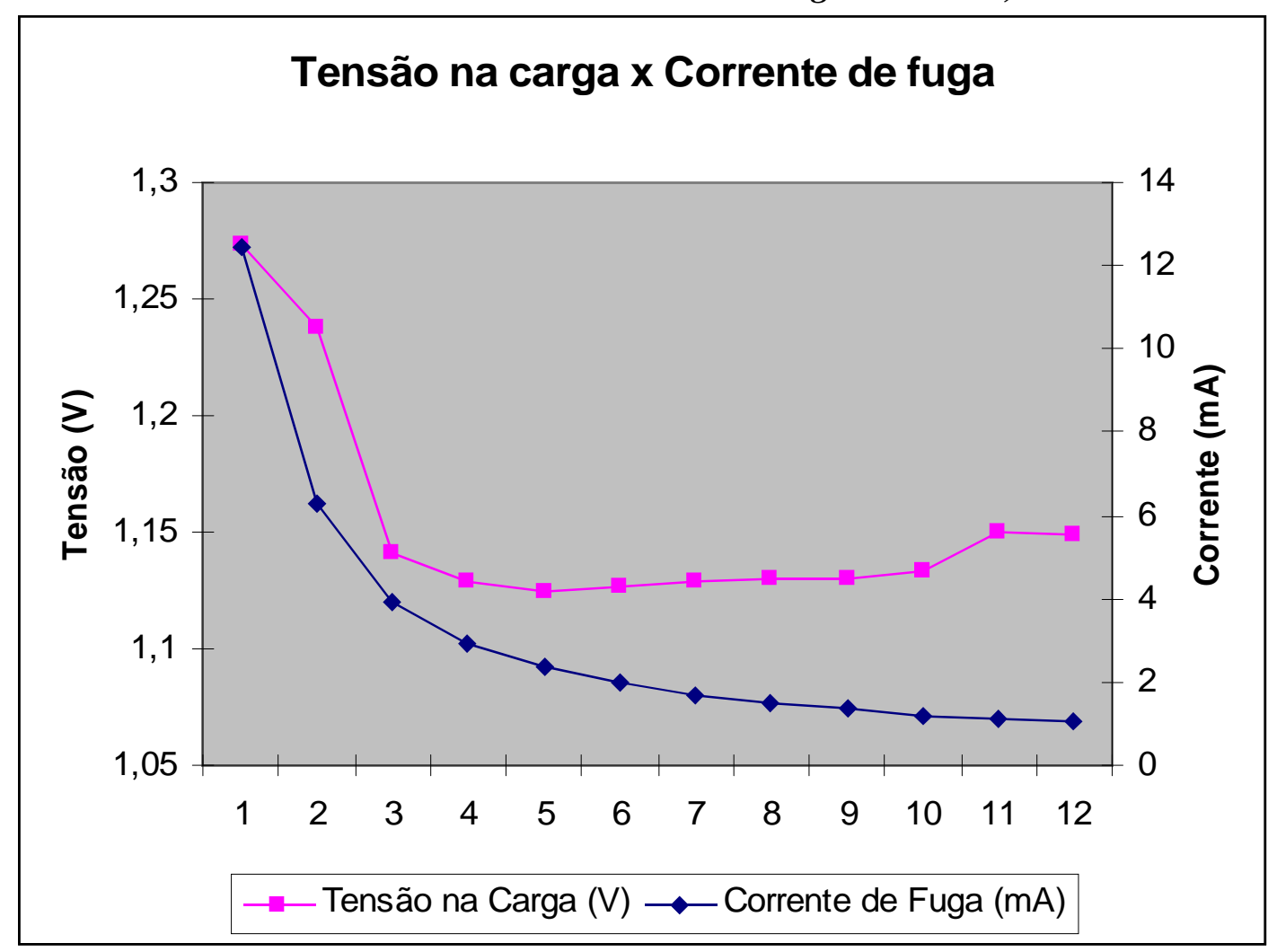

Gráfico 6.9 - Corrente de Fuga versus Tensão na carga no regulador de 1,2V

Neste teste as duas curvas mantiveram basicamente o mesmo comportamento. No final aconteceu a subida que aconteceu nos outros testes. Optou-se pelos valores 11 vezes maiores que o original, visto que nesta configuração o valor de tensão caiu 9,66\% enquanto que a corrente 
caiu $1105 \%$. Este foi o teste onde a diferença entre tensão inicial e final e a corrente inicial e final foi mais pronunciada.

\subsubsection{Substituição dos resistores}

Fazendo as substituições de resistências sugeridas nos itens acima, houve um ganho significativo no consumo de corrente e, por conseguinte, um aumento na eficiência do sistema. Os valores antigos de corrente e os novos valores com a substituição dos resistores pode ser observados na tabela abaixo:

\begin{tabular}{|l|c|c|c|}
\hline \multirow{2}{*}{ Regulador de 4,8V V } & Corrente antiga & $12,46 \mathrm{~mA}$ & Ganho de \\
\cline { 2 - 3 } & Corrente atual & $3,198 \mathrm{~mA}$ & $389 \%$ \\
\hline \multirow{2}{*}{ Regulador de 3,6V } & Corrente antiga & $12,478 \mathrm{~mA}$ & Ganho de \\
\cline { 2 - 3 } & Corrente atual & $1,328 \mathrm{~mA}$ & $939 \%$ \\
\hline \multirow{2}{*}{ Regulador de 2,4V } & Corrente antiga & $12,386 \mathrm{~mA}$ & Ganho de \\
\cline { 2 - 3 } & Corrente atual & $1,631 \mathrm{~mA}$ & $759 \%$ \\
\hline \multirow{2}{*}{ Regulador de 1,2V } & Corrente antiga & $12,448 \mathrm{~mA}$ & Ganho de \\
\cline { 2 - 3 } & Corrente atual & $1,207 \mathrm{~mA}$ & $1031 \%$ \\
\hline
\end{tabular}

Tabela 6.29 - Valores de corrente antes e depois da troca dos resistores

No total, uma corrente que era anteriormente da ordem de 67,252 $\mathrm{mA}$ passou a ficar em torno de $25 \mathrm{~mA}$, propiciando um ganho de eficiência de $37 \%$.

\subsection{Resultados dos testes do circuito}

Os testes de autonomia foram realizados conforme a topologia indicada na figura 5.18.

\subsubsection{Primeiro teste de autonomia}

O primeiro teste de autonomia foi realizado com as pilhas 1A, 1B, $1 \mathrm{C}$ e $2 \mathrm{~A}$ depois destas terem sofrido a carga descrita pelo item 6.2.4. Os valores de resistência utilizados nos reguladores são os indicados pelo item 6.4.1. 
Os resultados obtidos podem ser observados na tabela e no gráfico que seguem:

\begin{tabular}{|c|c|c|c|c|c|}
\hline $\begin{array}{c}\text { Tempo } \\
\text { (min) }\end{array}$ & $\begin{array}{c}\text { Tensão } \\
\text { Bateria }\end{array}$ & $\begin{array}{c}\text { Tensão } \\
\text { Reg. 4,8V }\end{array}$ & $\begin{array}{c}\text { Tensão } \\
\text { Reg. 3,6V }\end{array}$ & $\begin{array}{c}\text { Tensão } \\
\text { Reg. 2,4V }\end{array}$ & $\begin{array}{c}\text { Tensão } \\
\text { Reg. 1,2V }\end{array}$ \\
\hline 0 & 5,051 & 3,452 & 3,458 & 2,415 & 1,267 \\
\hline 5 & 4,994 & 3,404 & 3,452 & 2,415 & 1,267 \\
\hline 10 & 4,957 & 3,37 & 3,426 & 2,415 & 1,267 \\
\hline 15 & 4,929 & 3,343 & 3,402 & 2,415 & 1,267 \\
\hline 20 & 4,947 & 3,36 & 3,418 & 2,415 & 1,267 \\
\hline 30 & 4,906 & 3,32 & 3,379 & 2,415 & 1,267 \\
\hline 40 & 4,865 & 3,279 & 3,337 & 2,415 & 1,267 \\
\hline 60 & 4,815 & 3,228 & 3,286 & 2,415 & 1,267 \\
\hline 90 & 4,741 & 3,156 & 3,214 & 2,415 & 1,267 \\
\hline 120 & 4,651 & 3,069 & 3,126 & 2,415 & 1,267 \\
\hline 150 & 3,224 & 1,721 & 1,734 & 1,699 & 1,265 \\
\hline
\end{tabular}

Tabela 6.30 - Valores de tensão nos reguladores para cada tensão na pilha

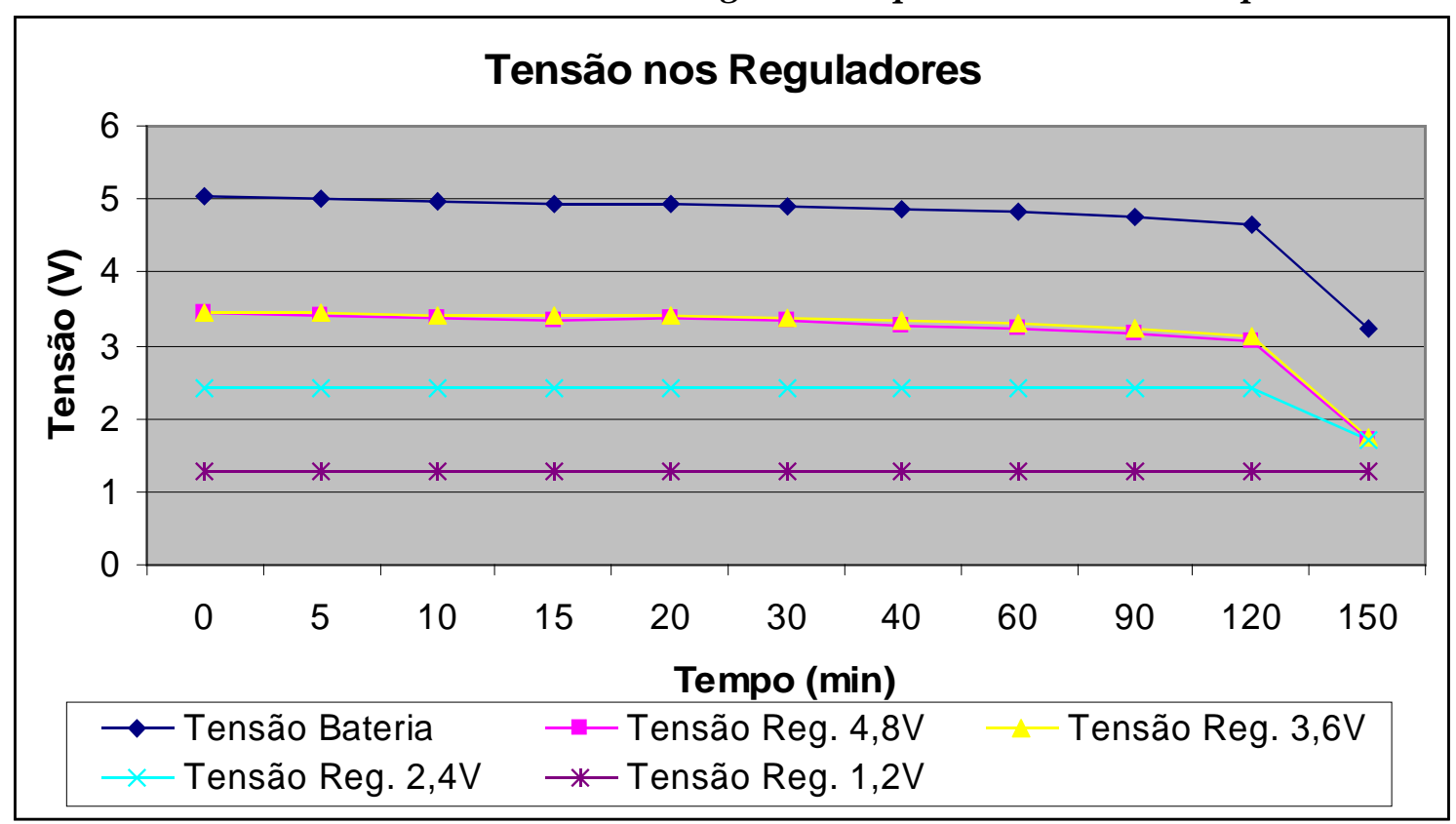

Gráfico 6.10 - Tensão de saída na bateria e nos reguladores

Podemos perceber claramente que não houve regulação para o regulador de $4,8 \mathrm{~V}$. Isso foi devido ao fato da diferença entre a tensão de entrada e tensão de saída ser menor que o especificado no item 6.4.2. Mais uma vez lembramos que o uso do regulador LM317 para a saída de 4,8V não será válido, uma vez que a tensão de entrada nunca terá um potencial satisfatório para fornecer $4,8 \mathrm{~V}$ na saída. 
De qualquer maneira verifica-se que as baterias não duraram satisfatoriamente mais do que 2 horas. Isso provavelmente se deve por 2 motivos: as baterias poderiam não estar completamente carregadas ou então o sistema está consumindo muita potência.

\subsubsection{Segundo teste de autonomia}

Este teste foi concebido para poder verificar o que aconteceu de anormal no teste do item 6.5.1. Agora os resistores dos reguladores foram modificados, conforme descrito no item 6.4 .3 e o jogo de baterias utilizado (3A, 3B, 3C e 3D) foi carregado por 48 horas com uma carga de $30 \mathrm{~mA}$, conforme ilustrado no item 6.2.8. O gráfico correspondente segue abaixo:

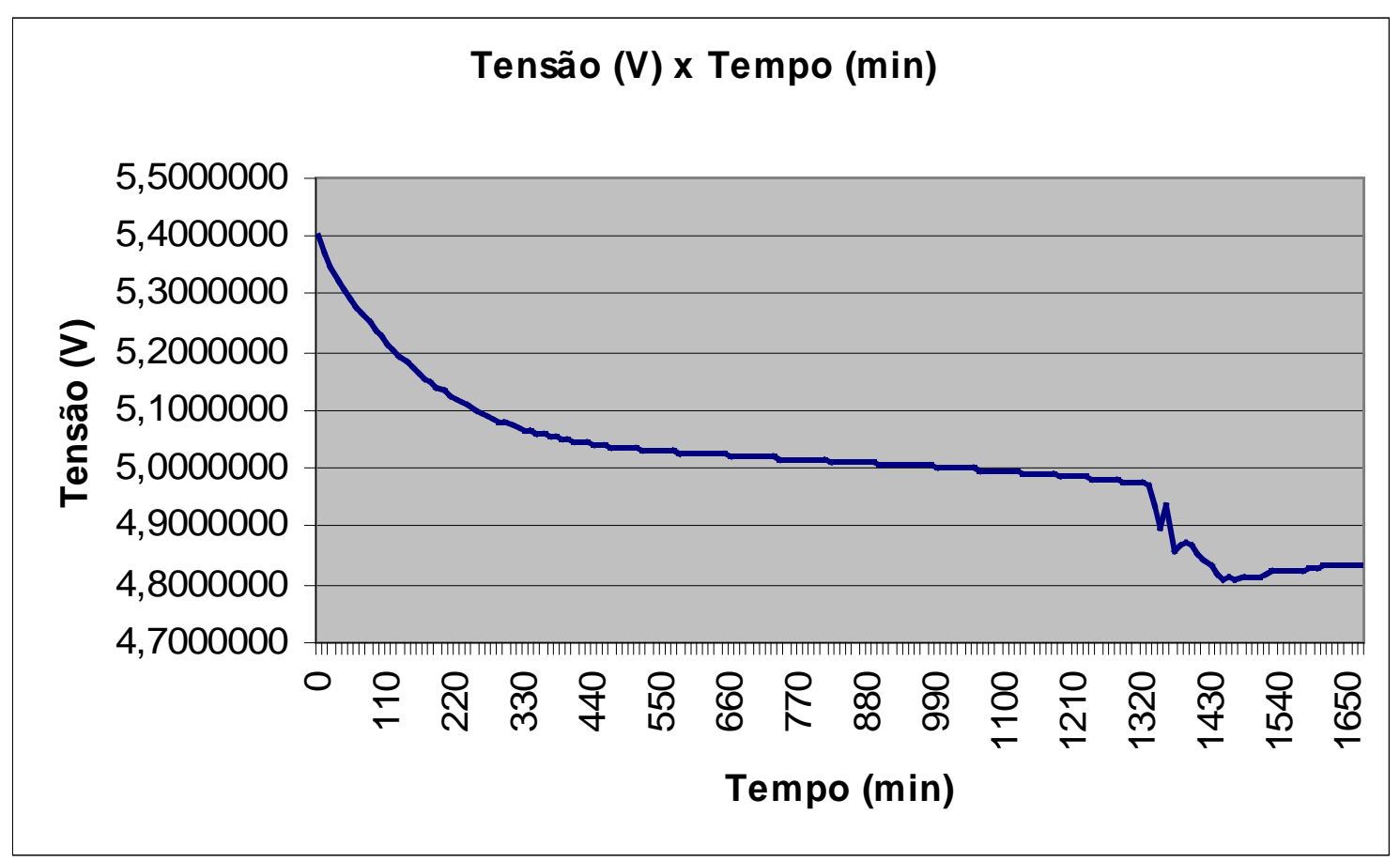

Gráfico 6.11 - Tensão nas baterias no teste de autonomia

Podemos verificar uma queda de tensão de $0,2 \mathrm{~V}$ entre as horas $22 \mathrm{e}$ 24 com variações entre estes momentos e, logo depois, uma queda mais suave com um pequeno crescimento na tensão até o final do teste.

Esse pequeno crescimento de tensão no final do teste pode ser interpretado como uma queda na corrente dos reguladores de $4,8 \mathrm{~V}$ e de 
3,6V. Segundo a tabela 6.30 , quando a tensão das pilhas está por volta de $4,8 \mathrm{~V}$, a tensão do regulador de $4,8 \mathrm{~V}$ cai para $3,2 \mathrm{~V}$ e a tensão do regulador de 3,6V cai para 3,3V. Essas quedas de tensão causam uma diminuição na corrente que passa pelos reguladores, fazendo com que a tensão na bateria suba um pouco.

O teste foi interrompido com 29 horas de duração e a tensão ainda estava acima da tensão nominal das baterias. Além disso, a configuração de resistores de carga dos reguladores estava para o máximo consumo de potência, ou seja, se na mais onerosa das configurações o sistema funcionou satisfatoriamente por, pelo menos 29 horas, na situação de campo, onde o nó estará recebendo luz solar quase que diariamente e os circuitos de carga só irão atuar esporadicamente, este cenário tende a durar vários dias.

\subsubsection{Teste "dia" e "noite"}

Este teste foi concebido para tentar simular a situação em que por um momento há ajuda do painel solar e depois o painel sai de cena, sendo responsabilidade das baterias segurar o sistema. O jogo de baterias utilizado foi o 3 (3A, 3B, 3C e 3D), os testes foram realizados segundo a topologia indicada na figura 5.19 e o gráfico dos resultados segue abaixo: 


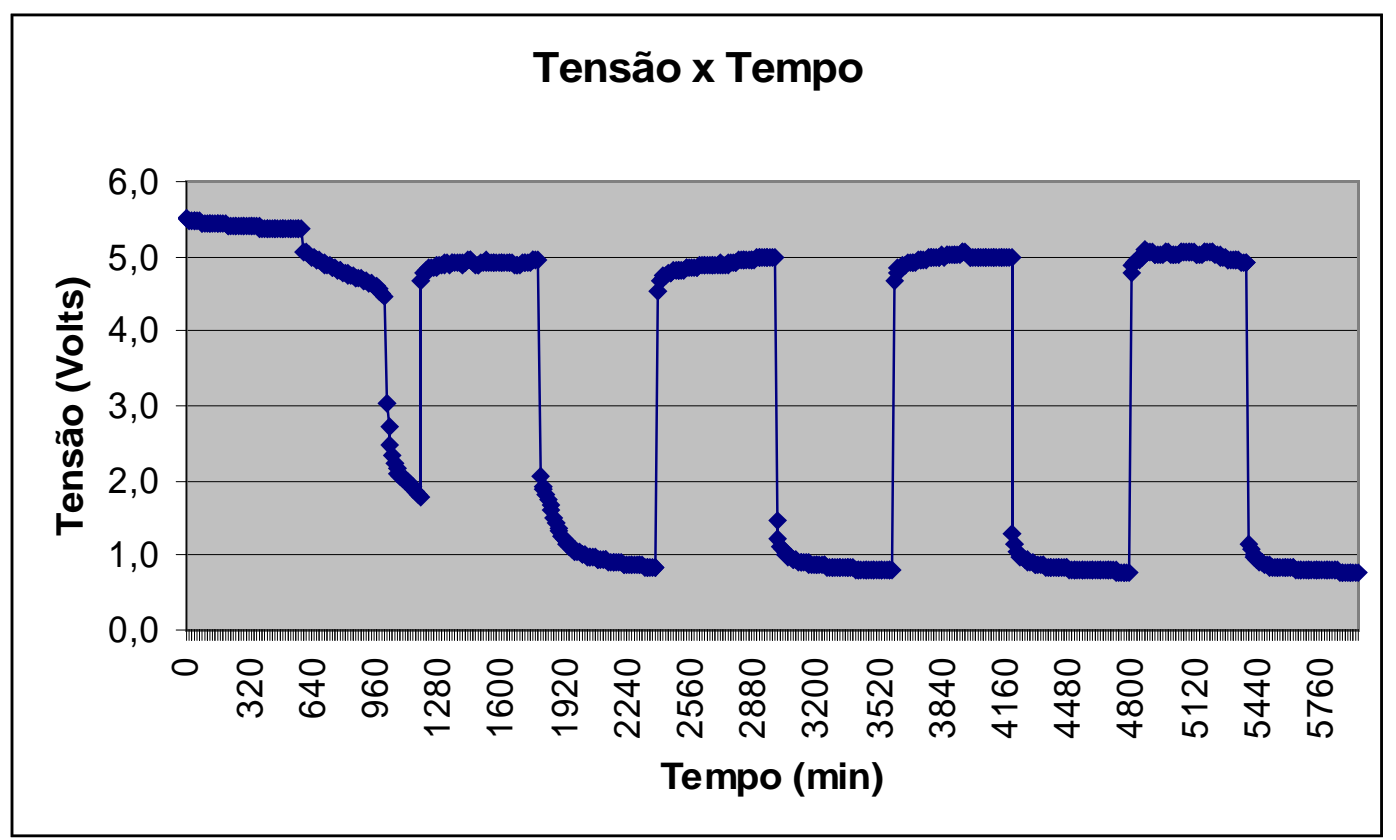

Gráfico 6.12 - Tensão nas baterias no teste de dia e noite

Este gráfico nos mostra que o tempo de carga das baterias não foi suficiente para suprir a corrente na ausência da fonte de alimentação, ou seja, quando a fonte de tensão estava atuando a maior parte da corrente estava fluindo pelos reguladores e não pelas pilhas, fazendo com que estas não carregassem conforme o ideal. 


\section{Conclusão}

Neste projeto foi possível idealizar e dimensionar uma topologia para a construção da fonte de alimentação das estações remotas de campo e montar uma estrutura equivalente em laboratório, com dispositivos e equipamentos que permitiram elaborar e realizar uma série de testes que nos remeteram a várias conclusões.

Infelizmente não foi possível tentar simular o ambiente em que o circuito de alimentação da fonte realmente se encontrará quando implementado no sistema de controle de irrigação, como temperatura e umidade, por exemplo. Devido ao tempo exíguo foi possível apenas a realização de alguns testes básicos para verificar os dados fornecidos pelos fabricantes e para testar a funcionalidade do sistema equivalente.

Para o projeto idealizado podemos contar com o resultado dos testes realizados com o circuito equivalente. Eles servem como subsídio para a elaboração de novos testes, verificação de falhas, validação da topologia e dos dispositivos recomendados para o projeto final.

O projeto realizado é extremamente válido para comprovar o funcionamento da topologia utilizada, das pilhas, das tensões utilizadas e das correntes em questão.

Tivemos a oportunidade de identificar como limitação do LM317 a utilização como regulador de tensão para a saída de $4,8 \mathrm{~V}$. Devido às características intrínsecas desse modelo de regulador, não é possível que a tensão de entrada tenha um valor próximo ao da tensão de saída. Como foram utilizadas no funcionamento do circuito apenas 4 pilhas com tensão nominal de $4,8 \mathrm{~V}$ e tensão de carga de $6 \mathrm{~V}$, o regulador de $4,8 \mathrm{~V}$ não operou em nenhum momento em condições ideais. Só quando a fonte de tensão era conectada, permitindo a carga das baterias, é que o regulador funcionava em condições de operação. 
Isso não acontecerá tão facilmente no projeto idealizado, visto que o regulador recomendado, o LP2985, possui uma queda de tensão para a corrente que vai passar de apenas $60 \mathrm{mV}$, ou seja, quando as baterias atingirem perto de $4,8 \mathrm{~V}$ na entrada, a saída começará a cair gradativamente.

Portanto, acreditamos que o projeto idealizado pode ser colocado em prática futuramente, com o desenvolvimento de novos testes como, por exemplo, variação brusca de temperatura, variação de umidade, testes de autonomia para diversas condições de carga, além de ser testado um painel solar que esteja conforme as especificações que constam neste projeto. 


\section{Bibliografia}

[1] Instituto do Milênio. SCMN. Especificações para o Sistema de Controle de Irrigação (Livro Branco). Campinas, SP. Julho de 2003.

[2] Sedra, A.S. and Smith, K.C. Microeletrônica. Makron Books, 2000.

[3] Rezende, Sérgio M. A física de materiais e dispositivos eletrônicos. Recife, 1996.

[4] AA Battery Solar Charger. Apresenta um circuito solar que carrega baterias AA. Disponível: <http://www.solorb.com/elect/solarcirc/aacharge/ >. Acesso em: 4 dezembro 2003.

[5] Harry Lythall. Batteries by SM0VPO. Apresenta tecnologias de baterias.

Disponível

em: <http://w1.859.telia.com/ u85920178/begin/batt-00.htm >. Acesso em: 4 dezembro 2003.

[6] Seiichi Inoue. Circuit explanation for Battery charger. Mostra uma das aplicações do LM317. Disponível em: <http://www.interq.or.jp/japan/se-inoue/e_car2_3.htm >. Acesso em: 4 dezembro 2003.

[7] Han Summers. Datasheets. Apresenta datasheets de vários dispositivos. Disponível em: http://www.hanssummers.com/electronics/datasheets/ >. Acesso em: 4 dezembro 2003.

[8] Peter Hayles. NiCd Battery Charger. Apresenta o modelo de topologia de circuito utilizando o microprocessador PIC16C711. Disponível em:

http://www.angelfire.com/electronic/hayles/charge1.html >. Acesso em: 4 dezembro 2003. 
[9] Chris. Power supplies and Battery Chargers. Mostra esquemáticos de reguladores idealizados pelo autor. Disponível em: < http://www.acs.comcen.com.au/buildregs.html >. Acesso em: 4 dezembro 2003.

[10] Techlib.com Power Supplies. Regulators and Power Supplies. Mostra algumas utilizações do LM317 e alguns circuitos. Disponível em: $<$ http://www.techlib.com/electronics/regulators.html $>$. Acesso em: 4 dezembro 2003.

[11] Silicon Solar. Solar Cells. Mostra os produtos fabricados pela empresa: painéis e células solares. Disponível em: < http://www.siliconsolar.com/solar cells.htm>. Acesso em: 4 dezembro 2003.

[12] Cláudio Monteiro. Sistemas Fotovoltaicos. Fornece explicações sobre sistemas fotovoltaicos. Disponível em: < http://power.inescn.pt/claudio/PV.html>. Acesso em: 4 dezembro 2003.

[13] Go Sollar Power. Solar Cells. Mostra empresas fornecedoras de produtos para aplicações solares. Disponível em: < http://www.gosolarpower.com/solarcells/>. Acesso em: 4 dezembro 2003.

[14] EcoBusinessLinks. Solar Energy Manufacturers. Mostra empresas fornecedoras de produtos para aplicações solares. Disponível em: < http://www.ecobusinesslinks.com/links/solar energy solar_power panels .htm\#2.\%20PV\%20Manufacturers>. Acesso em: 4 dezembro 2003.

[15] Tony Van Roon. Solar-cell NiCad Charger, with the MAX639 from Maxim. Mostra um circuito de carregamento utilizando o microprocessador MAX639. Disponível em: < http://www.uoguelph.ca/ antoon/gadgets/solar1g.htm>. Acesso em: 4 dezembro 2003. 
[16] Solar-e.com. Solar-e.com - Solar cells for electricity. Mostra como montar um simples carregador solar. Disponível em: < http://www.solartec.iinet.net.au/solare/secondary/solarcellsforelectricity4.

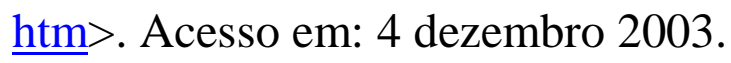

[17] INMET - Instituto Nacional de Meteorologia. Gráficos Climatológicos. Mostra uma série de informações de temperatura, umidade, insolação para as diferentes regiões brasileiras. Disponível em: < http://www.inmet.gov.br/climatologia/combo climatologia I.html>. Acesso em: 4 dezembro 2003.

[18] Unicamp. Instituto do Milênio. Fornece um resumo das atividades do Instituto do Milênio. Disponível em: < http://www.ccs.unicamp.br/scmn/>. Acesso em: 4 dezembro 2003.

[19] Gold Peak Industries. Batteries. Fornece os datasheets das pilhas fabricadas pela empresa. Disponível em: < http://www.gpina.com/industrial/batteries/NiCd/NiCdspecs.htm>. Acesso em: 4 dezembro 2003.

[20] Google. Google Directory. Fornece vários fabricantes de baterias recarregáveis. Disponível em:

http://directory.google.com/Top/Business/Electronics and Electrical/Batt eries/Rechargeable/>. Acesso em: 4 dezembro 2003.

[21] GPI. Nickel Cadmium. Fornece informações sobre as baterias GP. Disponível em:

http://www.gpbatteries.com.hk/Consumer/General/Nickel Cadmium/Nic kel Cadmium.asp >. Acesso em: 4 dezembro 2003.

[22] Panasonic. Panasonic Nickel Cadmium Batteries. Fornece informações sobre as baterias de níquel cádmio da Panasonic. Disponível em: < http://www.panasonic.com/industrial/battery/oem/chem/niccad/>. Acesso em: 4 dezembro 2003. 
[23] Sanyo. Sanyo Industrial Batteries. Permite realizar uma pesquisa em busca das baterias fabricadas pela empresa. Disponível em: < http://www.panasonic.com/industrial/battery/oem/chem/niccad/http://ww W.sanyo.com/batteries/specs.cfm >. Acesso em: 4 dezembro 2003.

[24] Ken A. Nishimura. Some Ramblings about NiCd Batteries. Esclarece os mitos acerca das pilhas de NiCd. Disponível em: < http://www.columbia.edu/ fuat/cuarc/NiCd.html >. Acesso em: 4 dezembro 2003.

[25] House of Batteries. Nickel Cadmium. Revendedora de várias marcas de pilhas. Disponível em:

http://www.houseofbatteries.com/nickel.htm>. Acesso em: 4 dezembro 2003.

[26] Revista Lumiére. Energia Solar. Faz uma pequena explicação sobre efeito o fotovoltaico e semicondutores. Disponível em: < http://www.brasilsolar.com.br/energiasolar.htm >. Acesso em: 4 dezembro 2003.

[27] Saft. SAFT : The Battery Company. Apresenta os modelos de baterias fabricados pela empresa. Disponível em: < http://www.saftbatteries.com/120-Techno/10-10 produit.asp?

paramtechno $=$ Nickel+systems\&Intitule $\_$Produit $=\mathrm{VT}$ >. Acesso em: 4 dezembro 2003.

[28] Jiangmen. Jiangmen J.J.J Battery Co.,Ltd. Apresenta os modelos de baterias fabricadas pela empresa. Disponível em: < http://www.jjibattery.com/en/product nicd.htm\# >. Acesso em: 4 dezembro 2003.

[29] BYD Company. BYD COMPANY LIMITED. Apresenta os modelos de baterias fabricadas pela empresa. Disponível em: < http://www.byd.com.cn/products.asp >. Acesso em: 4 dezembro 2003. 


\section{[30] CANROM PHOTOVOLTAICS INC. SOLAR ENERGY}

PRODUCTS. Apresenta os modelos de células solares fabricadas pela empresa. Disponível em: < http://www.canrom.com/products/index.htm >. Acesso em: 4 dezembro 2003.

[31] Plastecs. Solar Cells. Apresenta os modelos de células solares fabricadas pela empresa. Disponível em: < http://www.plastecs.com/solar_cells.htm $>$. Acesso em: 4 dezembro 2003.

[32] Quark. Solar Cells. Apresenta os modelos de células solares fabricadas pela empresa. Disponível em: < http://www.quarkpvp.com/SCells.htm >. Acesso em: 4 dezembro 2003.

[33] Astro Power. Solar Cells. Apresenta os modelos de células solares fabricadas pela empresa. Disponível em: < http://www.astropower.com/solarcells.htm >. Acesso em: 4 dezembro 2003.

[34] EspectroLab. Solar Cells. Apresenta os modelos de células solares fabricadas pela empresa. Disponível em: < http://www.spectrolab.com/cells/ >. Acesso em: 4 dezembro 2003.

[35] Shell Solar. Solar Cells. Apresenta os modelos de células solares fabricadas pela empresa. Disponível em: < http://www.shell.com/home/Framework?siteId=shellsolar >. Acesso em: 4 dezembro 2003.

[36] Atlantic Solar. Solar Cells. Apresenta os modelos de células solares fabricadas pela empresa. Disponível em: < http://www.atlanticsolar.com/panels/oem.htm >. Acesso em: 4 dezembro 2003.

[37] ST Microelectronics. ST Power Schottky. Apresenta os modelos de diodos fabricados pela empresa. Disponível em: < 
http://www.st.com/stonline/products/selector/541.htm $>$. Acesso em: 4 dezembro 2003.

[38] National Semiconductor. National Semiconductor Products Catalog: Analog - Regulators. Apresenta alguns modelos de reguladores fabricados pela empresa. Disponível em: < http://www.national.com/catalog/AnalogRegulators.html >. Acesso em: 4 dezembro 2003.

[39] Analog Devices. Power/ Supervisory/ Hot-Swap : Power Management Products. Apresenta alguns modelos de reguladores fabricados pela empresa. Disponível em: < http://www.analog.com/Analog Root/sitePage/mainSectionContent/0,21 32,level4\%253D\%25252D1\%2526ContentID \%253D18536\%2526level1\%253D263\%2526level2\%253D \%25252D1\%2526level3\%253D\%25252D1,00.html >. Acesso em: 4 dezembro 2003.

[40] Maxim. Battery Charger Regulates Input Voltage. Apresenta o modelo de topologia de circuito utilizando o microprocessador MAX639. Disponível em: < http://www.maximic.com/appnotes.cfm/appnote number/56/ln/en

>. Acesso em: 4 dezembro 2003.

[41] Fairchild Semiconductor. Fairchild P/N 1N4004. Apresenta especificações do diodo 1N4004. Disponível em: < http://www.fairchildsemi.com/pf/1N/1N4004.html >. Acesso em: 4 dezembro 2003.

[42] Fairchild Semiconductor. Sistemas Solares fotovoltáicos. Apresenta considerações sobre a influência da inclinação do painel na eficiência. Disponível em:

http://www.ecolatina.com.br/br/download/Roberto_Zilles-

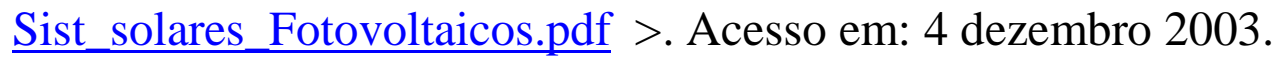


[43] Walt Kester. Battery Chargers. Apresenta um quadro comparativo entre os diferentes tipos de tecnologias de pilhas. Disponível em: < http://www.analog.com/UploadedFiles/Associated Docs/5158552889520 91670040857Power sect5.pdf >. Acesso em: 4 dezembro 2003.

[44] AAU CUBESAT - Student Satelitte. System Analysis. Apresenta um grande estudo sobre a caracterização de painéis solares. Disponível em: < http://www.cubesat.auc.dk/documents/psu/Chapter3.pdf $>$. Acesso em: 4 dezembro 2003. 


\section{Anexos}

\subsection{Anexo 1 - Datasheet LM317}

Absolute Maximum Ratings (Note 1)

If Military/Aerospace specified devices are required, please contact the National Semiconductor Sales Office/ Distributors for availability and specifications.

Power Dissipation

Input-Output Voltage Differential

Internally Limited $+40 \mathrm{~V},-0.3 \mathrm{~V}$

Storage Temperature

$-65^{\circ} \mathrm{C}$ to $+150^{\circ} \mathrm{C}$

Lead Temperature

Metal Package (Soldering, 10 seconds)

Plastic Package (Soldering, 4 seconds)

$300^{\circ} \mathrm{C}$

$260^{\circ} \mathrm{C}$
ESD Tderance (Note 5)

\section{Operating Temperature Range}

LM117
LM317A
LM317

$\begin{aligned}-55^{\circ} \mathrm{C} & \leq T_{J} \leq+150^{\circ} \mathrm{C} \\ -40^{\circ} \mathrm{C} & \leq T_{J} \leq+125^{\circ} \mathrm{C} \\ 0^{\circ} \mathrm{C} & \leq T_{J} \leq+125^{\circ} \mathrm{C}\end{aligned}$

Preconditioning

Thermal Limit Burn-In

All Devices $100 \%$

Electrical Characteristics (Note 3)

Specifications with standard type face are for $T_{J}=25^{\circ} \mathrm{C}$, and those with boldface type apply over full Operating Temperature Range. Unless otherwise specified, $\mathrm{V}_{\mathrm{IN}}-\mathrm{V}_{\mathrm{OUT}}=5 \mathrm{~V}$, and $\mathrm{I}_{\mathrm{OUT}}=10 \mathrm{~mA}$.

\begin{tabular}{|c|c|c|c|c|c|c|c|c|}
\hline \multirow[t]{2}{*}{ Parameter } & \multirow[t]{2}{*}{ Conditions } & \multicolumn{3}{|c|}{ LM317A } & \multicolumn{3}{|c|}{ LM317 } & \multirow[t]{2}{*}{ Units } \\
\hline & & Min & Typ & Max & Min & Typ & Max & \\
\hline \multirow[t]{2}{*}{ Reference Voltage } & & 1.238 & 1.250 & 1.262 & & & & $\mathrm{~V}$ \\
\hline & $\begin{array}{l}3 \mathrm{~V} \leq\left(\mathrm{V}_{\mathrm{IN}}-\mathrm{V}_{\text {OUT }}\right) \leq 40 \mathrm{~V} \\
10 \mathrm{~mA} \leq \mathrm{I}_{\mathrm{OUT}} \leq \mathrm{I}_{\mathrm{MaX}}, \mathrm{P} \leq \mathrm{P}_{\mathrm{MaX}}\end{array}$ & 1.225 & 1.250 & 1.270 & 1.20 & 1.25 & 1.30 & $\mathrm{~V}$ \\
\hline \multirow[t]{2}{*}{ Line Regulation } & \multirow[t]{2}{*}{$3 \mathrm{~V} \leq\left(\mathrm{V}_{\text {IN }}-\mathrm{V}_{\text {OUT }}\right) \leq 40 \mathrm{~V}$ (Note 4$)$} & & 0.005 & 0.01 & & 0.01 & 0.04 & $\% / V$ \\
\hline & & & 0.01 & 0.02 & & 0.02 & 0.07 & $\% / \mathrm{V}$ \\
\hline \multirow[t]{2}{*}{ Laad Regulation } & \multirow[t]{2}{*}{$10 \mathrm{~mA} \leq \mathrm{I}_{\text {OUT }} \leq \mathrm{I}_{\text {MAX }}($ Note 4$)$} & & 0.1 & 0.5 & & 0.1 & 0.5 & $\%$ \\
\hline & & & 0.3 & 1 & & 0.3 & 1.5 & $\%$ \\
\hline Thermal Regulation & $20 \mathrm{~ms}$ Pulse & & 0.04 & 0.07 & & 0.04 & 0.07 & $\% / W$ \\
\hline Adjustment Pin Current & & & 50 & 100 & & 50 & 100 & $\mu \mathrm{A}$ \\
\hline $\begin{array}{l}\text { Adjustment Pin Current } \\
\text { Change }\end{array}$ & $\begin{array}{l}10 \mathrm{~mA} \leq \mathrm{I}_{\text {OUT }} \leq \mathrm{I}_{\mathrm{MAX}} \\
3 \mathrm{~V} \leq\left(\mathrm{V}_{\text {IN }}-\mathrm{V}_{\text {OUT }}\right) \leq 40 \mathrm{~V}\end{array}$ & & 0.2 & 5 & & 0.2 & 5 & $\mu \mathrm{A}$ \\
\hline Temperature Stability & $T_{\text {MIN }} \leq T_{J} \leq T_{\text {MaX }}$ & & 1 & & & 1 & & $\%$ \\
\hline Minimum Load Current & $\left(\mathrm{V}_{\mathrm{IN}}-\mathrm{V}_{\mathrm{OUT}}\right)=40 \mathrm{~V}$ & & 3.5 & 10 & & 3.5 & 10 & $\mathrm{~mA}$ \\
\hline \multirow[t]{7}{*}{ Current Limit } & $\left(V_{I N}-V_{\text {OUT }}\right) \leq 15 V$ & & & & & & & \\
\hline & K, T, S Packages & 1.5 & 2.2 & 3.4 & 1.5 & 2.2 & 3.4 & A \\
\hline & H Package & 0.5 & 0.8 & 1.8 & 0.5 & 0.8 & 1.8 & A \\
\hline & MP Package & 1.5 & 2.2 & 3.4 & 1.5 & 2.2 & 3.4 & A \\
\hline & $\begin{array}{r}\left(\mathrm{V}_{\mathrm{IN}}-\mathrm{V}_{\text {OUT }}\right)=40 \mathrm{~V} \\
\mathrm{~K}, \mathrm{~T}, \mathrm{~S} \text { Packages }\end{array}$ & 0.15 & 0.4 & & 0.15 & 0.4 & & A \\
\hline & H Package & 0.075 & 0.2 & & 0.075 & 0.2 & & A \\
\hline & MP Package & 0.55 & 0.4 & & 0.15 & 0.4 & & A \\
\hline RMS Output Noise, $\%$ of $V_{\text {OUT }}$ & $10 \mathrm{~Hz} \leq \mathrm{f} \leq 10 \mathrm{kHz}$ & & 0.003 & & & 0.003 & & $\%$ \\
\hline \multirow[t]{2}{*}{ Ripple Rejection Ratio } & $\begin{array}{l}\mathrm{V}_{\text {OUT }}=10 \mathrm{~V}, \mathrm{f}=120 \mathrm{~Hz} \\
\mathrm{C}_{\text {ADJ }}=0 \mu \mathrm{F}\end{array}$ & & 65 & & & 65 & & $\mathrm{~dB}$ \\
\hline & $\begin{array}{l}V_{\text {OUT }}=10 \mathrm{~V}, \mathrm{f}=120 \mathrm{~Hz} \\
\mathrm{C}_{\text {ADJ }}=10 \mu \mathrm{F}\end{array}$ & 66 & 80 & & 66 & 80 & & $\mathrm{~dB}$ \\
\hline Long-Term Stability & $\mathrm{T}_{\mathrm{J}}=125^{\circ} \mathrm{C}, 1000 \mathrm{hrs}$ & & 0.3 & 1 & & 0.3 & 1 & $\%$ \\
\hline \multirow[t]{4}{*}{$\begin{array}{l}\text { Thermal Resistance, } \\
\text { Junction-to-Case }\end{array}$} & $\begin{array}{l}\text { K Package } \\
\text { MDT Package }\end{array}$ & & & & & $\begin{array}{c}2.3 \\
5\end{array}$ & 3 & $\begin{array}{l}{ }^{\circ} \mathrm{C} / \mathrm{W} \\
{ }^{\mathrm{C}} \mathrm{W}\end{array}$ \\
\hline & H Package & & 12 & 15 & & 12 & 15 & $\mathrm{C} / \mathrm{W}$ \\
\hline & T Package & & 4 & 5 & & 4 & & $\mathrm{C} / \mathrm{W}$ \\
\hline & MP Package & & 23.5 & & & 23.5 & & $\mathrm{C} / \mathrm{W}$ \\
\hline \multirow{5}{*}{$\begin{array}{l}\text { Thermal Resistance, } \\
\text { Junction-to-Ambient (No Heat } \\
\text { Sink) }\end{array}$} & K Package & & 35 & & & 35 & & ${ }^{\circ} \mathrm{C} / \mathrm{W}$ \\
\hline & MDT Package(Note 6) & & & & & 92 & & $\mathrm{C} / \mathrm{W}$ \\
\hline & H Package & & 140 & & & 140 & & $\mathrm{C} / \mathrm{W}$ \\
\hline & T Package & & 50 & & & 50 & & ${ }^{\circ} \mathrm{C} / \mathrm{W}$ \\
\hline & S Package (Note 6) & & 50 & & & 50 & & $\mathrm{C} / \mathrm{W}$ \\
\hline
\end{tabular}

Figura 9.1 - Datasheet resumido do LM317 


\subsection{Anexo 2 - Datasheet GPBatteries GP-60AAS}

\begin{tabular}{|c|c|c|}
\hline Type & \multicolumn{2}{|c|}{$\begin{array}{l}\text { Rechargeable Nickel Cadmium } \\
\text { Cylindrical Cell }\end{array}$} \\
\hline $\begin{array}{l}\text { Nominal Dimension } \\
\text { (with Sleeve) }\end{array}$ & \multicolumn{2}{|l|}{$\begin{array}{l}\Phi=14.4 \mathrm{~mm} \\
\mathrm{H}=48.2 \mathrm{~mm}\end{array}$} \\
\hline Applications & \multicolumn{2}{|c|}{$\begin{array}{l}\text { Recommended discharge current } \\
30 \text { to } 1800 \mathrm{~mA}\end{array}$} \\
\hline Nominal Voltage & \multicolumn{2}{|l|}{$1.2 \mathrm{~V}$} \\
\hline Capacity & \multicolumn{2}{|c|}{$\begin{array}{l}\text { Minimum: } 600 \mathrm{mAh} \\
\text { Typical: } 660 \mathrm{mAh} \\
\text { when discharged at } 120 \mathrm{~mA} \text { to } 1.0 \mathrm{~V} \text { at } 20^{\circ} \mathrm{C}\end{array}$} \\
\hline Charging Condition & \multicolumn{2}{|c|}{$60 \mathrm{~mA}$ for $16 \mathrm{hrs}$ at $20^{\circ} \mathrm{C}$} \\
\hline Fast Charge & \multicolumn{2}{|c|}{$\begin{array}{l}300 \mathrm{~mA} \text { to } 600 \mathrm{~mA}(0.5 \text { to } 1 \mathrm{C}) \\
\text { with charge termination control } \\
\text { Recommended control parameters: } \\
-\Delta \mathrm{V}: 10-20 \mathrm{mV} \\
\text { Timer : } 120 \% \text { nominal input }\end{array}$} \\
\hline Service Life & \multicolumn{2}{|c|}{$>500$ cycles (IEC standard) } \\
\hline $\begin{array}{l}\text { Continuous } \\
\text { Overcharge }\end{array}$ & \multicolumn{2}{|c|}{$\begin{array}{l}60 \mathrm{~mA} \text { maximum current for } 1 \text { year } \\
\text { No conspicuous deformation } \\
\text { and/or leakage }\end{array}$} \\
\hline Weight & \multicolumn{2}{|l|}{$19.0 \mathrm{~g}$} \\
\hline Internal Resistance & \multicolumn{2}{|c|}{$\begin{array}{l}\text { Average } 36 \mathrm{~m} \Omega \text { upon fully charged } \\
\text { (Range } 27-42 \mathrm{~m} \Omega \text { ) at } 1000 \mathrm{~Hz}\end{array}$} \\
\hline Max. Charging Voltage & \multicolumn{2}{|c|}{$1.5 \mathrm{~V}$ at $60 \mathrm{~mA}$ charging } \\
\hline $\begin{array}{l}\text { Ambient Temperature } \\
\text { Range }\end{array}$ & $\begin{array}{l}\text { Standard Charging } \\
\text { Fast Charging } \\
\text { Discharging } \\
\text { Storage }\end{array}$ & $\begin{array}{r}0 \text { to } 45^{\circ} \mathrm{C} \\
10 \text { to } 45^{\circ} \mathrm{C} \\
-20 \text { to } 50^{\circ} \mathrm{C} \\
-20 \text { to } 35^{\circ} \mathrm{C}\end{array}$ \\
\hline
\end{tabular}

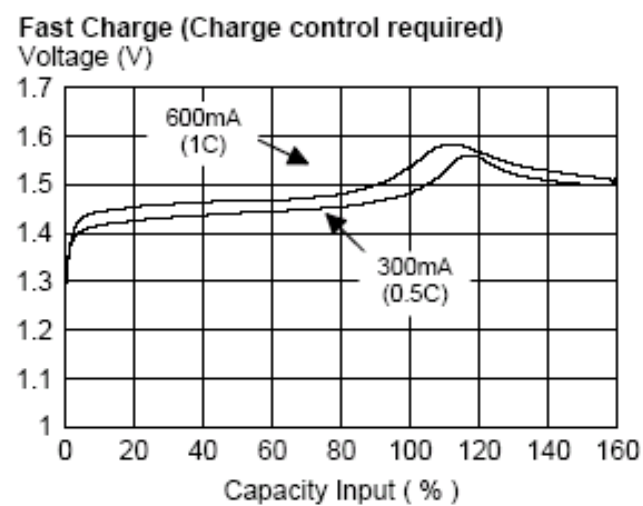

Low Rate Discharge Voltage (V)

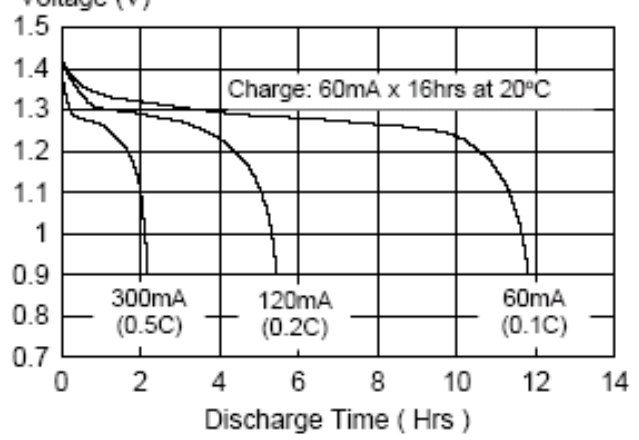

High Rate Discharge Voltage (V)

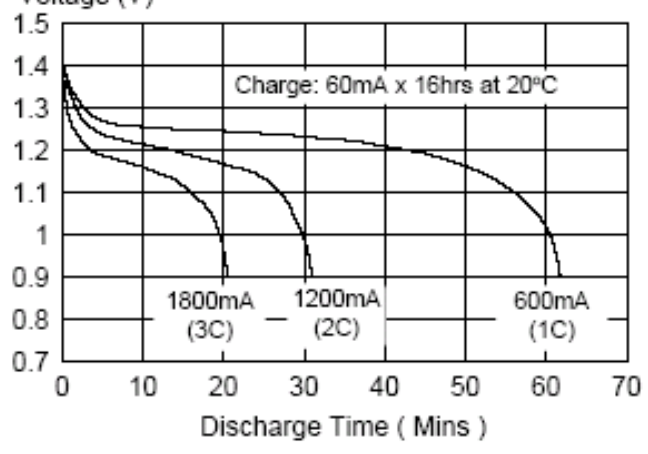

* The information (subject to change without prior notice) contained in this document is for reference only and should not be used as a basis for product guarantee or warranty. For applications other than those described here, please consult your nearest GP Sales and Marketing Office or Distributors.

Figura 9.2 - Datasheet GP60AAS 
LP2985

\section{Micropower 150 mA Low-Noise Ultra Low-Dropout Regulator in SOT-23 and micro SMD Packages Designed for Use with Very Low ESR Output Capacitors}

\section{General Description}

The LP2985 is a $150 \mathrm{~mA}$, fixed-output voltage regulator designed to provide ultra low-dropout and low noise in battery powered applications.

Using an optimized VIP $m$ (Vertically Integrated PNP) process, the LP2985 delivers unequalled performance in all specifications critical to battery-powered designs:

Dropout Voltage: Typically $300 \mathrm{mV} @ 150 \mathrm{~mA}$ load, and $7 \mathrm{mV} @ 1 \mathrm{~mA}$ load.

Ground Pin Current: Typically $850 \mu \mathrm{A} @ 150 \mathrm{~mA}$ load, and $75 \mu \mathrm{A} @ 1 \mathrm{~mA}$ load.

Enhanced Stability: The LP2985 is stable with output capacitor ESR as low as $5 \mathrm{~m} \Omega$, which allows the use of ceramic capacitors on the output.

Sleep Mode: Less than $1 \mu \mathrm{A}$ quiescent current when ON/ OFF pin is pulled low.

Smallest Possible Size: SOT-23 and micro SMD packages use absolute minimum board space.

Precision Output: $1 \%$ tolerance output voltages available (A grade).

Low Noise: By adding a $10 \mathrm{nF}$ bypass capacitor, output noise can be reduced to $30 \mu \mathrm{V}$ (typical).

Multiple voltage options, from $2.5 \mathrm{~V}$ to $5.0 \mathrm{~V}$, are available as standard products. Consult factory for custom voltages.

\section{Features}

- Ultra low dropout voltage

- Guaranteed $150 \mathrm{~mA}$ output current

- Smallest possible size (SOT-23, micro SMD package)

- Requires minimum external components

- Stable with low-ESR output capacitor

- $<1 \mu \mathrm{A}$ quiescent current when shut down

- Low ground pin current at all loads

- Output voltage accuracy $1 \%$ (A Grade)

- High peak current capability

- Wide supply voltage range $(16 \mathrm{~V}$ max)

- Low $\mathrm{Z}_{\text {Out: }} 0.3 \Omega$ typical (10 Hz to $1 \mathrm{MHz}$ )

- Overtemperature/overcurrent protection

- $-40^{\circ} \mathrm{C}$ to $+125^{\circ} \mathrm{C}$ junction temperature range

- Custom voltages available

\section{Applications}

- Cellular Phone

- Palmtop/Laptop Computer

- Personal Digital Assistant (PDA)

- Camcorder, Personal Stereo, Camera

\section{Block Diagram}

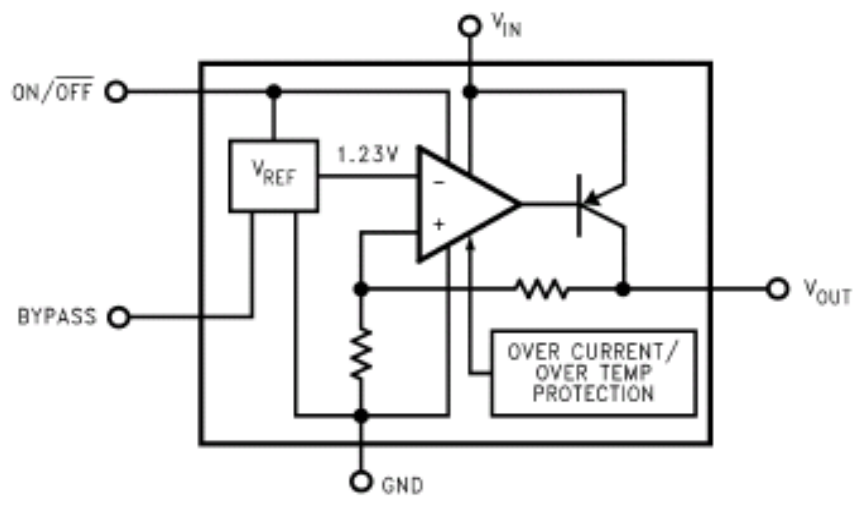


Absolute Maximum Ratings (Note 1)

If Military/Aerospace specified devices are required, please contact the National Semiconductor Sales Office/ Distributors for availability and specifications.

Storage Temperature Range

$-65^{\circ} \mathrm{C}$ to $+150^{\circ} \mathrm{C}$

Operating Junction Temperature

Range

Lead Temp. (Soldering, 5 sec.)

ESD Rating (Note 2)

Power Dissipation (Note 3) $-40^{\circ} \mathrm{C}$ to $+125^{\circ} \mathrm{C}$ $260^{\circ} \mathrm{C}$ $2 \mathrm{kV}$ Internally Limited
Input Supply Voltage (Survival) Input Supply Voltage (Operating)

$-0.3 \mathrm{~V}$ to $+16 \mathrm{~V}$ $2.5 \mathrm{~V}$ to $+16 \mathrm{~V}$ Shutdown Input Voltage (Survival) Output Voltage (Survival, (Note 4)) Iout (Survival)

$-0.3 \mathrm{~V}$ to $+16 \mathrm{~V}$ $-0.3 \mathrm{~V}$ to $+9 \mathrm{~V}$

Short Circuit

Protected

Input-Output Voltage (Survival, (Note 5))

\section{Electrical Characteristics (Note 10)}

Limits in standard typeface are for $\mathrm{T}_{J}=25^{\circ} \mathrm{C}$. and limits in boldface type apply over the full operating temperature range. Unless otherwise specified: $\mathrm{V}_{\mathrm{IN}}=\mathrm{V}_{\mathrm{O}}(\mathrm{NOM})+1 \mathrm{~V}, \mathrm{I}_{\mathrm{L}}=1 \mathrm{~mA}, \mathrm{C}_{\mathrm{IN}}=1 \mu \mathrm{F}, \mathrm{C}_{\text {OUT }}=4.7 \mu \mathrm{F}, \mathrm{V}_{\text {ONOFF }}=2 \mathrm{~V}$.

\begin{tabular}{|c|c|c|c|c|c|c|c|c|}
\hline \multirow[t]{2}{*}{ Symbol } & \multirow[t]{2}{*}{ Parameter } & \multirow[t]{2}{*}{ Conditions } & \multirow[t]{2}{*}{ Тур } & \multicolumn{2}{|c|}{$\begin{array}{c}\text { LP2985Al-X.X } \\
\text { (Note 6) }\end{array}$} & \multicolumn{2}{|c|}{$\begin{array}{l}\text { LP2985I-X.X } \\
\text { (Note 6) }\end{array}$} & \multirow[t]{2}{*}{ Units } \\
\hline & & & & Min & Max & Min & Max & \\
\hline \multirow[t]{5}{*}{$\Delta \mathrm{V}_{\circ}$} & \multirow{5}{*}{$\begin{array}{l}\text { Output Voltage } \\
\text { Tolerance }\end{array}$} & $\mathrm{I}_{\mathrm{L}}=1 \mathrm{~mA}$ & & -1.0 & 1.0 & -1.5 & 1.5 & \multirow{5}{*}{$\% V_{\text {NOM }}$} \\
\hline & & $1 \mathrm{~mA} \leq \mathrm{I}_{\mathrm{L}} \leq 50 \mathrm{~mA}$ & & -1.5 & 1.5 & -2.5 & 2.5 & \\
\hline & & & & -2.5 & 2.5 & -3.5 & 3.5 & \\
\hline & & \multirow[t]{2}{*}{$1 \mathrm{~mA} \leq \mathrm{I}_{\mathrm{L}} \leq 150 \mathrm{~mA}$} & & -2.5 & 2.5 & -3.0 & 3.0 & \\
\hline & & & & -3.5 & 3.5 & -4.0 & 4.0 & \\
\hline$\Delta V_{0}$ & Output Voltage & \multirow[t]{2}{*}{$V_{O}(N O M)+1 V \leq V_{I N} \leq 16 V$} & \multirow[t]{2}{*}{0.007} & & 0.014 & & 0.014 & \multirow{2}{*}{$\% N$} \\
\hline$\Delta \mathrm{V}_{\mathrm{IN}}$ & Line Regulation & & & & 0.032 & & 0.032 & \\
\hline \multirow[t]{10}{*}{$\mathrm{V}_{\mathbb{I N}}-\mathrm{V}_{\mathrm{O}}$} & \multirow{10}{*}{$\begin{array}{l}\text { Dropout Voltage } \\
\text { (Note 7) }\end{array}$} & \multirow[t]{2}{*}{$I_{L}=0$} & \multirow[t]{2}{*}{1} & & 3 & & 3 & \multirow{10}{*}{$\mathrm{mV}$} \\
\hline & & & & & 5 & & 5 & \\
\hline & & \multirow[t]{2}{*}{$\mathrm{I}_{\mathrm{L}}=1 \mathrm{~mA}$} & \multirow[t]{2}{*}{7} & & 10 & & 10 & \\
\hline & & & & & 15 & & 15 & \\
\hline & & \multirow[t]{2}{*}{$\mathrm{I}_{\mathrm{L}}=10 \mathrm{~mA}$} & \multirow[t]{2}{*}{40} & & 60 & & 60 & \\
\hline & & & & & 90 & & 90 & \\
\hline & & \multirow[t]{2}{*}{$\mathrm{I}_{\mathrm{L}}=50 \mathrm{~mA}$} & \multirow[t]{2}{*}{120} & & 150 & & 150 & \\
\hline & & & & & 225 & & 225 & \\
\hline & & \multirow[t]{2}{*}{$\mathrm{I}_{\mathrm{L}}=150 \mathrm{~mA}$} & \multirow[t]{2}{*}{280} & & 350 & & 350 & \\
\hline & & & & & 575 & & 575 & \\
\hline $\mathrm{I}_{\text {GND }}$ & Ground Pin Current & $\mathrm{I}_{\mathrm{L}}=0$ & 65 & & 95 & & 95 & \\
\hline & & & & & 125 & & 125 & \\
\hline & & $\mathrm{I}_{\mathrm{L}}=1 \mathrm{~mA}$ & 75 & & 110 & & 110 & \\
\hline & & & & & 170 & & 170 & \\
\hline & & $\mathrm{I}_{\mathrm{L}}=10 \mathrm{~mA}$ & 120 & & 220 & & 220 & \\
\hline & & & & & 400 & & 400 & $\mu \mathrm{A}$ \\
\hline & & $\mathrm{I}_{\mathrm{L}}=50 \mathrm{~mA}$ & 350 & & 600 & & 600 & \\
\hline & & & & & 1000 & & 1000 & \\
\hline & & $\mathrm{I}_{\mathrm{L}}=150 \mathrm{~mA}$ & 850 & & 1500 & & 1500 & \\
\hline & & & & & 2500 & & 2500 & \\
\hline & & $\mathrm{V}_{\text {ONMFF }}<0.3 \mathrm{~V}$ & 0.01 & & 0.8 & & 0.8 & \\
\hline & & $V_{\text {ONOFF }}<0.15 \mathrm{~V}$ & 0.05 & & 2 & & 2 & \\
\hline$V_{\text {ONIOFF }}$ & ON/OFF Input Voltage & High = O/P ON & 1.4 & 1.6 & & 1.6 & & V \\
\hline & (Note 8) & Low $=0 / P$ OFF & 0.55 & & 0.15 & & 0.15 & 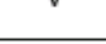 \\
\hline IONOFF & ON/OFF Input Current & $\mathrm{V}_{\text {ONOFF }}=0$ & 0.01 & & -2 & & -2 & $\mu \mathrm{A}$ \\
\hline & & $V_{\text {ONOFF }}=5 \mathrm{~V}$ & 5 & & 15 & & 15 & \\
\hline
\end{tabular}

Figura 9.3 - Datasheet resumido LP2985 


\section{LP2983}

\section{Micropower $150 \mathrm{~mA}$ Voltage Regulator in SOT-23 Package For Output Voltages $\leq 1.2 \mathrm{~V}$}

\section{Designed for Use with Very Low ESR Output Capacitors}

\section{General Description}

The LP2983 is a $150 \mathrm{~mA}$, fixed-output voltage regulator designed to provide tight voltage regulation in applications with output voltages $\leq 1.2 \mathrm{~V}$.

Using an optimized VIP ${ }^{\mathrm{N}}$ (Vertically Integrated PNP) process, the LP2983 delivers unequalled performance in all critical specifications:

Ground Pin Current: Typically $825 \mu \mathrm{A} \oplus 150 \mathrm{~mA}$ load, and $75 \mu \mathrm{A} @ 1 \mathrm{~mA}$ load.

Enhanced Stability: The LP2983 is stable with output capacitor ESR down to zero, which allows the use of ceramic capacitors on the output.

Smallest Possible Size: SOT-23 package uses absolute minimum board space.

Precision Output: $1 \%$ tolerance output voltages available (A grade).

\section{Features}

- Guaranteed 150 mA output current

- Smallest possible size (SOT-23 package)

- Requires minimum external components

- Stable with low-ESR output capacitor

- Low ground pin current at all loads

- Output voltage accuracy $1 \%$ (A Grade)

- High peak current capability

- Wide supply voltage range (16V max)

- Low $Z_{\text {out: }} 0.3 \Omega$ typical $(10 \mathrm{~Hz}$ to $1 \mathrm{MHz})$

- Overtemperature/overcurrent protection

- $-40^{\circ} \mathrm{C}$ to $+125^{\circ} \mathrm{C}$ junction temperature range

\section{Applications}

- Cellular Phone

- Palmtop/Laptop Computer

- Personal Digital Assistant (PDA)

- Camcorder, Personal Stereo, Camera

\section{Block Diagram}

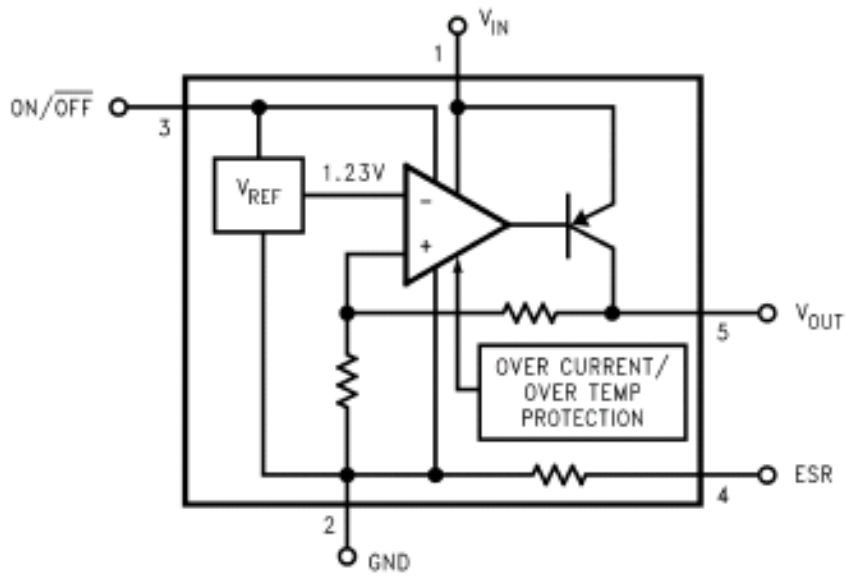


Absolute Maximum Ratings (Note 1)

If Military/Aerospace specified devices are required, please contact the National Semiconductor Sales Officel Distributors for availability and specifications.

Storage Temperature Range

Operating Junction Temperature

Range

Lead Temp. (Soldering, $5 \mathrm{sec}$.)

ESD Rating (Note 2) $-65^{\circ} \mathrm{C}$ to $+150^{\circ} \mathrm{C}$

$-40^{\circ} \mathrm{C}$ to $+125^{\circ} \mathrm{C}$

$260^{\circ} \mathrm{C}$

$2 \mathrm{kV}$
Power Dissipation (Note 3)

Input Supply Voltage (Survival)

Input Supply Voltage (Operating)

Shutdown Input Voltage (Survival)

Output Voltage Survival, (Note 4)

Iout (Survival)

Internally Limited

$-0.3 \mathrm{~V}$ to $+16 \mathrm{~V}$

$2.2 \mathrm{~V}$ to $+16 \mathrm{~V}$

$-0.3 \mathrm{~V}$ to $+16 \mathrm{~V}$

$-0.3 \mathrm{~V}$ to $+9 \mathrm{~V}$

Short Circuit

Protected

Input-Output Voltage Survival,(Note 5)

\section{Electrical Characteristics}

Limits in standard typeface are for $T_{j}=25^{\circ} \mathrm{C}$. and limits in boldface type apply over the full operating temperature range. Unless otherwise specified: $V_{I N}=V_{O}(N O M)+1 V, I_{L}=1 \mathrm{~mA}, C_{I N}=1 \mu F, C_{O U T}=2.2 \mu F, V_{\text {ON OFF }}=2 \mathrm{~V}$.

\begin{tabular}{|c|c|c|c|c|c|c|c|c|}
\hline \multirow[t]{2}{*}{ Symbol } & \multirow[t]{2}{*}{ Parameter } & \multirow[t]{2}{*}{ Conditions } & \multirow[t]{2}{*}{ Typ } & \multicolumn{2}{|c|}{$\begin{array}{l}\text { LP2983AI-X.X } \\
\text { (Note 6) }\end{array}$} & \multicolumn{2}{|c|}{$\begin{array}{c}\text { LP29831-X.X } \\
\text { (Note 6) }\end{array}$} & \multirow[t]{2}{*}{ Units } \\
\hline & & & & Min & Max & Min & Max & \\
\hline \multirow[t]{5}{*}{$\Delta \mathrm{V}_{0}$} & \multirow{5}{*}{$\begin{array}{l}\text { Output Voltage } \\
\text { Tolerance }\end{array}$} & & & -1.0 & 1.0 & -1.5 & 1.5 & \multirow{5}{*}{$\%$} \\
\hline & & \multirow[t]{2}{*}{$1 \mathrm{~mA} \leq \mathrm{I}_{\mathrm{L}} \leq 50 \mathrm{~mA}$} & & -2.0 & 2.0 & -2.5 & 2.5 & \\
\hline & & & & -2.5 & 2.5 & -3.5 & 3.5 & \\
\hline & & \multirow[t]{2}{*}{$1 \mathrm{~mA} \leq \mathrm{I}_{\mathrm{L}} \leq 150 \mathrm{~mA}$} & & -2.5 & 2.5 & -3.0 & 3.0 & \\
\hline & & & & -3.5 & 3.5 & -4.0 & 4.0 & \\
\hline$\Delta \mathrm{V}_{0}$ & Output Voltage & \multirow[t]{2}{*}{$V_{O}(N O M)+1 V \leq V_{I N} \leq 16 V$} & \multirow[t]{2}{*}{0.01} & & 0.016 & & 0.016 & \multirow{2}{*}{$\% / N$} \\
\hline$\frac{\Delta V_{\text {IN }}}{\text { leno }}$ & Line Regulation & & & & 0.032 & & 0.032 & \\
\hline \multirow[t]{12}{*}{ land } & \multirow[t]{12}{*}{ Ground Pin Current } & \multirow[t]{2}{*}{$I_{L}=0$} & \multirow[t]{2}{*}{65} & & 95 & & 95 & \multirow{12}{*}{$\mu \mathrm{A}$} \\
\hline & & & & & 125 & & 125 & \\
\hline & & \multirow[t]{2}{*}{$\mathrm{I}_{\mathrm{L}}=1 \mathrm{~mA}$} & \multirow[t]{2}{*}{75} & & 110 & & 110 & \\
\hline & & & & & 170 & & 170 & \\
\hline & & \multirow[t]{2}{*}{$\mathrm{I}_{\mathrm{L}}=10 \mathrm{~mA}$} & \multirow[t]{2}{*}{120} & & 220 & & 220 & \\
\hline & & & & & 400 & & 400 & \\
\hline & & \multirow[t]{2}{*}{$\mathrm{I}_{\mathrm{L}}=50 \mathrm{~mA}$} & \multirow[t]{2}{*}{300} & & 500 & & 500 & \\
\hline & & & & & 900 & & 900 & \\
\hline & & \multirow{2}{*}{$\mathrm{I}_{\mathrm{L}}=150 \mathrm{~mA}$} & \multirow[t]{2}{*}{825} & & 1200 & & 1500 & \\
\hline & & & & & 2000 & & 2000 & \\
\hline & & $V_{\text {ONIOFF }}<0.15 \mathrm{~V}$ & 6 & & 12 & & 12 & \\
\hline & & $V_{\text {ONIOFF }}<0.05 \mathrm{~V}$ & 0.2 & & 2 & & 2 & \\
\hline$V_{I N}(\min )$ & $\begin{array}{l}\text { Minimum } V_{\mathbb{N}} \text { required } \\
\text { to maintain Output } \\
\text { Regulation }\end{array}$ & & 2.05 & & 2.20 & & 2.20 & V \\
\hline \multirow[t]{2}{*}{ VONOFF } & ON/OFF Input Voltage & High $=\mathrm{O} / \mathrm{P}$ ON & 1.4 & 1.6 & & 1.6 & & \\
\hline & (Note 7) & Low $=\mathrm{O} / \mathrm{P}$ OFF & 0.1 & & 0.05 & & 0.05 & \\
\hline JONOFF & ON/OFF Input Current & $V_{\text {ONIOFF }}=0$ & 0.01 & & -2 & & -2 & ИA \\
\hline & & $V_{\text {ONIOFF }}=5 \mathrm{~V}$ & 5 & & 15 & & 15 & $\mu \mathrm{A}$ \\
\hline$e_{n}$ & $\begin{array}{l}\text { Output Noise } \\
\text { Voitage (RMS) }\end{array}$ & $\begin{array}{l}\mathrm{BW}=10 \mathrm{~Hz} \text { to } 100 \mathrm{kHz} \\
\mathrm{C}_{\text {OUT }}=10 \mu \mathrm{F} \\
\mathrm{V}_{\text {OUT }}=1.2 \mathrm{~V}\end{array}$ & 60 & & & & & $\mu V$ \\
\hline$\frac{\Delta \mathrm{V}_{\text {OUT }}}{\Delta \mathrm{V}_{\mathrm{IN}}}$ & Ripple Rejection & $\begin{array}{l}\mathrm{f}=1 \mathrm{kHz} \\
\mathrm{C}_{\mathrm{OuT}}=2.2 \mu \mathrm{F}\end{array}$ & 65 & & & & & $\mathrm{~dB}$ \\
\hline $\mathrm{Io}(\mathrm{SC})$ & Short Circuit Current & $\begin{array}{l}\mathrm{R}_{\mathrm{L}}=0 \text { (Steady State) } \\
\text { (Note 8) }\end{array}$ & 400 & & & & & $\mathrm{~mA}$ \\
\hline$I_{0}(P K)$ & Peak Output Current & $V_{\text {OUT }} \geq V_{0}($ NOM $)-5 \%$ & 250 & & & & & \\
\hline
\end{tabular}

Figura 9.4 - Datasheet resumido LP2983 